$10 / 3092950$
9300
OAK RIDGE
NATIONAL
LABORATORY

MALTW MARUITA

\section{Effect of Translucence of Engineering Ceramics on Heat Transfer in Diesel Engines}

\author{
Final Report
}

S. Wahiduzzaman
T. Morel

S. Wahiduzzaman
T. Morel

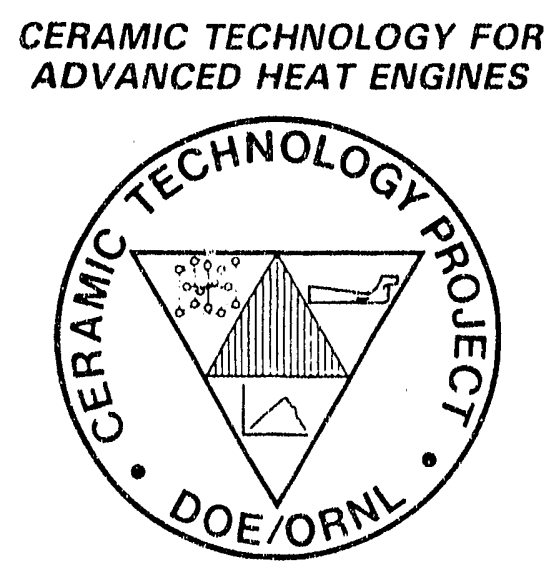

MANAGED BY

MARTIN MARIETTA ENERGY SYSTEMS, INC.

FOR THE UNITED STATES

DEPARTMENT QF ENERGY 
This report has been reproduced directly from the best available copy.

Avaliable to DOE and DOE contractors from the Office of Scientific and Technical Information, P.O. Box 62, Oak Ridge, TN 37831 ; prices available from (615) 576-8401, FTS 626-8401.

Avallable to the public from the National Technical Information Service, U.S. Department of Commerce, 5235 Port Royal Rd., Springfield, VA 22161.

This report was prepared as an account of work sponsored by an agency of the United States Government. Neither the United Siates Government nor any agency thereof, nor any of their employees, makes a.jy warranty, express or implied, or assumes any legal liability or responsibility for the accuracy, conpleteness, or usefulness of any information, apparatus, product, or process disclosed, or represents that its use would not infringe privately owned rights. Reference herein to any specific commercial product, process, or service by trade name, trademark, manufacturer, or otherwise, does not necesserily constitute or imply its endorsement, recomrnendation, or favoring by the United States Government or any agency thereof. The views and opinions of authors expressed herein do not necessurlly state or reflect those of the United States Government or any agency thereot. 
ORNL/Sub--88-22042/2

DE92. 041384

\title{
EFFECT OF TRANSLUCENCE OF ENGINEERING CERAMICS ON HEAT TRANSFER IN DIESEL ENGINES
}

S. Wahiduzzaman and Thomas Morel

Date Published-April 1992

FINAL REPORT

\author{
Prepared by \\ Integral Technologies Incorporated \\ 645 Blackhawk Drive \\ Westmont, Illinois 60559 \\ $86 \mathrm{X}-22042 \mathrm{~V}$
}

\begin{abstract}
Funded by
Office of Transportation Materials

Office of Transportation Technologies

the Assistant Secretary for Conservation and Renewable Energy

U.S. Department of Energy

EE 5101000
\end{abstract}

for
OAK RIDGE NATIONAL LABORATORY

Oak Ridge, Tennessee 37831

managed by

MARTIN MARIETTA ENERGY SYSTEMS, INC.

for the

U.S. DEPARTMENT OF ENERGY

under Contract DE-AC05-84OR21400

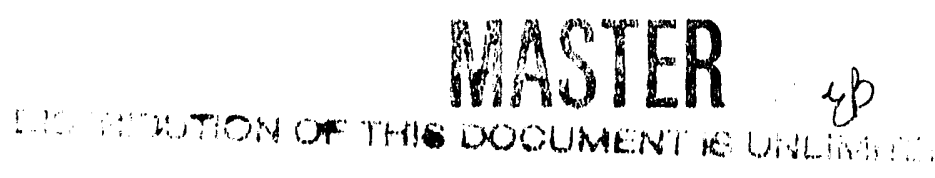




\section{ACKNOWLEDGEMEN'I}

Research sponsored by the U.S. Department of Energy, Assistant Secretary for Conservation and Renewable Energy, Office of Transportation Technologies, as part of the Ceramic Technology Project of the Advanced Materials Development Program, under contract DE-AC05-84OR21400 with Martin Marietta Energy systems, Inc. The authors also acknowledge the helpful suggestions provided by the contract manager, Dr.David L. McElroy, Oak Ridge National Laboratory, and the assistance of Prof. David P. DEWitt, Purdue University, who served as a consultant. 
CONTENTS

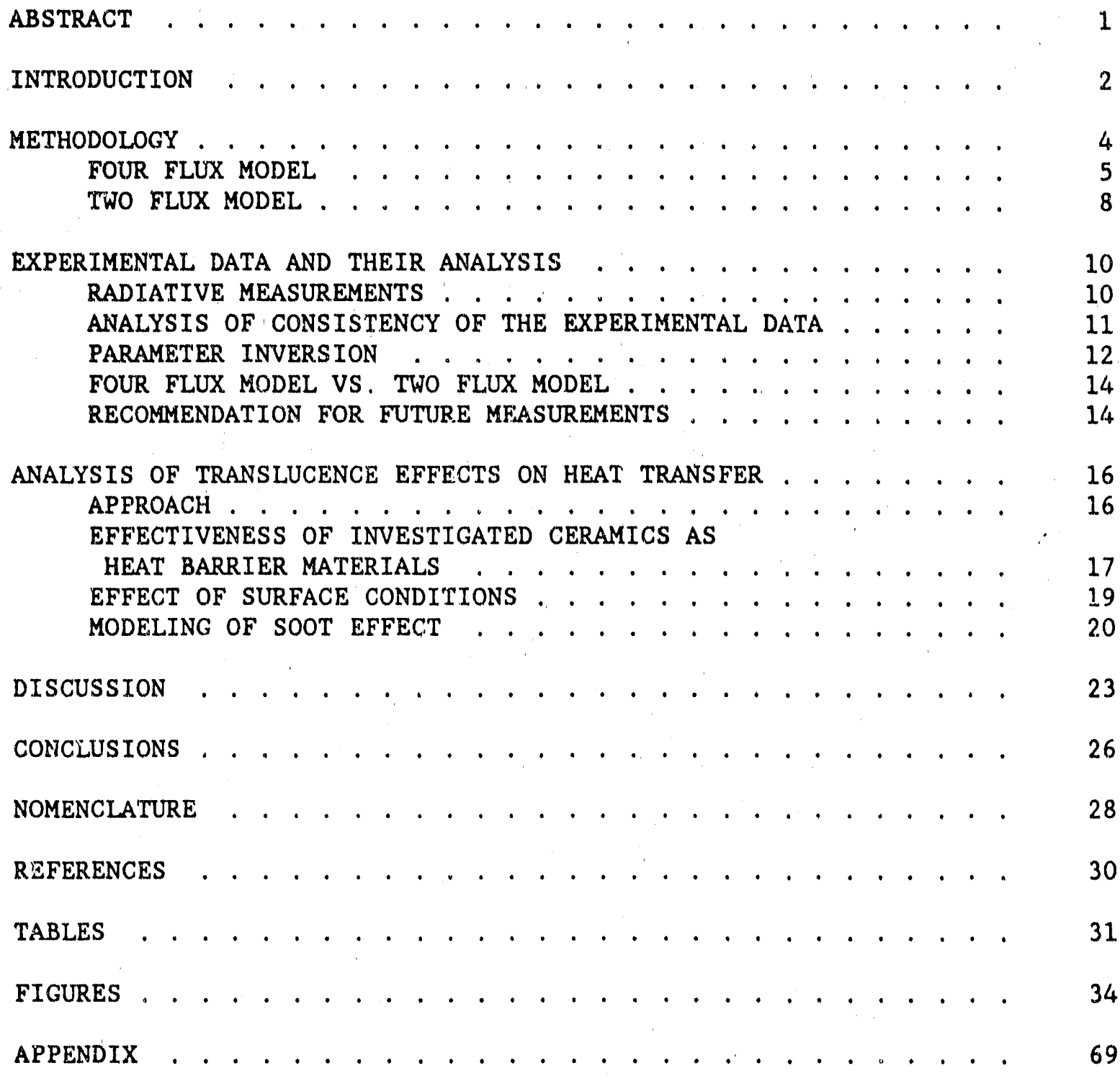




\section{EINAL REPORT}

\section{EFFECT OF TRANSLUCENCE OF ENGINEERING CERAMICS \\ QN HEAT TRANSFER IN DIESEL ENGINES}

PART II

\section{EXPERIMENTS ON RADIATIVE PROPERTIES OF CERAMICS}

S. Wahiduzzaman and T. Morel.

\section{ABSTRACT}

This report describes, the experimental portion of a broader study undertaken to assess the effects of translucence of coramic materials used as thermal barrier coatings in diesel engines. In an earlier analytical work a parametric study was performed, varying several radiative properties over ranges typical of engineering ceramics, thereby identifying the most important radiative properties and their impact on in-cylinder heat transfer. In the current study these properties were experimentally determined for several specific zirconia coatings considered for thermal barrier applications in diesel engines.

The methodology of this study involved formulation of a model capable of describing radiative transfer through a semitransparent medium as a function of three independent model parameters, le, absorption coefficient, scattering coefficient and refractive index. A set of radiative measurements was then fitted to this model by optimization of the above model parameters. The radiative measurements were comprised of hemispherical reflectance and transmittance spectra from samples of several different thicknesses of each ceramic under collimated (unidirectional) illumination. A four-flux model was required to extract accurate radiative properties from the measurements.

For the zirconia-based ceramics investigated in this study, it was concluded that for usual coating thicknesses $(1.5-2.5 \mathrm{~mm})$ these ceramics are optically thick and hence, are effective as radiative heat transfer barriers. These ceramics possess high scattering coefficients and low absorition coefficients causing them to be highly reflective $(60-808)$ in the spectral region where thermal radiation is important. As a consequexce, only a small portion of the incident energy is captured by the coating system and transmitted to the metal substrate via conduction.

The convective heat flux, which is driven by the temperature differential between the gas and the ceramic-gas interface, was found to be highly dependent on the location where radiative energy is absorbed. If a significant amount of energy is absorbed near the surface, as is the case for ceramics investigated, surface temperature is raised causing convective heat flux to be decreased. On the other hand, for ceramics that are transparent the radiative energy is absorbed at the ceramic/metal interface 
and consequently, the gas/ceramic interface remains relatively cool promoting convective heat transfer.

The performance of the investigated ceramics and the mechanism of heat transfer were found to depend on surface condition, specifically on soot deposition. If the surface fouling is small, the ceramics behaved as described above, 1.e., as optically thick materials characterized by high scattering coefficient and low absorption coefficient. In this case, the energy transport is primarily due to convective heat transfer since only a small fraction of the incident radiant energy can be trapped by the coating. On the other hand, if the coating surface is totally covered by soot, its performance will be similar to that of a clean optically thick material characterized by small scattering coefficient and high absorption coefficlent. In this case, there will be a significant increase in radiation heat transfer absorbed at the surface with an associated decrease in convective heat transfer.

Although the coatings investigated in this study were found to be optically thick at or near nominal thicknesses $(2.5 \mathrm{~mm})$, this is by no means representative of all engineering ceramics. For example, based on available literature data, monolithic ceramics have been found to be more transparent than the ceramics investigated in this study and, consequently, are less effective as radiation heat transfer barriers.

Based on the results, it is concluded that ceramics with high scattering and low absorption coefficients are the most suitable for engine applications where in-cylinder surfaces can be expected to remain clean. If surfaces are expected to be sooted an opaque ceramic characterized by either high scattering coefficient and/or high absorption coefficient should be chosen in order to bring about a substantial decrease in convective heat flux. Thus, to insure the optimum thermal barrier operation for either clean or heavily sooted surfaces, a ceramic material with high scattering coefficient provides the best choice.

\section{INTRODUCTION}

Ceramic materials are being developed for application as heat barrier materials in insulated diesel engines. Their purpose is to reduce the heat transfer rate from the gases to the walls, with the twin benefits of increased engine efficiency and of lower heat rejection to the coolant.

The Idea of a heat barrier layer is to create a path of high resistance to heat transfer, and this is accomplished by using high temperature materials which have low thermal conductivity. Certain ceramics, e.g. zirconia, combine these properties with the potential for low material cost, which accounts for the interest in their development for this application. Computer simulations of in-cylinder heat transfer processes and of the heat conduction through the structural components of the engine indicate that ceramics can indeed provide very substantial reductions in engine heat transfer, translating into important thermal efficiency gains, reduced heat rejection to coolant and increased exhaust energy availability. 1 
However, it is increasingly being realized that some of the ceramics proposed for diesel eng ine thermal barrlers are partially transparent in the spectral region where most of the thermal energy associated with the combustion process is concentrated (Liebert ${ }^{2} 3$ and Makino et $a 1^{4}$ ). This causes concern about the effectiveness of such ceramic layers in reducing heat transfer in insulated diesel engines, where t.t is known that ${ }_{6}$ radiation can account for a significant portion of the total heat transfer.

The gas-to-wall heat transfer in diesel engines is produced by convection from cylinder gases and by radiation from the soot-laden burning zone. In the high output turbocharged engines typically used in highway txuck applications, the heat radiation accounts for some 20 percent of the total heat transfer from gases to walls at the rated engine conditions. When the combustion chamber is insulated, the convective component of the heat transfer is selectively reduced. The proportion of heat transfer that is due to radiation then rises to over 50 percent, thereby becoming a much more significant fraction of ${ }_{5}$ the overall heat rejection and a more important design consideration.

In all simulations of diesel engine heat transfer processes reported to date, the assumption has been made that the absorption coefficient of the ceramic is very large so that all of the incident radiation is deposited at the gas/ceramic interface -. 1.e., the radiation has not been allowed to penetrate into the interior. This is a carryover from studies of metallic engines where this treatment provides a fairly accurate description of the actual process. However, since some ceramics of engineering interest are known to be translucent, especlally at infrared radiation wavelengths, this approximation may be quite incorrect.

The work carried out on this contract is divided into two parts. A previous report7 described the results of the first part, which concerned an analytical study of the radiation process within engineering ceramics, and showed how heat transfer is affected by the radiation properties of ceramics (absorption coefficient, scattering coefficient, index of refraction and surface reflectivities). This report presents the results of the second part of the work concentrating on an experimental determination of the radiative properties of some specific ceramics, and then predicting their effectiveness as heat barrier materials when used in a diesel engine environment.

There were three principal aspects to work described in this report. The first was the selection and implementation of an appropriate methodology to determine the radiative properties of the ceramic materials. The second was the use of the method to determine the radiative properties of several existing coatings that have been developed for diesel engine application. The last was an analysis of the heat transfer through a ceramic-coated wall of a diesel engine, including all three heat transfer mechanisms -. convection, radiation and conduction - - and through f.t an assessment of the effectiveness of these specific ceramics as heat barrier materials. 


\section{METHODOLOGY}

The principal parameters required to describe radiative transport in a semitransparent mediun are the absorption coefficient (k), scattering coefficient ( $s$ ), refractive index ( $n$ ) and scattering phase function ( $p$ ). For many ceramic materials in which scattering can be assumed to be isotropic, the first three parameters are adequate to describe radiative transport, and in this work we concentrate on these three. An additional assumption, implicit in this description, is that the interfacial reflectivities are known or can be determined using Fresnel's equation. The latter approach is chosen for this study which requires that the interfaces are optically smooth.

The approach adopted here to determine these parameters for a given material is :o take radiative measurements of several samples of that materlal fashloned into thin coupons of different thicknesses. A model describing the radiative transfer in semi-transparent media can be then fitted to the acquired data to determine the above radiative properties. The parameter inversion process involves matching the measured reflectance and transmittance data of a set of coupons of different thicknesses with the model computed values. An objective function based on a sum of: squares of normalized differences between measured and computed reflectance and transmittance values can be minimized to obtain the values of $n$, $k$ and $s$ which give the best correspondence between measurement and model predictions.

The approach discussed above was implemented using measurements obtained at two different locations (wavelengths of 0 . to $2.5 \mu \mathrm{m}$ at $\mathrm{NBS}^{*}$ and 2.0 to 20.0 at willey Corporation ${ }^{* *}$ ). In both laboratories hemispherical reflectance and transmittance spectra were measured under collimated illumination and consequently include contributions of the collimated flux in addition to the diffuse flux which can be created from the collimated flux undergoing multiple scattering. This necessitates the use of a radiation model capable of describing decay of the collimated flux into a diffuse flux due to multiple scattering unless the incident radiation is diffuse to begin with. A four flux model as opposed to a two flux model is better equipped to handle the problem at hand. Initially a two flux model was used for paramete: inversion and was soon discovered to be inadequate at low scattering levels and was discarded in favor of a four flux model. However, for the sake of completeness both models will be discussed below and a comparison of the model performances will. be presented in a later section.

\footnotetext{
* Center for Radiation Research, National Measurement Laboratory, National Bureau of Standards, Gaithersburg, Maryland 20899.

**illey Corporation, P.0. Box 670, Melbourne, Florida 32901.
} 
FOUR FLUX MODEL

The model chosen in this study is the four-flux model, which predicts specular and diffuse reflectivity and transmissivity for a planar medium illuminated by diffuse and or collimated flux. The parameters $k, s, n$ and the material thickness are the gnly inputs to the model. The model (Ishimaru and Makino ard Kunitomo ${ }^{4}$ ) assumes that the radiation transport In a cold (non-emitting) medium can be described by four fluxes. Two of these are a diffuse forward flux and a diffuse backward flux, both of which remain diffuse upon interfaclal reflection and scattering. The other two fluxes are a collimated forward and a collimated backward flux which undergo isotropic scattering, thereby contributing equally to the forward and backward diffuse fluxes. The collimated fluxes are assumed to remain collimated after specular (mirror-like) interfacial reflections. Under these assumptions the governing equations and associated boundary conditions are (Figure 1):

governing equations :

$$
\begin{aligned}
& \frac{d D^{+}}{d x}--(2 k+s) D^{+}+s D^{-}+\frac{s}{2} C^{+}+\frac{s}{2} C^{-} \\
& -\frac{d D^{-}}{d x}--(2 k+s) D^{-}+s D^{+}+\frac{s}{2} C^{-}+\frac{s}{2} C^{+} \\
& \frac{d C^{+}}{d x}=-(k+s) C^{+} \\
& -\frac{d C^{-}}{d x}--(k+s) C^{-}
\end{aligned}
$$

boundary conditions :

$$
\begin{aligned}
& D^{+}(0)=\left(1-R_{d o}\right) F_{d}+F_{d i} D^{-}(0) \\
& D^{-}(d)=R_{d i} D^{+}(d) \\
& C^{+}(0)=\left(1-R_{c o}\right) F_{c}+R_{c i} C^{-}(0) \\
& C^{-}(d)=R_{c i} C^{+}(d)
\end{aligned}
$$

where 0 and $d$ denotes front and back surface, respectively.

A general solution to the above set of equations is:

$$
D^{+}(x)-\alpha_{1} A e^{-\tau}+\alpha_{2} B e^{\tau}+\alpha_{3}(1+\beta) e^{-2 \beta r}+\alpha_{4}(1-\beta) e^{2 \beta r}
$$




$$
\begin{aligned}
& D^{-}(x)-\alpha_{1} B e^{-r}+\alpha_{2} A e^{r}+\alpha_{3}(1-\beta) e^{-2 \beta \tau}+\alpha_{4}(1+\beta) e^{2 \beta r} \\
& C^{+}(x)-\alpha_{1} e^{-\tau} \\
& C^{-}(x)-\alpha_{2} e^{r}
\end{aligned}
$$

where

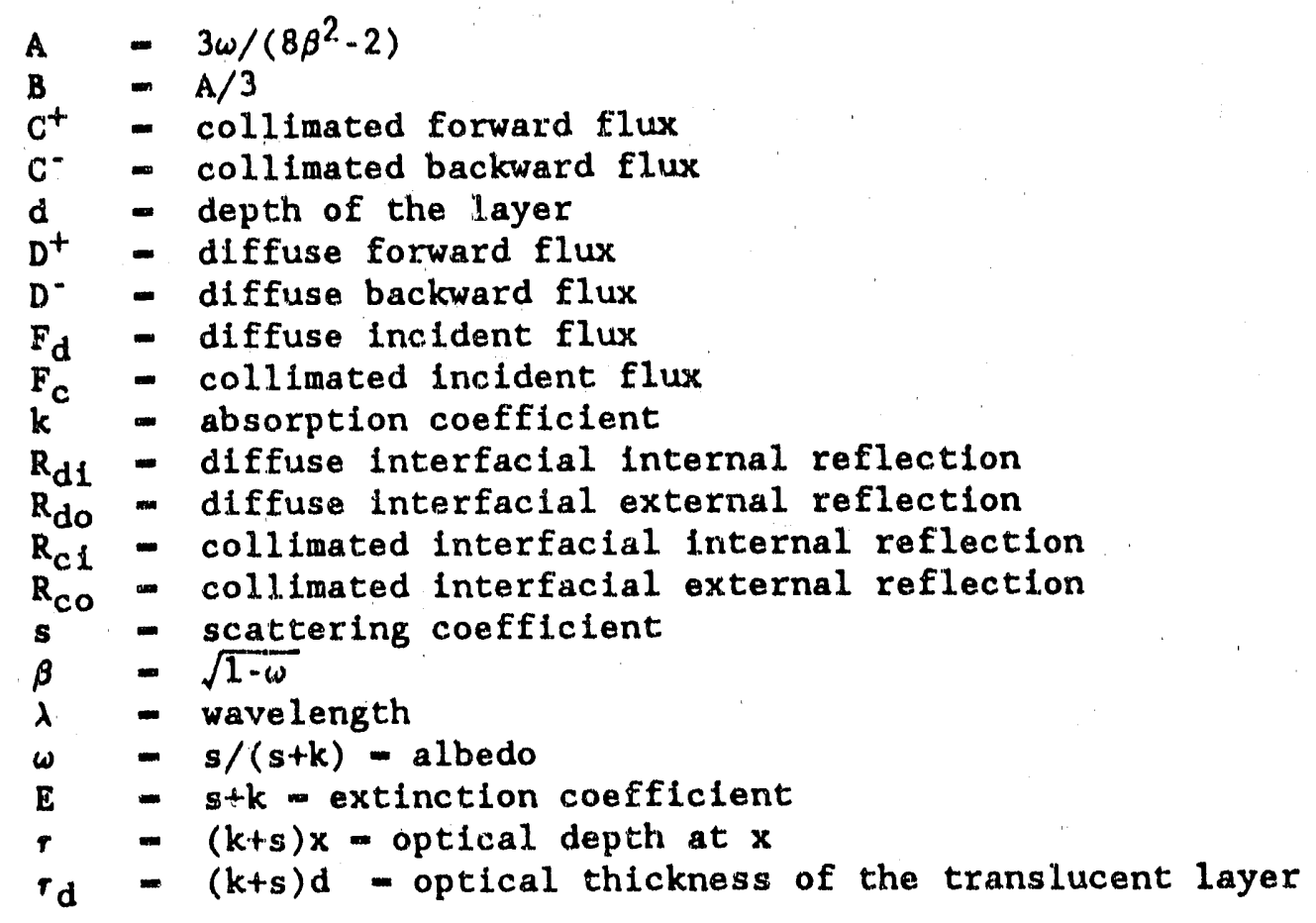

The coefficients $\alpha_{1}, \alpha_{2}, \alpha_{3}$ and $\alpha_{4}$ are determined by solving the following simultaneous equations obtained using the boundary conditions: 


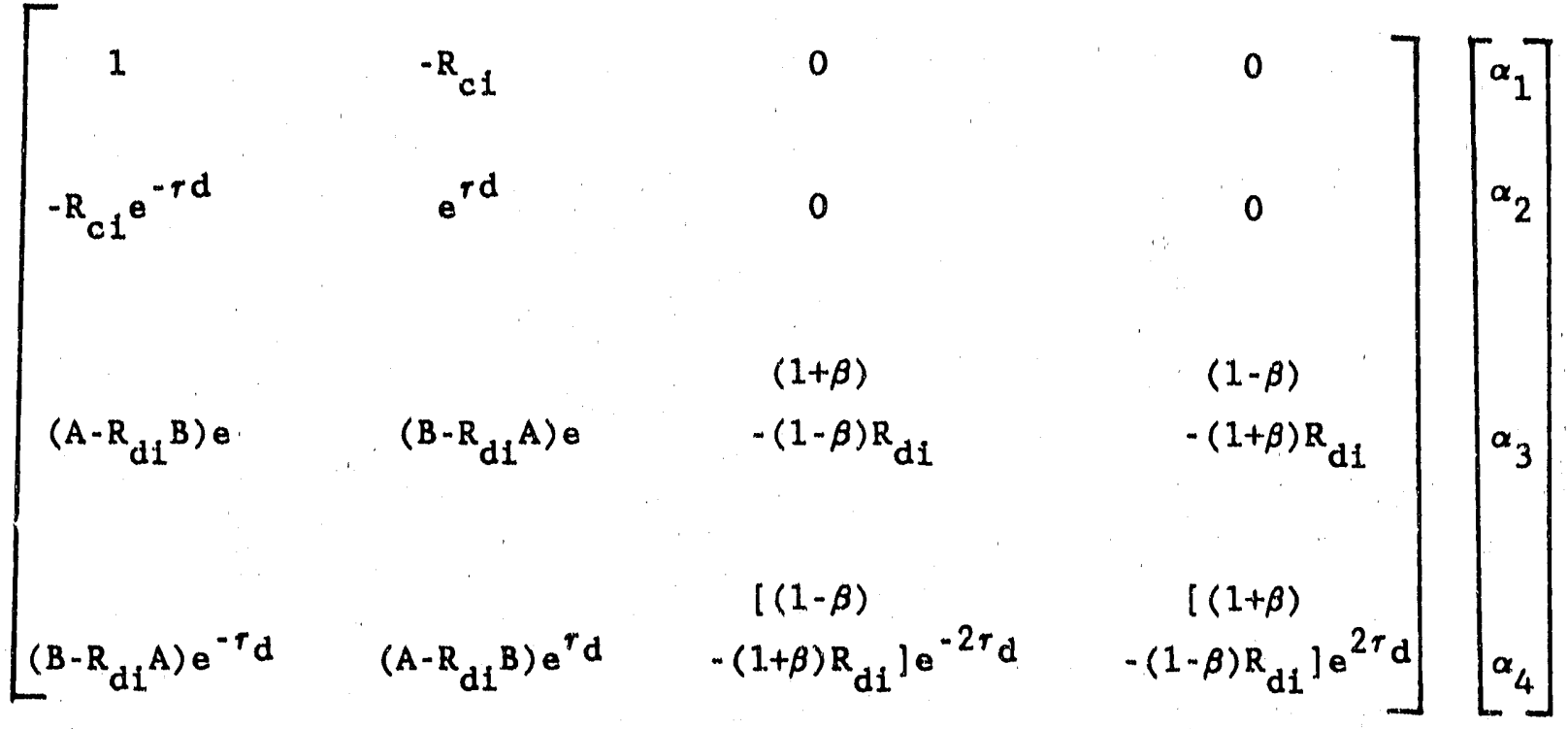

$$
\begin{aligned}
& -\left[\begin{array}{c}
\left(1-R_{c o}\right) F_{c} \\
0 \\
\left(1-R_{d o}\right) F_{d} \\
0
\end{array}\right]
\end{aligned}
$$

Then collimated and diffused reflected fluxes at the inside front surface can be calculated after substitution of Eqs. (10) and (12) in the following equations:

$$
\begin{aligned}
& S_{c}=R_{c o} F_{c}+\left(1-R_{c i}\right) C^{-}(0) \\
& S_{d}=R_{d o} F_{d}+\left(1-R_{d i}\right) D^{-}(0)
\end{aligned}
$$

respectively.

Similarly, the collimated and diffused transmitted fluxes at the back surface of the ceramic are obtained after substituting Eqs. (9) and (11) in the following equations:

$$
\begin{aligned}
& H_{c}-\left(1-R_{c l}\right) C^{+}(d) \\
& H_{d}=\left(1-R_{d i}\right) D^{+}(d)
\end{aligned}
$$

From these fluxes reflectance and transmittance can be appropriately defined as follows: 


$$
\begin{aligned}
& R_{h}-\left(S_{c}+H_{c}\right) /\left(F_{d}+F_{c}\right) \\
& T_{h}=\left(S_{d}+H_{d}\right) /\left(F_{d}+F_{c}\right)
\end{aligned}
$$

TWO FLUX MODEL

Under purely diffuse Illumination, only tro diffuse fluxes are necessary to describe radiative transport in a planar medium provided assumptions previously made are still valid. It was assumed that a collimated flux transforms into diffuse forward and backward fluxes by undergoing 1sotropic scattering. If the scattering level is high this conversion will happen early and simpler two (diffuse) flux model can then be usad as a further approximation of tine radiative transport in such media. The flux equations and the boundary conditions for the model can be written as:

$$
\begin{aligned}
& \frac{d D^{+}}{d R}=-(2 k+s) D^{+}+s D^{-} \\
& -\frac{d D^{-}}{d x}=-(2 k+s) D^{-}+s D^{+}
\end{aligned}
$$

The accompanying boundary conditions are:

$$
\begin{aligned}
& D^{+}(0)=\left(1-R_{d o}\right) F_{d}+R_{d i} D^{-}(0) \\
& D^{-}(d)=R_{d i} D^{+}(d)
\end{aligned}
$$

It should be noted here that the above equations are Identical to those obtained from the four flux model under purely diffuse illunination.

The general solution to the above equations is:

$$
\begin{aligned}
& D^{+}-\alpha_{3}(1+\beta) e^{-2 \beta r}+\alpha_{4}(1-\beta) e^{2 \beta r} \\
& D^{-}-\alpha_{3}(1-\beta) e^{-2 \beta r}+\alpha_{4}(1+\beta) e^{2 \beta r}
\end{aligned}
$$

The coefficients $\alpha_{3}$ and $\alpha_{4}$ are then determined from the boundary conditions as follows: 


$$
\left[\begin{array}{cc}
(1+\beta)-(1-\beta) \mathrm{R}_{\mathrm{d} I} & (1-\beta)-(1+\beta) \mathrm{R}_{\mathrm{di}} \\
{\left[(1-\beta)-\left(1+\beta \mathrm{R}_{\mathrm{di}}\right] \mathrm{e}^{-2 \beta r_{\mathrm{d}}}\right.} & {\left[(1+\beta)-(1-\beta) \mathrm{R}_{\mathrm{di}}\right] \mathrm{e}^{2 \beta r_{\mathrm{d}}}}
\end{array}\right]\left[\begin{array}{l}
\alpha_{3} \\
\alpha_{1 / 4}
\end{array}\right]-\left[\begin{array}{c}
\left(1-\mathrm{R}_{\mathrm{do}}\right) \mathrm{F}_{\mathrm{d}} \\
0
\end{array}\right]
$$

After solution one obtains

$$
\begin{aligned}
& \alpha_{3}-\frac{F_{d}\left(1-R_{d o}\right) U e^{2 \beta r_{d}}}{u^{2} e^{2 \beta r_{d}}-v^{2} e^{-2 \beta r_{d}}} \\
& \alpha_{4}-\frac{-F_{d}\left(1-R_{d o}\right) V e^{-2 \beta r_{d}}}{u^{2} e^{2 \beta r_{d}}-v^{2} e^{-2 \beta r_{d}}}
\end{aligned}
$$

where

$$
\begin{aligned}
& \mathrm{U}=(1+\beta)-\mathrm{R}_{\mathrm{d} I}(1-\beta) \\
& \mathrm{V}-(1-\beta)-\mathrm{R}_{\mathrm{dI}}(1+\beta)
\end{aligned}
$$

The reflected and transmitted fluxes are:

$$
\begin{aligned}
& S_{d}-R_{d o} F_{d}+\left(1-R_{d i}\right) D^{-}(0) \\
& H_{d}=\left(1-R_{d 1}\right) D^{+}(d)
\end{aligned}
$$

Then the reflectance is given by:

$$
\begin{aligned}
R_{d} & =S_{d} / F_{d} \\
& -R_{d o}+\left(1-R_{d o}\right)\left(1-R_{d i}\right) \frac{(1-\beta) U e^{2 \beta r_{d}}-(1+\beta) V_{e}-2 \beta r_{d}}{u^{2} e^{2 \beta r_{d}}-v^{2} e^{-2 \beta r_{d}}}
\end{aligned}
$$

and the transmittance is given by:

9 


$$
\begin{aligned}
T_{d} & =H_{d} / F_{d} \\
& =\left(1-R_{d o}\right)\left(1-R_{d i}\right) \frac{(1+\beta) U-(1-\beta) V}{U^{2} e^{2 \beta r} d}-v^{2} e^{-2 \beta \tau d}
\end{aligned}
$$

It should be noted here that the reflectance and transmittance in equations $18,19,29$ and 30 are spectral quantities (1.e., have unique values for each wavelength).

The essence of the method involves minimizing the differences between the computed reflectance and transmittance spectra using these equations with the measured spistra by suitable cholce of model parameter in order to obtain spectral distributions for these parameters.

\section{EXPERIMENTAL DATA AND THEIR ANALYSIS}

\section{RADIATIVE MEASUREMENTS}

Four different ceramics were available for radiative parameter inversion. These included plasma sprayed zirconia (PSZ) (138 Yttria stabilized) from Plasma Technics*, PSZ and TZP (Tridiaconal Zirconia Polycrystals) from Oak Ridge National Laboratory ${ }^{\star}$ and PSZ (248 Ceria stabilized) from Caterpillar ${ }^{\star \star}$. The success of the above procedure, 1.e. obtaining the radiative properties of a given ceramic, depends on acquiring a set of experimental data which are independent of each other. This requires measurement of reflectances and transmittances at sufficiently distinct optical depths. Hence, it is desirable to select thicknesses of samples such that an optically thin, an optically thick and an intermediate optical thickness are included in the set of samples. However, without a priori information, which was the case in the present study, one can only guess at the best thicknesses for this purpose. Based on feasibility of fabrication of the thinnest samples, mechanical strength, and literature values of properties of similar materials, three to four thicknesses were specified and fabricated for each of the four ceramics investigated in this study. All of these samples are labeled and described in the Table I.

*Plasma Technics Inc., 1143 West Newport Center Drive, Deerfield Beach, Florida 33442 .

** Oak Ridge National Laboratory, P. O. Box 2008, Oak Ridge, Tennessee 37831 .

*** Caterpillar Inc., Technical Center, P.0. Box 1875, Peoria, Illinois $61656-1875$. 
The original plans were to obtain normal incidence diffuse reflectance for all thirteen samples. The transmittance measurements were planned only for nine samples, excluding the thickest sample of each set which were expected to bis too thick to allow any transmission. The first set of measurements was made over a wavelength band spanning $2 \mu \mathrm{m}$ to $20 \mu \mathrm{m}$ at Willey Corporation, a private firm speclalizing in radiometry. In this wavelength range meaningful transmittance measurement could be obtained only for seven samples, because only the thinnest sample of the PSZ samples from Caterpillar (set D) transmitted enough energy to obtain reliable transmittance data.

The measurements at lower wavelength, extending from 0.25 to $2.5 \mu \mathrm{m}$, were conducted at the National Bureau of Standards. Again for some of the samples (A2, D11, D12) poor transmittance results were obtained owing to low signal-to-noise ratio. In addition, sample Al was found to be broken during transit and no transmittance measurement could be sbtalned from this sample. The matrix of radiative measurements carried out by willey Corporation and NBS are summarized in Table II.

\section{ANALYSIS OF CONSISTENCY OF THE EXPERIMENTAL DATA}

In this study, the emphasis of the analysis was placed on the wavelength range from the visible $; 0.4 \mu \mathrm{m}$ ) to $5 \mu \mathrm{m}$ where thermal radiative energy is important in diesel engine applications. (Note that the peak radiant intensity of a blackbody occurs at $2.9 \mu \mathrm{m}$ at $1000 \mathrm{~K}$ and at $1.45 \mu \mathrm{m}$ at 2000K.) This wavelength band contains the overlap region $(2.0 \mu \mathrm{m}$ to 2.5 $\mu \mathrm{m})$ where data was obtained at both laboratories. The agreement between the data in the overlap range was examined from the two sources and it was found satisfactory. (It should be noted that the data from Willey Corporation exhibited noise inherent to the measuring instrument ${ }^{8}$ and had to be smoothed.) The composite plots of data belonging to both sources axe shown in Figures 2 to 5. (The unsmoothed data from Willey Corporation is presented in the Appendix.)

The available data were carefully scrutinized to determine their suitability for radiative parameter inversion. The following observations of unusual trends were made:

(1) Sample sets B and C from Oak Ridge exhibited very similar reflectance and transmittance spectra despite different composition (Figures 3 and 4). This similarity was evident in the data obtained at both Willey and NBS. It was concluded that the two sets are radiatively identical.

(2) The qualitative trend of the reflectance data of sample C9 was markedly different than those of thinner samples of the same material ( $C 7$ and $C 8$ ). The differences include a) lower reflectance values below $0.5 \mathrm{\mu m}$, b) relatively constant reflectance values between $0.5 \mu \mathrm{m}$ and $2.5 \mu \mathrm{ms}$ and $c$ ) most importantly, a dip in the reflectance values around $2.75 \mu \mathrm{m}$ (Figure 4b). These characteristic differences suggest that the 
sample C9 may have been contaminated during its fabrication. Hence it was necessary to exclude the data from this sample from parameter inversion analysis for set $C$. A similar conclusion can be made for sample B4 as evidenced in Figure $3 a$.

(3) Reflectance spectra for samples belonging to set D exhibited an inconsistent trend with thickness. The spectra of samples D10 and $D 13$ possessed characteristics which are absent in the spectra for samples D11 and D12 (Figure 5b). These characteristics include a dip at $2 \mu \mathrm{m}$ and high reflectance values beyond $3 \mu \mathrm{m}$. Since transmittance data were avallable for sample D10, it was decided that only data from samples D10 and D13 would be used for parameter inversion for set $D$. The choice D11 and D13 would only provide two sets of measurements as opposed to three sets of measurements for the cholce made.

After careful consideration of the above factors, consistent sets of data from the two laboratories were merged. Since data obtained at Willey Corporation are less rellable in the overlap region (2 $\mu \mathrm{m}$ to $2.5 \mu \mathrm{m}$ ), the data from NBS were given higher weight in this band during merger. Figures 6 to 8 show merged data for sample sets B, C and D. It can again be noted here, allowing for the measurement uncertainties, sets $B$ and $C$ possess identical spectra.

Unfortunately, the data for sample $A$ is too sparse for parameter inversion. It can be seen in Figure 2(b) that reflectance is nearly identical for all three samples (A1, A2, A3). (The spectrum A1 presented here was measured from a damaged sample and as such NBS has not certified this data.) This signifies that even at the smallest thickness $(0.51 \mathrm{~mm})$ the ceramic is optically thick and therefore the samples do not produce sufficiently independent information required for parameter inversion. It should be noted that transmittance spectrum of $\mathrm{Al}$ is unreliable since it was measured from a damaged sample. Despite the deficiencies in the measurements, some conclusions can still be drawn for this material and will be discussed in a later section.

\section{PARAMETER INVERSION}

As discussed in the previous section, for sets $B$ and/or $C$ we have two reflectance and two transmittance spectra that are consistent within each set. For the set $D$, there are only two reflectance and one transmittance spectra that have consistency. Thus, for both sets, the number of spectra available for parameter inversion is rather small. It was found that it is a difficult, if not impossible, task to extract three independent radiative parameters from such a sparse input data set. Initial analysis showed that of the three chosen parameters $(n, k, s)$, the refractive index $n$ is the least sensitive. Upon analysis, one observes that the refractive Index affects radiative transport in two ways; through interfacial reflectivities (Fresnel's reflectivity) and through the self-emission term. Since the ceramics studied here possess high scattering coefficients, interfacial reflectivities have little contribution to layer reflectances. In addition, reflectance and transmittance of the samples were measured at 
room temperature, consequently, tie self-emission term is negliglble in comparison to other fluxes and may be dropped from the transport equation. Under these circumstances, it was decided to keep the refractive index fixed at 1.58 and to determine only the remaining two parameters ( $s$ and $k$ ) through the parametex inversion procedure. This value of refractive index is based on previous observations and trends observed during current data analysis, It was reported in previous investigations (e.g. Makino and Kunitomo ${ }^{4}$ ), that refractive index remains nearly constant from $0.5 \mu \mathrm{m}$ to 5 $\mu \mathrm{m}$. Its value is expected to be between 1.2 to 2.5 . In yet another study (Matthews ${ }^{9}$ ) involving a similar nonlinear parameter inversion technique, the refractive index of zirconia was estimated to be 1.6. Thus the value of 1.58 chosen for this siudy is expected to be close to the actual value of the parameter. The total uncertainty on the remaining parameters introduced by this range in refractive index is of the order of 258 and 358 for scattering and absorption coefficient, respectively.

With the above restrictions, the parameter inversion model was applied to data obtained for sample sets $B$ and $C$. The results are shown in Figures 9 and 10. As expected, two samples exhibited nearly identical radiative properties. The scattering coefficient is found to be high in the visible band, and it steadily decreases as wavelength is increased. On the other hand, absorption coefficient is relatively small and remains constant except in the visible band $(0.4-0.7 \mu \mathrm{m})$, and beyond $4 \mu \mathrm{m}$ where 1 starts to increase very sharply. Figures $11 \mathrm{a}$ and $11 \mathrm{~b}$ show model-predicted reflectance and transmittance for sample set $C$ using the $k$ and $s$ values deduced from the data. It can be observed that the predicted reflectances and transmittance are in good agreement with the experiment except for the $10 \mathrm{~mm}$ sample (Figure 4b). It may be recalled that the measured reflectance spectrum for this sample was excluded from the data analysis owing to its inconsistent characteristics.

Analysis was also performed on the data belonging to set $D$. The inverted parameters are shown in Figures $12 \mathrm{a}$ and $12 \mathrm{~b}$. The predicted reflectance and transmittance are shown in Figure 13a. There is good agreement between measured (Figure 13b) and predicted (Figure 13a) transmittance values, however, the predicted reflectances for the two different thicknesses are nearly identical to the measured reflectance of the thinnest sample (D10). If an absorptance spectrum is computed for this sample from the measured reflectance and transmittance (Absorptance - 1 - Transmittance - Reflectance) spectra, it can be readily observed that for much of the spectrum the optical depth of the sample is high. Hence, there is no reason to belleve that for higher thickness reflectance will be markedly different, contrary to the trends suggested by the data. Rather, it is 11kely that the apparent differences in the measured reflectance spectra are due to variations in surface preparations.

The scattering coefficients for set $D$ possess the same qualitative trend as those of set $B$ and $C$ except their values are about twice as high. On the other hand, the absorption spectrum shows a distinctive peak at $3 \mu \mathrm{m}$ corresponding to the valleys in the reflectance and transmittance spectra. In general, set $D$ is more opaque than $B$ and $C$ due to 1 ts higher scattering and absorption coefficients. 
It is worth noting here that the radiative parameters obtained in this study are derived from room temperature measurements. However, in a previous study Makino and Kunitomo ${ }^{4}$ did not observe any major dependence of radiative properties on temperature for zirconla and alumina. Hence, it is belleved that the parameter values reported here will be valld for diesel engine applications where temperatures $(1000 \mathrm{~K})$ are not too dissimilar to the range investigated in the referenced study $(-300 \mathrm{~K}$ to $700 \mathrm{~K})$.

FOUR FLUX MODEL VS. TWO FLUX MODEL

The parameter inversion procedure discussed in the previous section utilizes a four flux radiation model. However, Initially a two flux radiation model was used before it was discarded in favor of the four flux model. The experinental measurements described earlier were made under collimated (near normal beam) 1llumination. The two flux model is inadequate for describing propagation of collimated flux through a semi-transparent medium. However, if the rraction of incident energy that penetrated the medium in properly calculated (using directional reflectivities), the two flux model may still be valid for a medium where collimated flux undergoes quick transformation into diffuse flux due to high scattering level. On the other hand, for samples having small optical depths where the extinction coefficient is of the order of unity the contribution of the internal collimated flux on total transmittance and reflectance will be comparable to the contribution from the internal diffuse flux. Hence, in this case it is necessary to solve for both collimated and diffuse fluxes simultaneously, which the two flux model cannot accomplish.

In order to remove this weakness in the originally planned radiative parameter inversion model, replacement of the the two flux model by a four flux model was essential as it was confirmed by comparisons of parameters evaluated by both models. (Both of these models have been described in previous sections.) Initial results obtained using the original two-flux inversion model revealed that for ceramics under study the scattering level. tapers off at higher wavelength. It seemed likely that the validity of two-flux model will break down at these high wavelengths. The revised model utilizing a four-flux model was applied to the avallable experimental data. The radiative parameters thus deduced were compared against the parameters from the two-flux model. Figures $14 \mathrm{a}$ and $14 \mathrm{~b}$ show a comparison of radiative parameters obtained using both models for ceramic $D$. It was observed that the two-flux model underpredicted the scattering coefficient by as much as 50 at higher wavelengths, whereas the absorption coefficient remained almost unchanged.

\section{RECOMMENDATION FOR FUTURE MEASUREMENTS}

It is evident that the proper chaice of the sample thicknesses is an essential prerequisite for successful parameter inversion. However, prior knowledge regarding optical thickness is required to make such choices. Hence the recommended procedure would be to make preliminary transmittance 
measurements to obtain some knowledge about the opacity of the sample, or making a larger number of samples (at least 5) of varlous thicknesses to increase the likelthood of capturing the right sample thlckness range. The recommended set of optical thicknesses is $\mathrm{kL}-0.5,1.0,1.5,2.0$ and 2.5 which assures that meaningful values of transmittance and reflectance can be attained. For example if a material has an extinction coefficient of $10,000 \mathrm{~m}^{-1}$ in the wavelength region of interest, the required samples will have thicknesses of $0.05 \mathrm{~mm}$ to $0.25 \mathrm{~mm}$. If samples that thin cannot be fabricated, a thicker set of samples may be substituted, but a lower accuracy will result.

As discussed earlier, the refractive index is the least sensitive of the chosen parameters. In order to extract this parameter, one needs measurement techniques which possess stronger dependence. One approach could be a separate measurement of the diffuse and directional reflectance and transmittance (In the present case the sum of the diffuse and directional values was measured). However, this would require greater attention to surface preperation; the sample surfaces should be smooth, parallel and consistent from sample to sample. Another approach would measure polarized components of this reflectance.

Further, the number of samples should be as large as possible. A large number of samples is often necessary (eight for Makino10) to obtain reliably at least three linearly Independent measurements. As for the data reduction method, it is recommended that it be based on the four-flux radiacion model (or a higher order model) which has been shown here to be better capable of dealing with radiative properties of typical engineering ceramics than the two-flux model. 


\section{ANALYSIS OF TRANSLUCENCE EFFECTS ON HEAT TRANSFER}

\section{APPROACH}

The general scheme of evaluating the heat transfor in diesel engines involves the solution of the energy equation (heat transfer) within the wall under appropriate gas side and coolant side boundary conditions. In the present study the cylinder walls were assumed to be composed of two layers: an insulating ceramlc wall facing the combustion gas and a metallic substrate. The energy equation is a one-dimensional conduction equation with an additional source term representing radiation energy absorbed/emitted within the medium. This energy equation was solved for two distinct regions: a semitransparent region within the ceramic, and a fully opaque region within the substrate. A two-flux radiative transport equation was solved to compute the radiative heat flux vector. Since the radiation process in a diesel engine has no collimated component, both the two-flux model and four-flux yield the same result. However, equations 1 , 2, 20 and 21 do not contain a self emission term. This term was included since the wall temperature of ceramics in diesel engine applications is expected to be in a region where self emission begins. to be important. The resulting equation is given in a previous report" (Wahiduzzaman and Morel ${ }^{7}$ ).

The gas side boundary conditions were established by computer simulation of in-cylinder processes taking place in a heavy duty truck diesel engine operating at rated conditions using IRIS engine design analysis codeli. This provides cyclic histories of radiation/convection temperatures, heat transfer coefficients and the products of soot volume fractions and radiation path length. These histories are shown in Figures 15a, 15b and 15c. The coolant side boundary condition consisted of a fixed coolant temperature (640K) and a very high heat transfer coefficient to impose a temperature of about $650 \mathrm{~K}$ at the ceramic/metal interface. Detalls of the implementation of the energy equation and the boundary conditions were given in an earlier report describing the analytical phase of the study (Wahiduzzaman and Morel ${ }^{f}$ ). It is worth noting here that during the part of the cycle when no radiating combustion gas is present, it was assumed that the volumetric and surface emission outward from the ceramic is exactly balanced by the energy recelved from the other walls. This is equivalent to the assumption of equal radiosity for all. walls.

For typical radiation temperatures encountered during combustion (' $T$ gas $1800-2500 \mathrm{~K})$, the fraction of total radiation energy existing beyond 5 gas is small (5-118). At the same time, it was also evident from the experimental results that the ceramics under study become highly opaque beyond this wavelength. Hence, the ceramic layer can be assumed to have an opaque band from $5 \mu \mathrm{m}$ to $\infty$, where the absorption and emission of radiation energy beyond $5 \mu \mathrm{m}$ is accounted for as a surface phenomenon. For the rest of the wavelength domain, the absorption and scattering coefficient spectra were discretized into a number of bands having constant radiative properties within each band. The number of bands was carefully chosen so as to preserve a satisfactory match with the original spectra, without imposing an excessive computational burden in the subsequent analysis. The band 
model representation of absorption and scattering coefficient spectra is summarized in the following tables.

Ceramic $B$ and $C$

$\begin{array}{lcccccc}\lambda(\mu \mathrm{m}) & 0.0-0.5 & 0.5-1.0 & 1.0-1.5 & 1.5-2.5 & 2.5-4.0 & 4.0-5.0 \\ \mathrm{k}(1 / \mathrm{m}) & 150.0 & 35.0 & 20.0 & 20.0 & 20.0 & 112.0 \\ \mathrm{~s}(1 / \mathrm{m}) & 35000 . & 27400 . & 10700 . & 7200 . & 6200 . & 4600 .\end{array}$

Ceramic D

$\begin{array}{lccccc}\lambda(\mu \mathrm{m}) & 0-1.5 & 1.0-1.5 & 1.5-2.75 & 2.75-3.5 & 3.5-5.0 \\ \mathrm{k}(1 / \mathrm{m}) & 710.0 & 300.0 & 10.0 & 1570.0 & 14.0 \\ \mathrm{~s}(1 / \mathrm{m}) & 45200 & 45200 . & 30600 & 14300 . & 20400\end{array}$

The thermophysical properties (conductivity and heat capacity) of the ceramic samples were not available and their determination was beyond the scope of the present study. It was shown earlier (Wahiduzzaman and More $1^{6}$ ) that thermal conductivity is an important parameter influencing the relative sensitivity to translucence. Presently, in the absence of such data, nominal values of $0.8 \mathrm{~W} / \mathrm{mK}$ and $2.91 \times 10^{6} \mathrm{~J} / \mathrm{Km}^{3}$, pertaining to Plasma Technics plasma sprayed PSZ, were used for thermal conductivity and volumetric heat capacity, respectively, of all the materials considered in this study.

Heat transfer analysis was carried out for several thicknesses of ceramic coatings ranging from $0.04 \mathrm{~mm}$ to $5.0 \mathrm{~mm}$, where $2.5 \mathrm{~mm}(-0.100$ inches $)$ is chosen as the nominal thickness for most of the calculation to be discussed later on. The grid points in the ceramic and the substrate were generated In such a manner that the grid spacing was compact near the gas-ceramic and ceramic-substrate interfaces. The smallest elements were located at either side of the ceranic-substrate interface and at the gas-ceramic interface, and they were $0.015 \mathrm{~mm}(0.0006$ incly) thick. There were twenty-one grid points in the insulating ceramic layer.

\section{EFFECTIVENESS OF INVESTIGATED CERAMICS AS HEAT BARRIER MATERIALS}

The effectiveness of the ceramics under study to act as a barrier to thermal radiation was investigated by subjecting these and three idealized (1imiting-case) ceramics to identical boundary conditions. The results of these simulations are summarized in Table III. The idealized ceramics were either completely transparent or completely opaque. The opaque limiting cases were of two types, le, ceramics characterized either by high scattering coefficient $\left(>10^{7} \mathrm{~m}^{-1}\right)$ and negligible absorption coefficient (denoted as opaque (s) in Table III) or by high absorption coefficient $\left(>10^{7} \mathrm{~m}^{-1}\right.$ ) and negligible scattering coefficient (denoted as opaque (a) in 
Table III). All five ceramics had a thickness of $2.5 \mathrm{~mm}$, and the nominal thermophysical properties discussed above. The resulting temporal history of various components of the total heat flux for ceramics $C$ and $D$ is shown In Figures $16 \mathrm{a}$ and $16 \mathrm{~b}$. The solid curve represents the net radiation flux just Inside the ceramic at node \#1. The dashed Iine represents the amount of this flux transmitted to the ceramic/metal interface. The dotted line represents the radiation flux comprising the reflected and emitted radiation from the ceramic coating to the gas. The remaining line represents the convective heat flux to the ceramic coating.

It: may be noted that the total flux for the clean $C$ case is only one quarter of the metal case. This is due to the much higher surface temperature which reduces the convective heat transfer. On the other hand the swing is about three times as high, and that is due to the lower value of the product pck.

It can be seen from Table III that the effectiveness of the two actual ceramic coatings (each $2.5 \mathrm{~mm}$ thick) as a barrier to total heat transfex is about the same. However, the ratio of the radiative heat flux to convective heat flux is different. For the more opaque ceramic (D), much of the radiation is absorbed near the surface, raising the mean surface temperature. This lowers the effective temperature difference between the combustion gas and the surface, and the convective heat flux is reduced. It is interesting to note that the radiative heat flux through ceramic $C$ is less than that with ceramic $D$, despite the fact that $C$ is more transparent than $D$. This is a consequence of differences in reflectance between the two materials. Since both materials have a high scattering coefficient, the one which has a lower absorption coefficient scatters more energy out of the coating before it can be absorbed. Hence ceramic $c$ has a higher total reflectance than ceramic $D$. Consequently, less net radiation energy is absorbed in ceramic $C$ than $D$.

If the thicknesses of the samples are sufficiently reduced this trend can be reversed, since for the ceramic $C$ more of the radiation energy will reach the ceramic-substrate interface and be absorbed there before being scattered back out. Figures $17 \mathrm{a}$ and $17 \mathrm{~b}$ show distributions of radiative and total heat fluxes as a function of layer thickness, and show that this reversal happens at around a thickness of $1.25 \mathrm{~mm}$. In either case, however, the heat flux decreases with increasing layer thickness. It may be noted that the total heat fluxes for the two ceramics appear to not converge as the coating thickness is reduced towards zero. That is not really so, because in the limit the two curves must colncide. However, at even very small thicknesses, e.g., $0.05 \mathrm{~mm}$ for these specific ceramics, the product of the scattering coefficient and the layer thickness is large enough to produce significant scattering which augments the reflected component of radiation heat flux. Since the scattering coefficient of ceramic $D$ is greater than that of ceramic $C$ its net radiative flux is smaller and this persists to even quite small thicknesses.

In terms of the total heat flux, it appears from Table III that the ceramics under study are much closer to both opaque limiting cases than to the transparent limiting case. However, the mechanism of the heat transfer 
process is closer to the opaque(s) limit; in this opaque limit most of the heat transfo: is due to the convective flux, since very little radiative flux can penetrate the coating due to high reflectance caused by Its high scattering and low absorption coefficients. In ceramics $C$ and $D$ a large fracilon of inoldent radiant energy will be reflected away for the same reason. Consequently, a smaller fraction of the radiation energy can be trapped by the coating system and the surface temperature only increases moderately due to absorption of this radiation energy. This in turn will cause a small reduction of the convective heat flux from the maximum value obtainable in the fully transparent case. For the opaque (a) 1imiting case much of the incident radiation will be absorbed at the surface raising its temperature which will cause a largex reduction in the convective heat flux at the cost of an increased radiative heat transfer.

In the case of the Ideal transparent case, both radiative and convective heat fluxes are high. Since there is no scattering, a very small portion of the incoming radiative energy ts reflected (due to interfacial Fresnel's reflectivity) and most of the energy is absorbed at the ceramic-substrate interface. This leaves the gas-ceramic interface at a relatively lower temperature, which Increases the convective heat transfer.

\section{EFFECT OF SURFACE CONDITIONS}

In the preceding analysis it is implicitly assumed that the surface of the ceramic thermal barrier is the same as that of the samples obtained for our analysis. Further it is assumed that it remains free of soot and other deposits and that its surface layer does not become impregnated with foreign materials and/or discolored.

These are very significant assumptions and one needs to understand how do the results obtained here translate to situations where the surface condition is different from that found on the supplied test samples. In an operating diesel engine it is expected that surface fouling will occur and degree of which will depend on the particular engine and the operating condition. This surface fouling could be due to absorption of molsture/fuel by the coating and/or deposition of solid particulates in the ceramic surface. The absorption of solid and liquid particulates can be expected to affect the thermophysical and radiative properties of the coating. The effect of this change is difficult to anticipate or model. In terms of radiative properties, the absorption of combustion products by the coating will tend to make the coating more radiatively opaque and the opaque (a) limit of the coating will provide an indication of its effect on heat transfer.

If the ceramic surface departs from being optically smooth $(\ell / \lambda<1$, where $\ell$ is rms value of surface roughness) more and more incident radiation will be trapped thereby reducing effective reflectance and increasing hemispherical erissivity. In general, this will tend to promote radiation heat transfer. It is difficult, if not impossible, to predict the effect of impregnated surface Impurities. It will, most likely, be dependent on the nature of impurities, It can however be speculated that impurities will also alter the surface finish and make it optically rough and thereby will have a 
similar Impact on radiant heat transfer as surface roughness. However, definttive conclusions can only be made if reflectance measurements are made for the ceramic coatings before and after being exposed to the engine environment.

\section{MODELING OF SOOT EFFECT}

The effect of soot deposit is one that can be modeled. Let us consider a thin layer of soot deposited on the coating. Since this deposit layer will be composed mostly of carbonaceous material it will readily absorb radiative heat flux incident on $1 \mathrm{t}$. This layer can be modeled as a thin coating of negligible thermal capacity (uniform temperature) and having a negligible thermal resistance between the layer and the ceramic coating. Under these assumptions, in order to compute radiative and convective heat flux, it is sufficient to modify the boundaxy condition imposed on the first ceramic node point. A modification of the boundary condition has to be constructed, which is capable of modeling any state of fouling between clean to completely soot-covered ceramic coating. In the first limiting case the ceramic is clean and the incident radiation penetrates directly into the ceramic without first being absorbed by intervening deposit layer. In the second limiting case the incident radiation is totally absorbed by the deposit a $d$ the deposit reradiates into the ceramic coating. Intermediate le els of fouling are represented by a fouling factor (G) which can take iny value between 0 and 1 . A value of one for the fouling factor represen s fully sooted surface and a value of zero represent clean surface. The dittermediate values can be thought of as a representation of soot layer with varying degrees of surface coverage. The detall of the requisite boundary conditions representing this physical situation is described below.

Radiation energy passing through at the gas-soot layer interface (node \#1)

$$
Q(0)-q_{1}-q_{2}-q_{3}+q_{4}
$$

where

$$
\begin{aligned}
& q_{1}-\int_{0}^{\lambda}\left(1-R_{d o}(1-G)\right) q_{i} d \lambda \\
& q_{2}-\int_{0}^{\lambda} G E_{b \lambda} d \lambda \\
& q_{3}-\int_{0}^{\lambda} c\left(1-R_{d i}\right)(1-G) F^{-}(0) d \lambda
\end{aligned}
$$




$$
\begin{aligned}
& q_{4}-\int_{\lambda_{c}}^{\infty}(\alpha+G(1-\alpha))\left(q_{f}+E_{b \lambda}\right) d \lambda \\
& E_{b \lambda}-\text { blackbody emissivo power } \\
& G \quad-\text { fouling factor } \\
& q_{1}-\text { Incident radiation } \\
& \lambda \quad-\text { wavelength } \\
& \lambda_{c} \quad-5 \mu m-\text { cutoff wavelength for transparent/opaque bands } \\
& \alpha \quad-\text { surface absorptance in the opaque band }
\end{aligned}
$$

The first term of equation (31) represents the fraction of the incident energy within the transparent band of the ceramic ( 0 to $\lambda_{c}$ ) that will be either absorbed or pass through the gas/ceramic interface. The second term represents emission of the soot deposit back to the radiating gas. The contribution of this term will be present only if there is a soot layor on the surface. The third term represents emitted and scattered radiation from within the coating escaping to the gas. Here again if the surface is fully sooted no radiation will escape and consequently this term will vanish. The final term of the equation (31) is the fraction of the incident energy within the opaque band ( $\lambda_{c}$ to $\infty$ ) that is absorbed at the surface. This term is composed of the difference between the net incident energy (incident energy " reflected energy) and the emitted energy from the surface.

This deposited energy at the first node w111 be transported to the interior node by either conduction or radiation. The radiation flux at node \#1 is given by

$$
q_{r}(0)-F^{+}(0)-F^{-}(0)
$$

where

$$
\begin{aligned}
& F^{+}(0)-q_{5}+q_{6}+q_{7} \\
& q_{5}=\int_{0}^{\lambda} c\left(1-R_{d o}\right)(1-G) q_{1} d \lambda \\
& q_{6}-\int_{0}^{\lambda} G n_{1}^{2} E_{b \lambda} d \lambda
\end{aligned}
$$




$$
\begin{aligned}
& q_{7}-\int_{0}^{\lambda} R_{d f} F^{-}(0)(1-G) d \lambda \\
& F^{+}(0)-\text { toward diffuse flux at node } 1 \text { (pointing to the intertor) } \\
& F^{-}(0)-\text { backward diffuse flux at node } 1 \text { (pointing to the exterior) }
\end{aligned}
$$

The first term in equation (33) is the fraction of the incident radiation within the transparent band that passes. -uagh the gas ceramic interface. (Note that this term is different from $q_{1}$ inasmuch as it does not include the radiation absorbed at the surface.) "The second term is the radiation energy within the transparent band $\left(0-\lambda_{c}\right)$ that is emitted by the surface into the coating. The final term is the portion of the backward flux that reflected back into the coating by the front interface. (This is the complementary term of $q_{3}$. )

The conduction flux at node $\# 1$ is the difference between the total flux passing through the surface and the radiation flux at that node

$$
q_{c}(0)-Q(0): q_{x}(0)+h_{g}\left(T_{g}-T_{w}\right)
$$

The other boundary conditions (e.g. at ceramic/metal interface and coolant/metal interface were given in a previous report (Wahiduzzaman and Morel ${ }^{6}$ ) and are only summarized here. The continuity condition for temperature at the ceramic/metal substrate is given by

$$
T_{\varepsilon}(d)-T_{m}(d)
$$

where $T_{c}$ and $T_{m}$ are ceramic side and metal side temperatures respectively. The radiative flux boundary condition at ceramic/metal interface is

$$
\int_{0}^{\lambda} c F^{-}(d) d \lambda-\int_{0}^{\lambda} c\left(\rho_{s} F^{+}(d)+\epsilon_{s}^{E} b \lambda\right) d \lambda
$$

and at the gas/ceramic interface it is

$$
\int_{0}^{\lambda} c F^{+}(0) d \lambda-\int_{0}^{\lambda} c\left(R_{d i}(1-G) F^{-}(0)+\left(1-R_{d o}\right)(1-G) q_{1}\right) d \lambda
$$

This model was checked by setting it to zero to obtain clean ceramic results. It should be noted here that the above integrations are performed over several discrete bands, as discussed in a previous section. 
The results obtained with this model are presented in Table III. With G set to unity (fully sooted case) the results labeled "sooted" were generated. It can be seen that the presence of the soct layer produced a varlety of changes. The surface temperature was increased, one big reason being the elimination of surface reflectivity by the presence of black soot and the resultant higher radiative flux. A larger change is seen in the surface swing, this being caused by the absorption right at the surface rather than sub-surface. The convective flux was reduced due to the highex surface temperature. Finally, the total heat flux was generally slightly Increased, except for the fully transparent case where a 10 reduction was seen due to the reduction in convective flux. It is very interesting to see that even though the soot reduced the differences in total heat flux between the fully transparent and the fully opaque cases from 70 to 49 $\mathrm{kW} / \mathrm{m}^{2}$, there remained a substantial difference between them. This indicates that if the ceramic surface temperature is high, exceeding $1000 \mathrm{~K}$, the time-averaged radiation produced by the soot layer with its high emissivity, approaches and can exceed that produced by the much hotter diesel flame, which however persists for only a short fraction of time. It is also interesting to note that for the two opaque limits soot deposit produces identical results. This is because in the opaque(s) case soot emitted radiation is reabsorbed by the soot layer after being scattered back to the soot/ceramic interface. This is very similar to the situation existing in opaque (a) case where soot radiation is quickly absorbed by the coating close to the soot/ceramic interface.

The distributions of the radiative, convective and total heat fluxes computed for different levels of fouling on a $2.5 \mathrm{~mm}$ ceramic (type $C$ ) coating are given in Figure 18. As the fouling level is increased, the radiative transport increases sharply, accompanied by a decrease in the convective heat flux. This decrease in convective heat flux is due to increasa in surface temperature caused by the absorption of radiative energy at the surface. As expected, at the highest fouling level ceramic $C$ behaves more like the sooted opaque lixiting case rather than the transparent one (Table III). This is again due to absorption of radiative energy at or very near the surface as in opaque limiting case. There is a small increase in total heat flux with increasing surface fouling, indicating that although the mechanism of the heat transfer changes with surface fouling, its impact on total heat transfer is moderate at least for the boundary conditions used in this study.

\section{DISCUSSION}

The radiative properties of several existing ceramic coating materials were determined experimentally. This involved measuring reflectance and transmittance spectra of the ceramic samples of different thicknesses. A model describing the radiative transport process in semitransparent media was then fitted to the measured data sets. An optimization technique was used to adjust the radiative parameters until the best fit to the measured data was obtained.

The model describes the radiative transport within a medium using three parameters, namely scattering coefficient, absorption coefficient and 
refractive Index. This Involves some impliclt assumptions about interfacial reflectivities and phase function for the material. It was assumed that the interfacial reflectivities can be approximated by Fresnel's equations which is strictly valld for optically smooth surfaces $(\ell / \lambda<1$, where $\ell$ is the rms value of the surface roughness). It was determined a posterfori that accurate determination of the surface reflectivities was not critical in view of the high scattering coefficients of the studied ceramics. Another assumption regards the phase function. Since the grains of the ceramic are densely packed and randomly oriented, there will not be any preferred direction of scattering. Consequently, a uniform scattering phase function was used. In addition, a fixed value of refractive index, as discussed earlier, was used for all parameter inversion. This constraint had to be imposed due to the small number of independent data points avallable, keeping in mind that the results are relatively insensitive to this parameter (Wahiduzzaman and Morel ${ }^{7}$ ).

In order to perform a systematic error analysis on the inverted parameter, the variability of the measured quantities (reflectance and transmittance spectra) are needed. This in turn depends on the repeatability of the sample preparation and uncertainty associated with the measuring instrument. Unfortunately, such study was beyond the scope of this program, since the number of samples of each material used in this study was limited and no repeat measurements with identical samples were made. Nevertheless, based on the assumptions involved in the technique and an expected variability in measured data, an assessment can be made of the uncertainty in the values of the inverted parameters. For errors of $\pm 5 \%$ in transmittance, $\pm 5 \%$ in reflectance and $\pm 25 \%$ in refractive index, maximum error over the entire spectral range was found to be of the order of 538 for scattering coefficients and 408 for absorption coefficient. Although this uncertainty appears to be large, the calculated heat transfer is affected only moderately over this range. Thus despite the uncertainty in the properties, the basic results of this work, as discussed below, should be unchanged.

The ceramic samples used in this study were found to be highly reflective (reflectance on the order of $0.6-0.8$ ) and optically thick even at thicknesses of the order of $2 \mathrm{~mm}$. In particular, the reflectance spectrum of the $0.51 \mathrm{~mm}$ sample (AI) of PSZ obtained from Plasma Technics was nearly identical to the corresponding spectra belonging to 1.092 and $5.74 \mathrm{~mm}$ samples (A2 and A3) indicating that even the thinnest sample is optically thick. It should be noted here that the level of reflectances of the material $A$ are of same order as for materials $B$ and $C$, and thus the scattering coefficients are probably of similar magnitude. However, the ceramics $B$ and $C$ are less optically dense than the ceramic $A$, based on the fact that their reflectances display dependence on thickness between 0.5 and $1 \mathrm{~mm}$ not seen in ceramic $A$. Thus one may make the indirect inference that the ceramic $A$ has much higher absorption coefficients than ceramics $B$ and $C$.

Ceramics $B$ and $C$ (PSZ and TZF from Oak RIdge Laboratory) were found to be radiatively identical. The refiactance and transmittance spectra of both materials were nearly identical and consequently, inverted properties were 
also the same for both materlals. The absorption coefficlents of ceramics $B, C$ and $D$ were found to be much smaller than the scattering coefficients (high scattering albedo). Material B and $C$ possessed lower scattering and absorption coefficlents in comparison to material $D$ and hence, were optically less dense than $D$. In any event, a nominal thickness of $2 \mathrm{~mm}$ of any of the studied ceramics would be sufficlent to prevent any appreciable radiation energy from reaching the metal substrate.

The radiative parameters of the materials studied here exhibited both qualitative and quantitative agreement with previous measurements (Makino et $\mathrm{al}^{4}$ ) made on a number of monolithic ceramios including zirconia (85\% $\mathrm{Zr02}$ by weight, with $\mathrm{Y}_{2} \mathrm{O}_{3}, \mathrm{~S}_{1} \mathrm{O}_{3}$ and $\left.\mathrm{Al}_{2} \mathrm{O}_{3}\right)$. The scattering coefficients obtained in that study displayed similar decreasing trends at higher wavelengths, although the values of the coefficlents were lower (12000 m" at shorter wavelengths). The absorption coefficients were of similar order of magnitude as those found here and the spectrum contained sharp rise around $4 \mu \mathrm{m}$, similar to that evidenced in the spectrum of ceramic $C$. The lower scattering coefficient found for the monolithic ceramics by Makino et al can be attributed primarily to the difference in microstructure of the two ceramics. To quantify the differences between the present coatings and Makino's monolithics, an analysis was carried out of the heat barrier effectiveness of a monolithic ceramic $2.5 \mathrm{~mm}$ thick subject to the same boundary conditions as done for the coatings in Table III. The results showed that for Makino's monolithic ceramics the radiation heat transfer was larger by 308 and the total heat transfer was 88 higher. This shows that these ceramics were less optically opaque and thus less effective as barriers to heat radiation than the present coatings (at the same thickness and assuming the same thermal conductivity and heat capacity).

A heat transfer analysis based on these radiative parameters showed that at the larger thicknesses (above $1.25 \mathrm{~mm}$ ) materials $C$ and $B$ are mure effective against radiative heat transfer than material $D$ of same thickness. At lower thicknesses the situation is reversed. This trend is a consequence of reflectivity of the coatings which can be substantially influenced by the ceramic/metal interface depending on the coating thickness.

In general, the studied ceramics exhibited similar characteristics in terms of preventing radiative heat transfer. The scattering albedo of these ceramics were found to be large, causing them to be fairly reflective (60-808) and optically thick at conventional coating thicknesses (1 to 2 $\mathrm{mm})$. As a result, most of the radiation that penetrates the coating is absorbed within the coating as opposed to at ceramic/metal interface. Since a significant portion of this absorption occurs at or near the surface, the surface temperature is increased. This has a beneficial effect of reducing the convective component of the total heat transfer.

In an operating engine, the coating surface will lose a lot of its reflectivity due to carbonaceous deposits. In such a case the incident radiant energy will be readily absorbed by the deposit layer causing the surface temperature to go up even higher. This will further reduce the convective heat flux and partially compensate for the increased radiant heat transfer at the surface (less reflected radiation). On the other 
hand, the radiation of the surface deposit layer towards the interior of the ceramic increases rapidly with the increasing surface temperature and at high enough temperature could exceed the radiation from the flame (because it has high emissivity and acts all the time, whereas the gas radiates only soma 5-7 percent of the time). It should be mentioned that when the surface temperature becomes sufficiently high the soot particles in the deposit layer w111 tend to burn off. Thus the ceramic will tend to return to its original clean state, probably before the point of excessive surface radiation is reached.

Based on the present results and the above observations, one can speculate on the ideal thermal barrier for engine applications. To prevent radiant heat transfer, the coating should be highly reflective, for example through a combination of high scattering coefficient $\left(>20000 \mathrm{~m}^{-1}\right)$ and low absorption coefficient. If a homogeneous ceramic satisfying these conditions could not be found, one could contemplate composite ceramic, or one having a thin reflective and opaque metallic coating on the surface. However, if significant soot deposition occurs at the coating surface a large portion of the incident radiation energy will be trapped by the deposit layer causing a substantial increase in radiation heat transfer. As mentioned previously, this will be associated with an increase in surface temperature. The level of this increase will depend on the location where the energy reradiated by the deposit layer is absorbed. If the coating is opaque it will be absorbed at or near the interface and the increase in surface temperature will be large which will in turn cause a large reduction in convective heat flux. This opacity could be achieved, as evidenced in Table III, elther through high scattering coefficient or high absorption coefficient or a combination of both. In the case of transparent ceramic the reradiated energy will be absorbed at the coating/metal interface, leaving the surface at a lower temperature (Table III) and consequently the reduction in the convective heat flux will be small. Hence, to insure the best thermal barrier for elther clean or heavily sooted surfaces, a ceramic material with high scattering and low absorption coefficient provides the best choice. To reduce the convective heat transfer relatively independently of the radiant heat transfer, one can follow the conventional approach of choosing a material having low thermal conductivity and as large as practicable coating thickness.

\section{CONCLUSIONS}

1) An experimental study was carried out to determine the radiative properties of four ceramics; A (PSZ, 138 yttria stabilized), B (PSZ), C (TZP) and D (PSZ, 248 ceria stabllized). Ceramics B and C were found to possess high scattering coefficient (in excess of $30000 \mathrm{~m}^{-1}$ in short wavelengths) and low absorption coefficients. Ceramic $D$ had even higher scattering coefficients (In excess of $40000 \mathrm{~m}^{-1}$ at short wavelengths) and moderate absorption coefficients $\left(2000 \mathrm{~m}^{-1}\right.$ at $\left.3 \mu \mathrm{m}\right)$. Although parameter inversion was not possible for material $A, a$ comparison of its reflection spectra with corresponding spectra of other ceramics tested Indicates it to be the most optically dense material in the group. 
2. In terms of overall radiation effect, these coatings were found to be highly reflective (reflectance around $0.6-0.8$ ) due to their high scattering coefficlents. They also were found optically thick even at thicknesses of $2 \mathrm{~mm}$, 1.e., permitting only a small fraction of radiation to pass through to the substrate. Comparison to 11terature data on monolithic zirconia ceramics showed those to be more transparent and thus less effective as barriers to heat radiation.

3. When compared to the limiting cases of csmpletely transparent and completely opaque, the total heat transfer through the studied ceramics for $2.5 \mathrm{~mm}$ thickness was substantially closer to either of the opaque limits than to the transparent limit. However, when the surface is clean, the mechanism of the heat transfer more closely approached the opaque(s) 1 imit rather than the opaque(a) Iimft. On the other hand, for a sooted surface, both opaque limits converged into a single limit.

4) With regard to the most desirable ceramic properties for diesel engine applications, it was concluded that a highly scattering ceramic with low absorption coefficlent would be the best heat barrier material for blocking therinal radiation. An alternative would be a composite ceramic coated with an opaque high reflectance surface layer. From the point of view of convective heat transfer, any scheme aimed at raising surface temperature will be effective in reducing convective heat transfer, and low thermal conductivity is an essential element in this respect. However, other factors such as volumetric efficiency, thermal stress, etc. have to be considered in selection of an appropriate insulation package.

5) In experimental determination of radiative properties of ceramics it is highly desirable to perform preliminary transmittance measurements to obtain some knowledge on the opacity of the material. This knowledge can then be used for proper selection of material thicknesses to obtain samples ranging from optically thin to optically thick. In order to extract the refractive index, alternate type of measurements are recommended. These may include separate measurements of diffuse and directional reflectance and transmittance, and/or measurement of polarized components of the reflectance.

6) Both four-flux and two-flux methods were used and it was concluded that the four-flux method is more appropriate for parameter inversion models than the simpler two-flux method. This method is better equipped to hendle collimated illumination and has the ability to predict both diffuse and directional quantities. It was found that the two-flux model underpredicts scattering coefficient substantially when the scattering level is low. 


\section{NOMENCLATURE*}

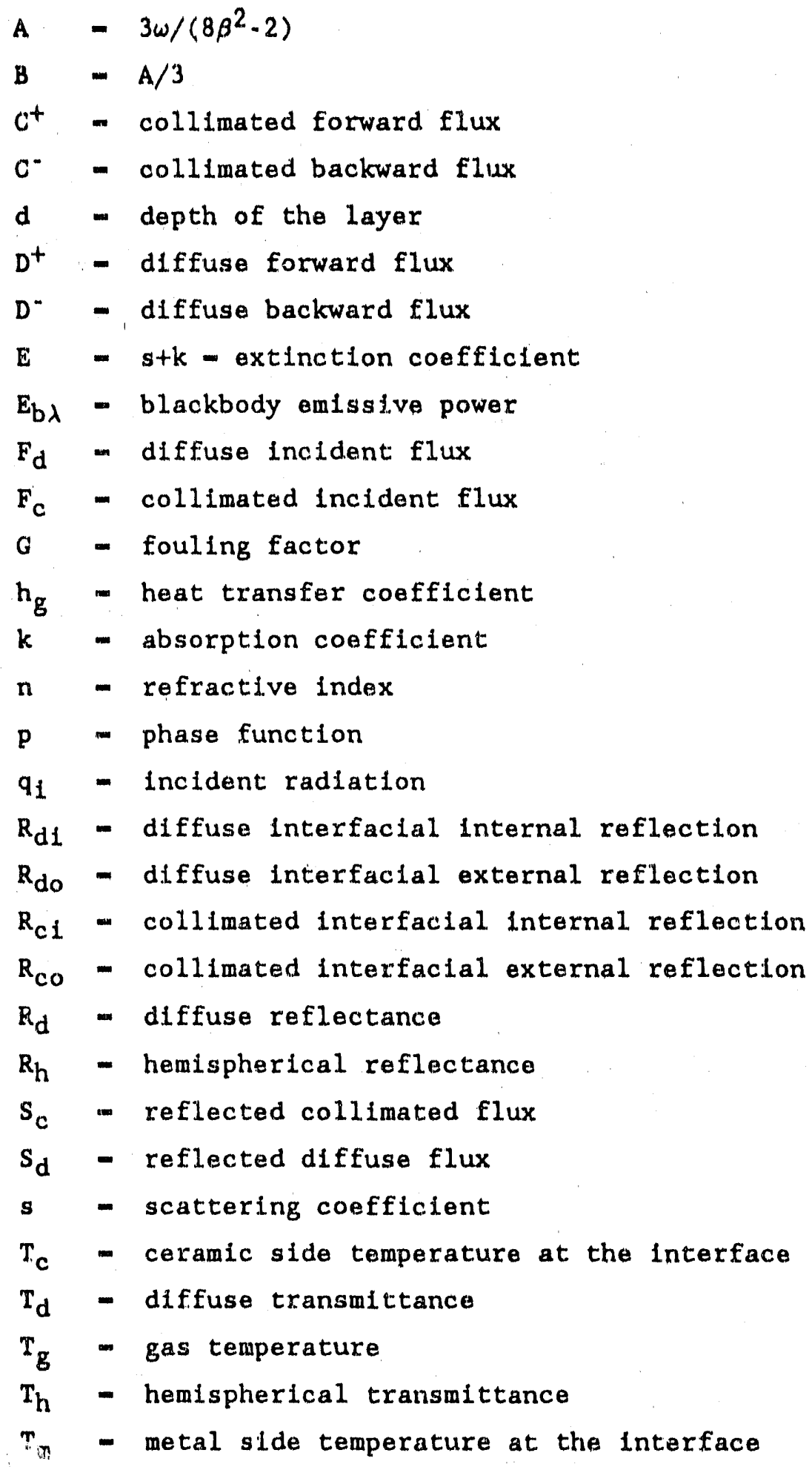

*A1l variables are in S.I. units except where noted. 


$$
\begin{aligned}
& T_{w} \text { - surface temperature of the wall } \\
& \text { a - surface absorptance In the opaque band } \\
& \alpha_{1} \text { - Iinear constant for flux equation } \\
& \alpha_{2} \text { - Iinear constant for flux equation } \\
& \alpha_{3} \text { - Inear constant for flux equation } \\
& \alpha_{4} \text { - Iinear constant for flux equation } \\
& \beta-\sqrt{1-\omega} \text {. } \\
& \lambda \quad-\text { wavelength } \\
& \omega \quad-s /(s+k)-\text { albedo } \\
& \text { r }-(k+s) x-\text { optical depth at } x \\
& r_{d}-(k+s) d-o p t i c a l \text { thickness of the entire translucent layer } \\
& \text { d - wavelength } \\
& \lambda_{c}-5 \mu \mathrm{m} \text { - cutoff wavelength for transparent/opaque bands }
\end{aligned}
$$




\section{REFERENCES}

1. T. Morel, R. Kerlbar, P. N. Blumberg and E. F. Fort (1984), "Methods for the Integrated Analysis of Heat Transfer, Component Temperatures and Performance in Insulated Engines", ATD -CCM, Dearborn, Michigan, 1384.

2. Ilebert, C. H. (1965), "Spectral Emlttance of Aluminum Oxide and Zinc Oxide on Opaque Substrates", NASA TN D-3115.

3. Liebert, C. H. (1978), "Emittance and Absorptance of NASA Ceramic Thermal Barrier Coating system", NASA Technical Paper 1190; also in Thin Solid Films, 53, pp. 235-240, 1978.

4. Makino, T. and Kunitomo, T. (1984), "Thermal Radiation Properties of Ceramic Materials". Transaction of the Japan Soclety of Mechanical Englneers, Vol, 50, No, 452, pp. 1045-1052.

5. Ishimaru, A. (1.978), Wave Propagation and Scattering in Random Media Volume 1, Academic Press, 111 Fifth Avenue, NY, NY 10003.

6. T. Morel and R. Kerlbar, "Heat Radiation in DI Diesel Engines", SAE Paper 860445.

7. S. Wahiduzzanan and T. Morel (1987), "Effect of Translucence of Engineering Ceramics on Heat Transfer in Diesel Engines", ORNL Report ORNL/Sub/86-22042/1, October 1987.

8. R. Willey (1976), "Fourler Transform Infrared Spectrometer for Transmittance and Diffuse Reflectance Measurements", Applied Spectroscopy, 30, No. 5 .

9. Matthews, L. K. (1982), "Experimencal and Theoretical Analysis of the High Flux - High Temperature Fleld in a Dielectric Subjected to Intense Solar Radiation," PhD Thesis, Purdue University, West Lafayette, Indlana, p. 94.

10. Makino, T. (1986), personal communication.

11. More1, T., Rackmil, C. I., Keribar, R. and Jennings, M. J. (1988), "A New Approach to Integrating Englne Performance and Component Design Analysis Through Simulation", SAE Paper 880131. 
Table I. List of Ceramic Samples

\begin{tabular}{|c|c|c|c|c|}
\hline Set & Sample & Matarial & supeller & Thickness $(\mathrm{mm})$ \\
\hline A & 1 & PSZ & Plasma Tech & 0.51 \\
\hline $\mathbf{A}$ & 2 & PSZ & Plasma Tech & 1.02 \\
\hline A & 3 & PSZ & Plasma Tech & 5.74 \\
\hline B & 4 & TZP & Oak Ridge Lab & 0.50 \\
\hline B & 5 & TZP & Oak RIdge Lab & 1.00 \\
\hline B & 6 & TZP & Oak Ridge Lab & 10.00 \\
\hline C & 7 & ESZ & Oak RIdge Lab & 0.50 \\
\hline C & 8 & PSZ & Oak RIdge Lab & 1.00 \\
\hline C & 9 & PSZ & Oak RIdge Lab & 10.00 \\
\hline D & 10 & PSZ & Caterpillar & 0.41 \\
\hline D & 11 & PSZ & Catexpillax & 0.58 \\
\hline D & 12 & PSZ & Caterpil1ar & 1.04 \\
\hline D & 13 & PSZ & Caterpillar & 2.49 \\
\hline
\end{tabular}


Table II. Matrix of Radiative Measurements

\section{Sample ID}

A1
A2
A3
B4
B5
B6
C7
C8
C9
D10
D11
D12
D13

\section{Refilectance}

$$
<2.5 \mu \mathrm{m} \quad 2-20 \mu \mathrm{m}
$$

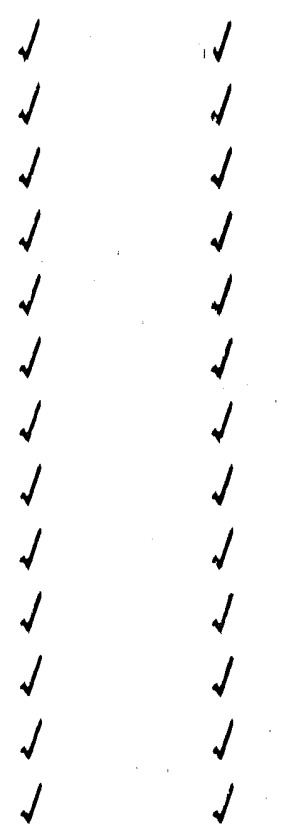

Tranamittance

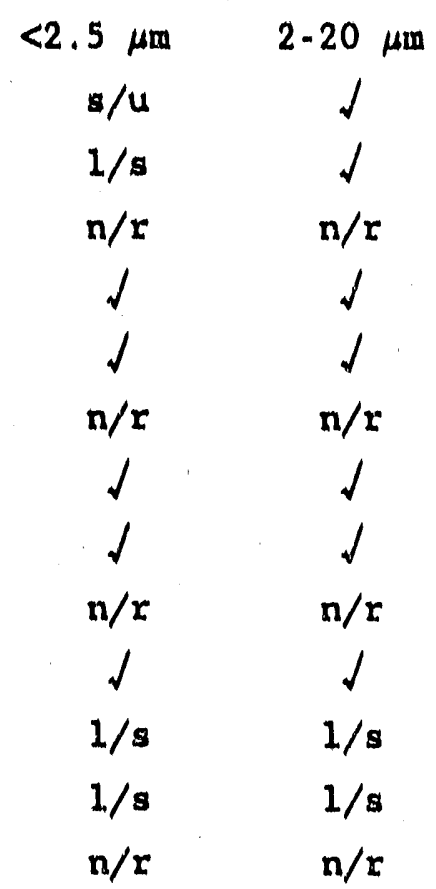

Key: $\checkmark$ - measurement made; s/u - sample unavallable; $n / r$ - measurement not requested; $1 / \mathrm{s}$ - measurement attempted but falled due to low signal-tonolse ratio. 
Table III. Effect of deramic Properties and Surface Fouling on Time - Averaged Heat Flux and Temperatures

\begin{tabular}{|c|c|c|c|c|c|c|}
\hline Ceramic & $\begin{array}{l}\text { Surface } \\
\text { Teme. }\end{array}$ & $\begin{array}{l}\text { Indep th* } \\
\text { Tenp. }\end{array}$ & $\begin{array}{l}\text { Surface } \\
\text { Swing }\end{array}$ & $\begin{array}{l}\text { Radiative } \\
\text { Flux }\end{array}$ & $\begin{array}{c}\text { Convactive } \\
\text { Elux }\end{array}$ & $\begin{array}{l}\text { Total } \\
\text { Elux }\end{array}$ \\
\hline & $k$ & & $k$ & $\mathrm{~kW} / \mathrm{m}^{2}$ & $\mathrm{~kW} / \mathrm{m} 2$ & $\mathrm{~kW} / \mathrm{m}^{2}$ \\
\hline Metal basellne & 701.9 & & 25.2 & 86,5 & 316.2 & 402.8 \\
\hline $\begin{array}{l}\text { Clean C } \\
\text { Clean D }\end{array}$ & $\begin{array}{l}943.5 \\
953.7\end{array}$ & $\begin{array}{l}650.0 \\
649.5\end{array}$ & $\begin{array}{l}90.7 \\
90.4\end{array}$ & $\begin{array}{l}22.0 \\
25.8\end{array}$ & $\begin{array}{l}84.0 \\
75.2\end{array}$ & $\begin{array}{l}106.0 \\
101.0\end{array}$ \\
\hline $\begin{array}{l}\text { Transparent } \\
\text { Opaque (a) \# } \\
\text { Opaque (s) \# }\end{array}$ & $\begin{array}{l}937.5 \\
995.2 \\
935.3\end{array}$ & $\begin{array}{l}657.0 \\
650.0 \\
648.6\end{array}$ & $\begin{array}{r}91.7 \\
116.6 \\
92.1\end{array}$ & $\begin{array}{r}91.3 \\
82.2 \\
0.7\end{array}$ & $\begin{array}{l}89.2 \\
28.1 \\
91.1\end{array}$ & $\begin{array}{r}180.5 \\
110.3 \\
91.8\end{array}$ \\
\hline $\begin{array}{l}\text { Sooted C } \\
\text { Sooted D }\end{array}$ & $\begin{array}{l}1.001 .4 \\
1001.3\end{array}$ & $\begin{array}{l}651.0 \\
650.7\end{array}$ & $\begin{array}{l}122.3 \\
121.4\end{array}$ & $\begin{array}{l}97.4 \\
96.8\end{array}$ & $\begin{array}{l}20.6 \\
18.1\end{array}$ & $\begin{array}{l}118.0 \\
114.9\end{array}$ \\
\hline $\begin{array}{l}\text { Sooted trans. } \\
\text { Sooted opaque (a) } \\
\text { Sooted opaque (s) }\end{array}$ & $\begin{array}{r}948.8 \\
1005.8 \\
1005.6\end{array}$ & $\begin{array}{l}655.2 \\
650.6 \\
650.6\end{array}$ & $\begin{array}{l}131.9 \\
121.2 \\
121.2\end{array}$ & $\begin{array}{l}97.6 \\
96.4 \\
96.5\end{array}$ & $\begin{array}{l}65.2 \\
17.1 \\
17.1\end{array}$ & $\begin{array}{l}162.8 \\
113.5 \\
113.6\end{array}$ \\
\hline
\end{tabular}

*Temperature at the ceramic/metal interface, 1.e. at a depth of $2.5 \mathrm{~mm}$ from the surface.

\#Opaque (a) is the opaque limit attained by high absorption and negligible scattering.

\#Opaque ( $s$ ) is the opaque limit attained by high scattering and negligible absorption. 


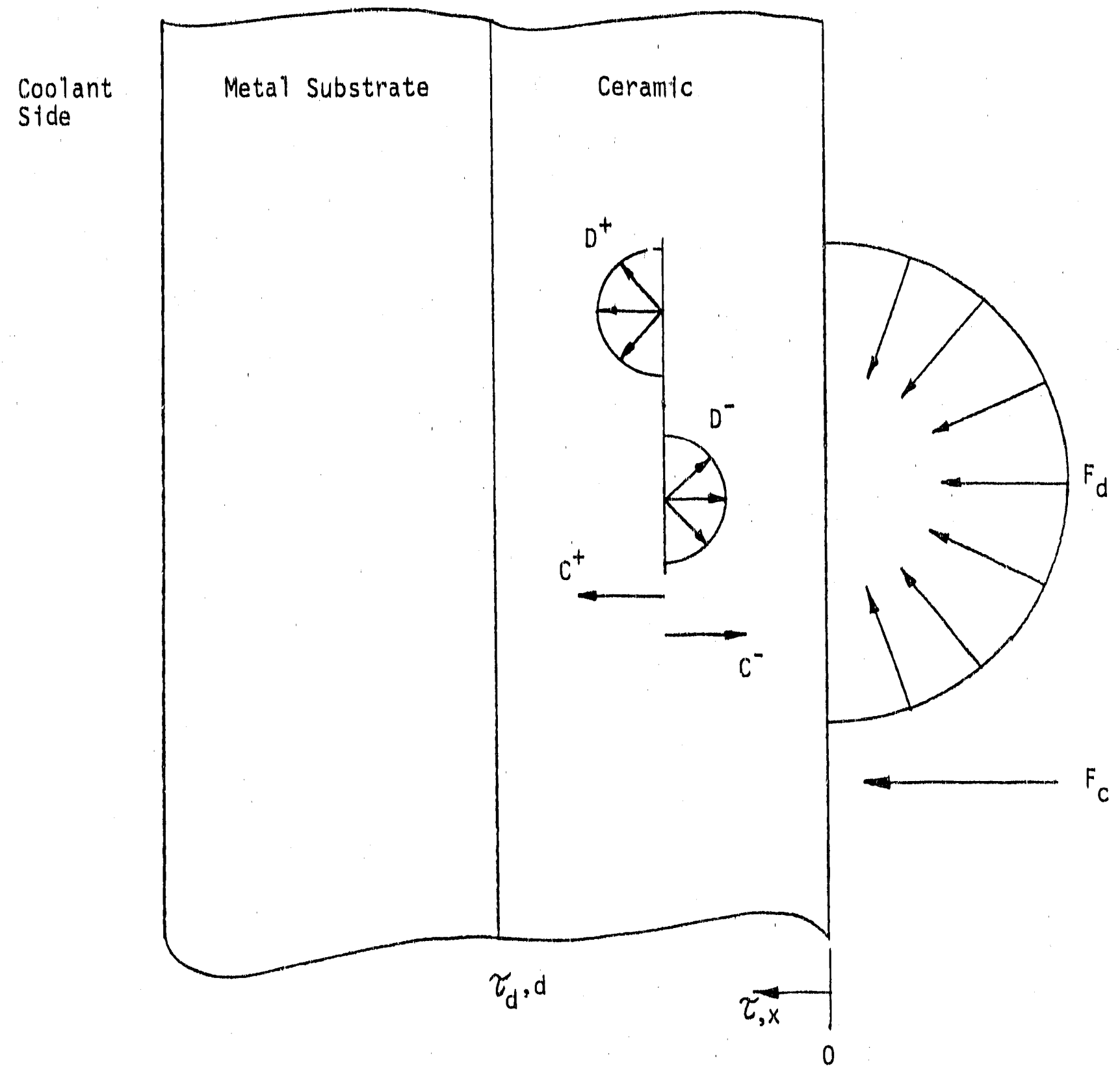

Figure 1. Physical model of the insulating coating. 


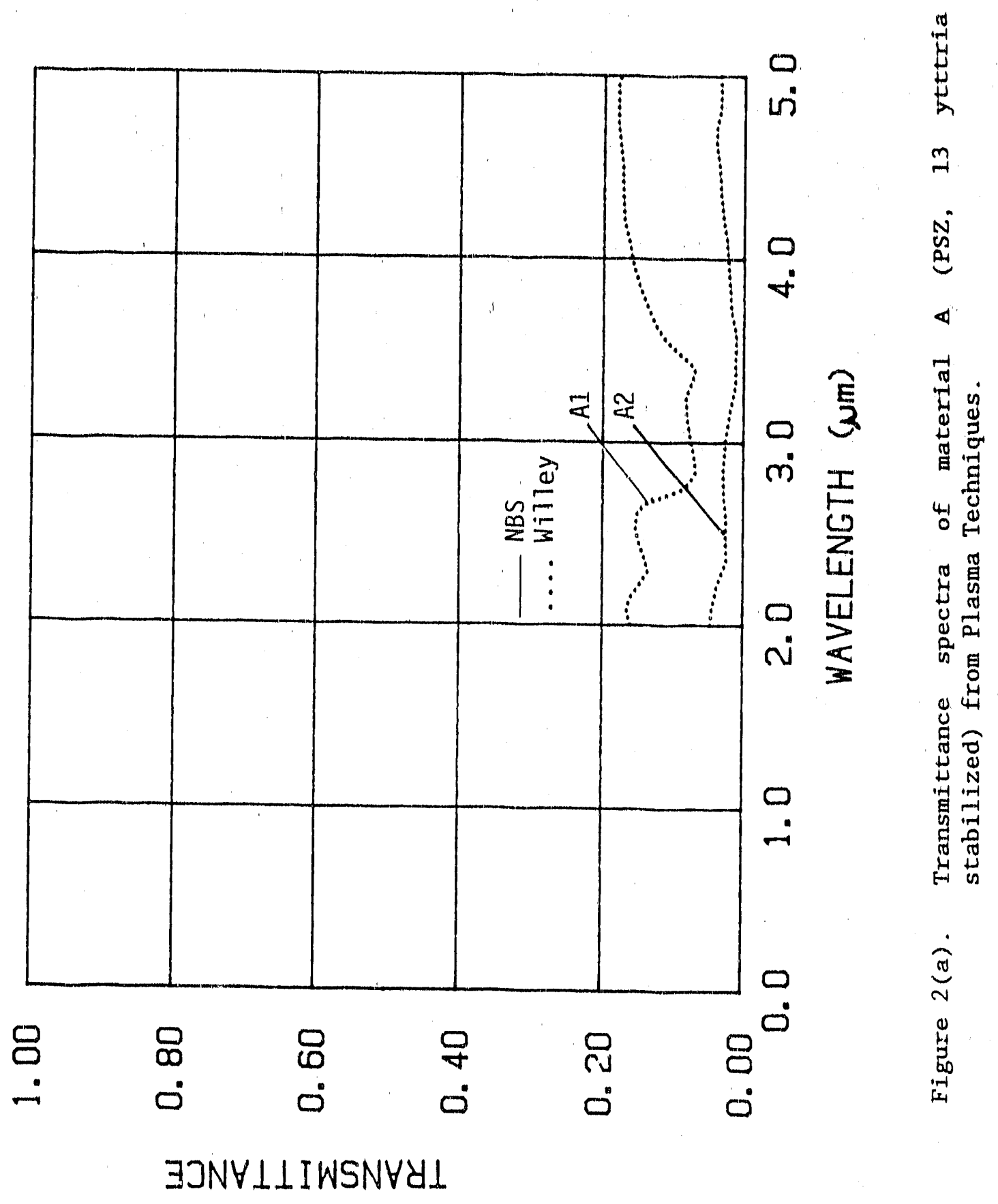




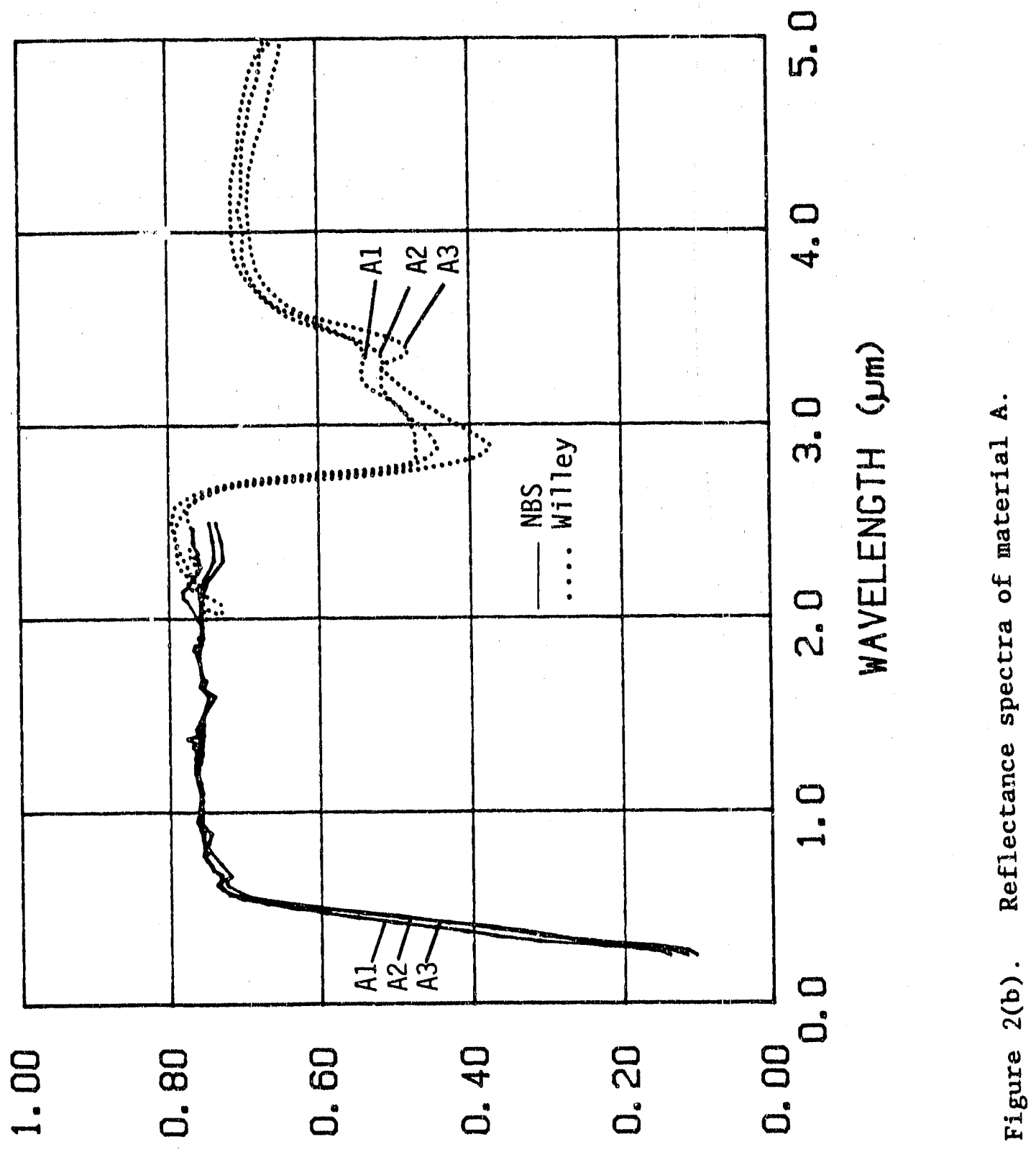

$\exists ว N \vee \perp ว \exists า \pm \exists y$ 


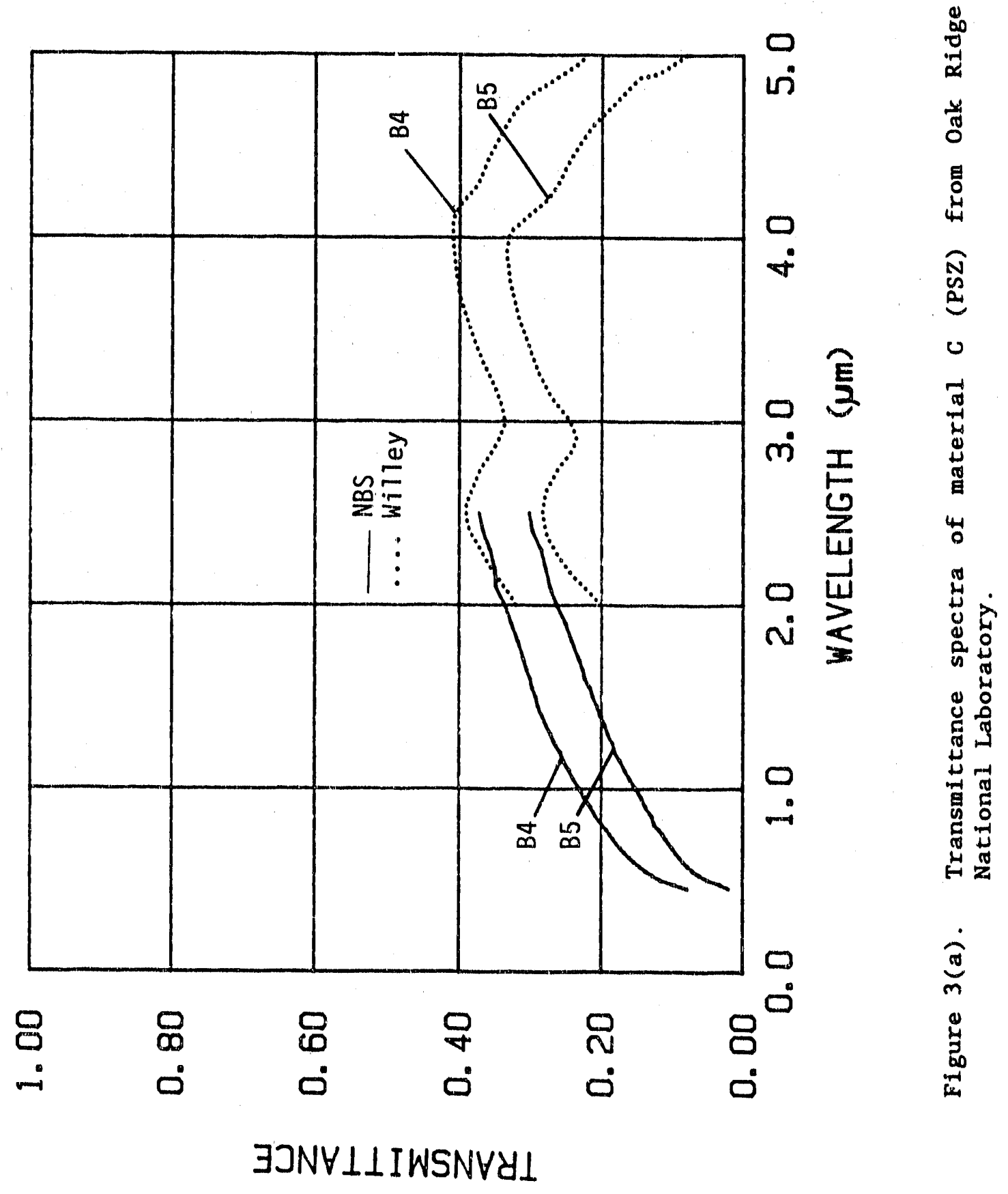




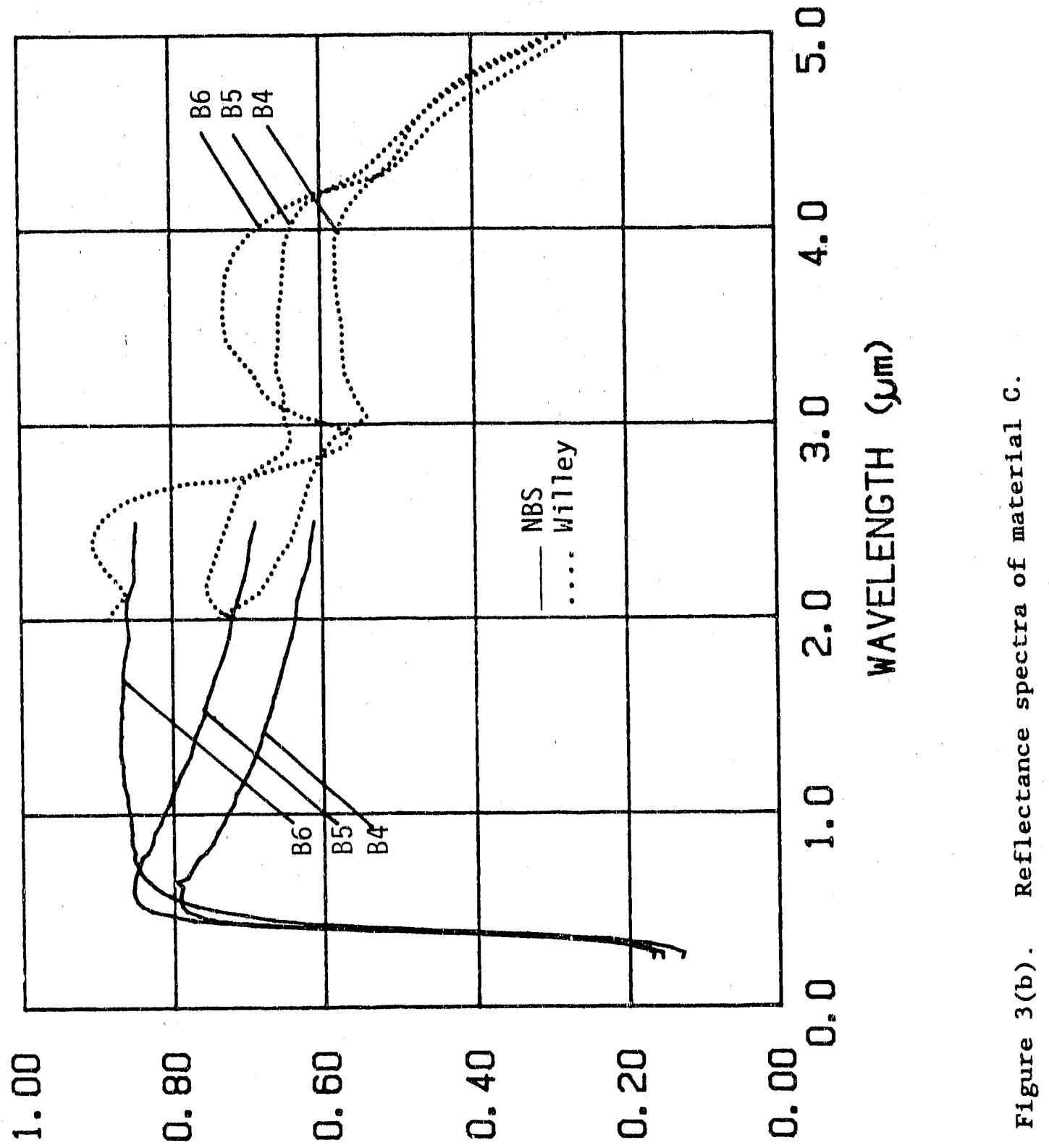

$\exists ว N \forall 1 ว \exists า \exists \exists y$ 


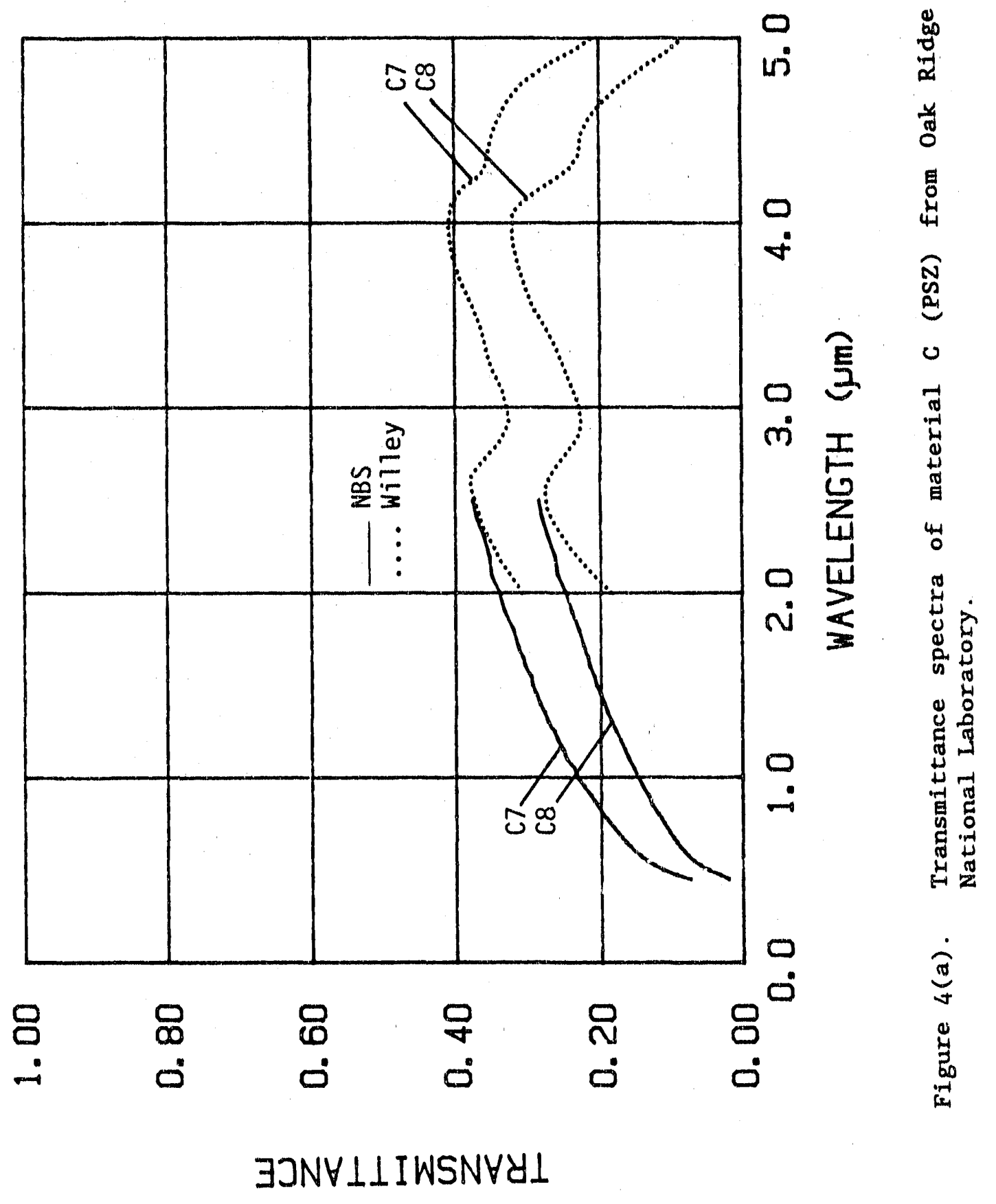




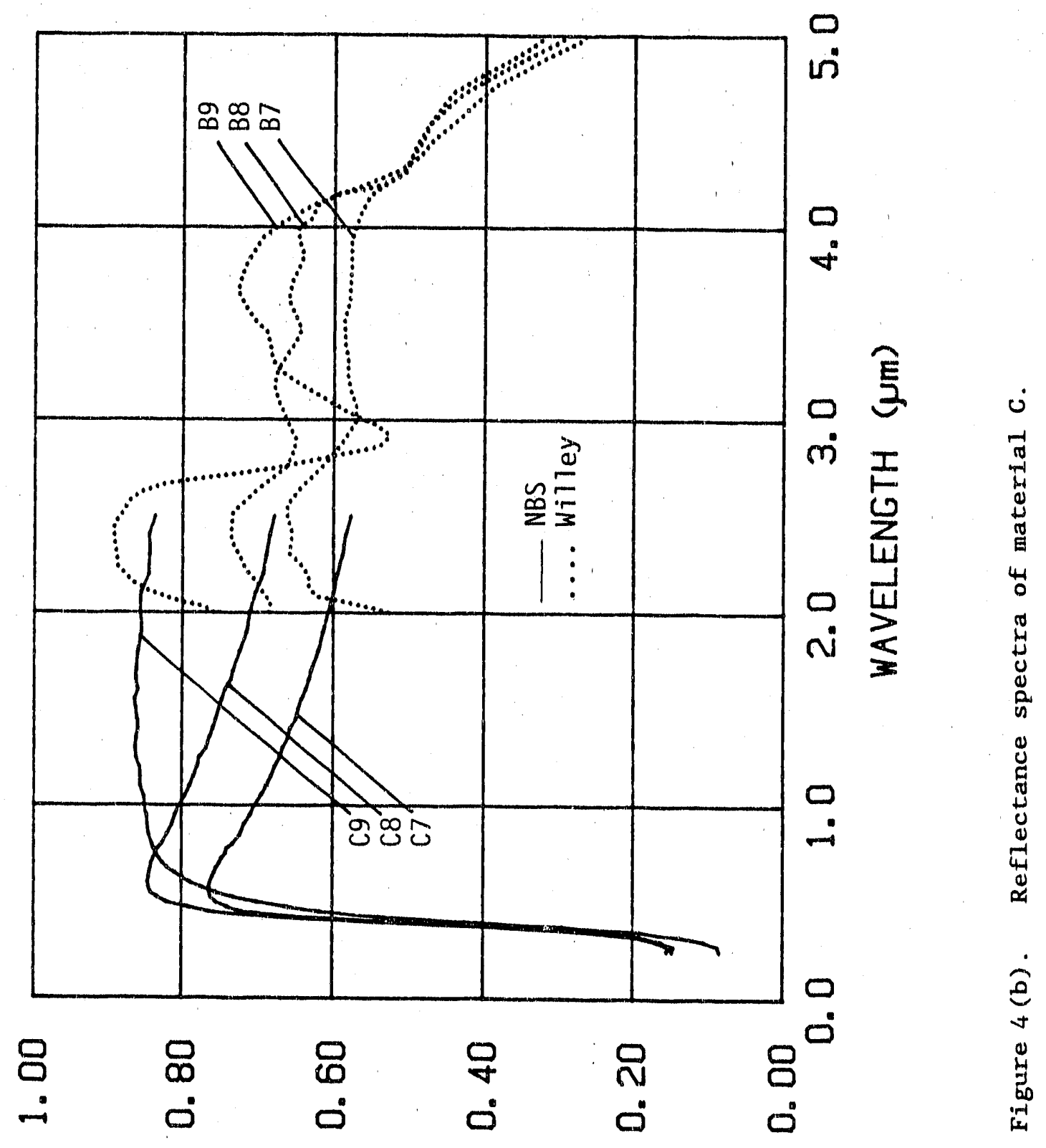

$\exists \supset N \forall 1 J \exists า \exists \exists y$ 


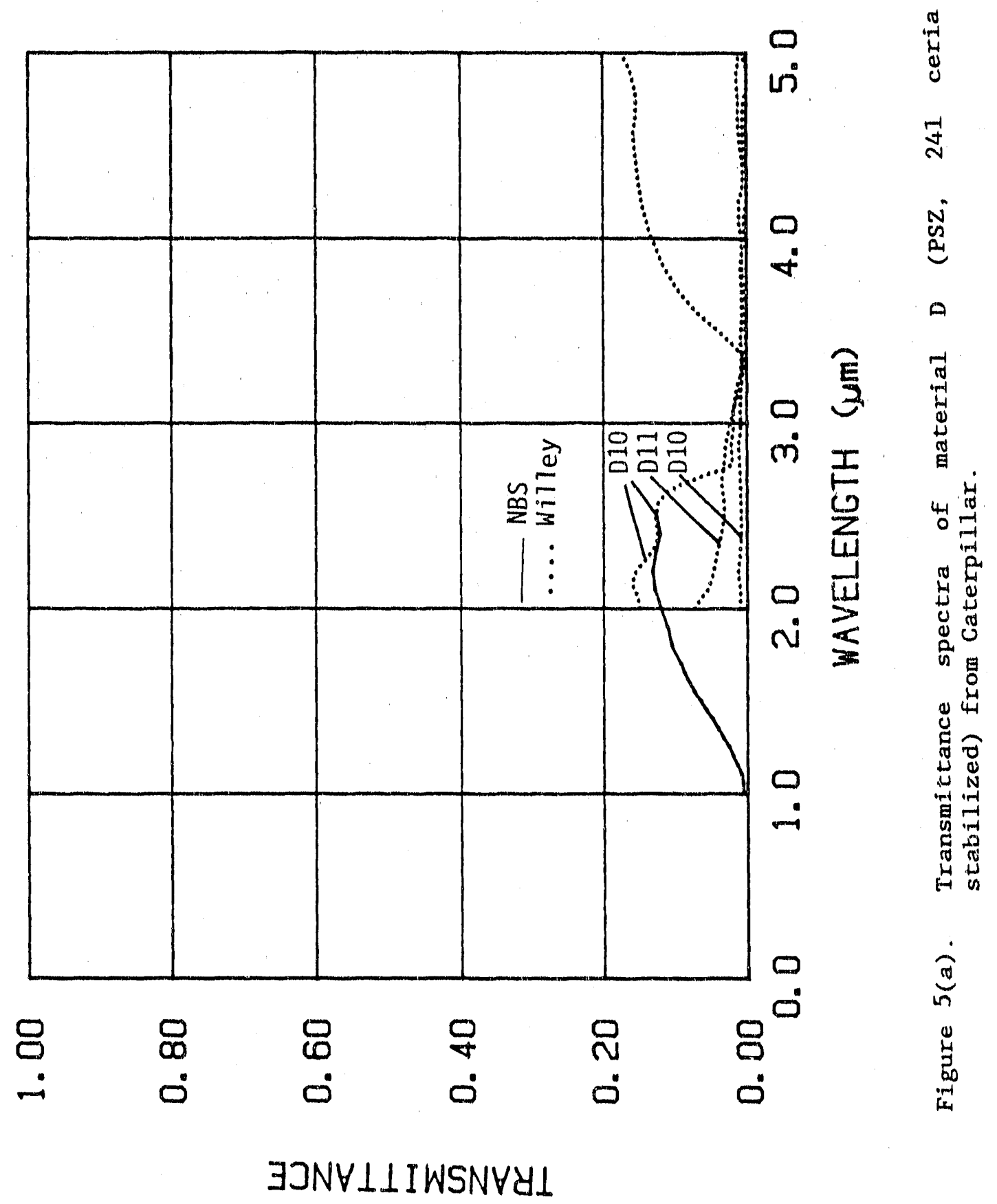




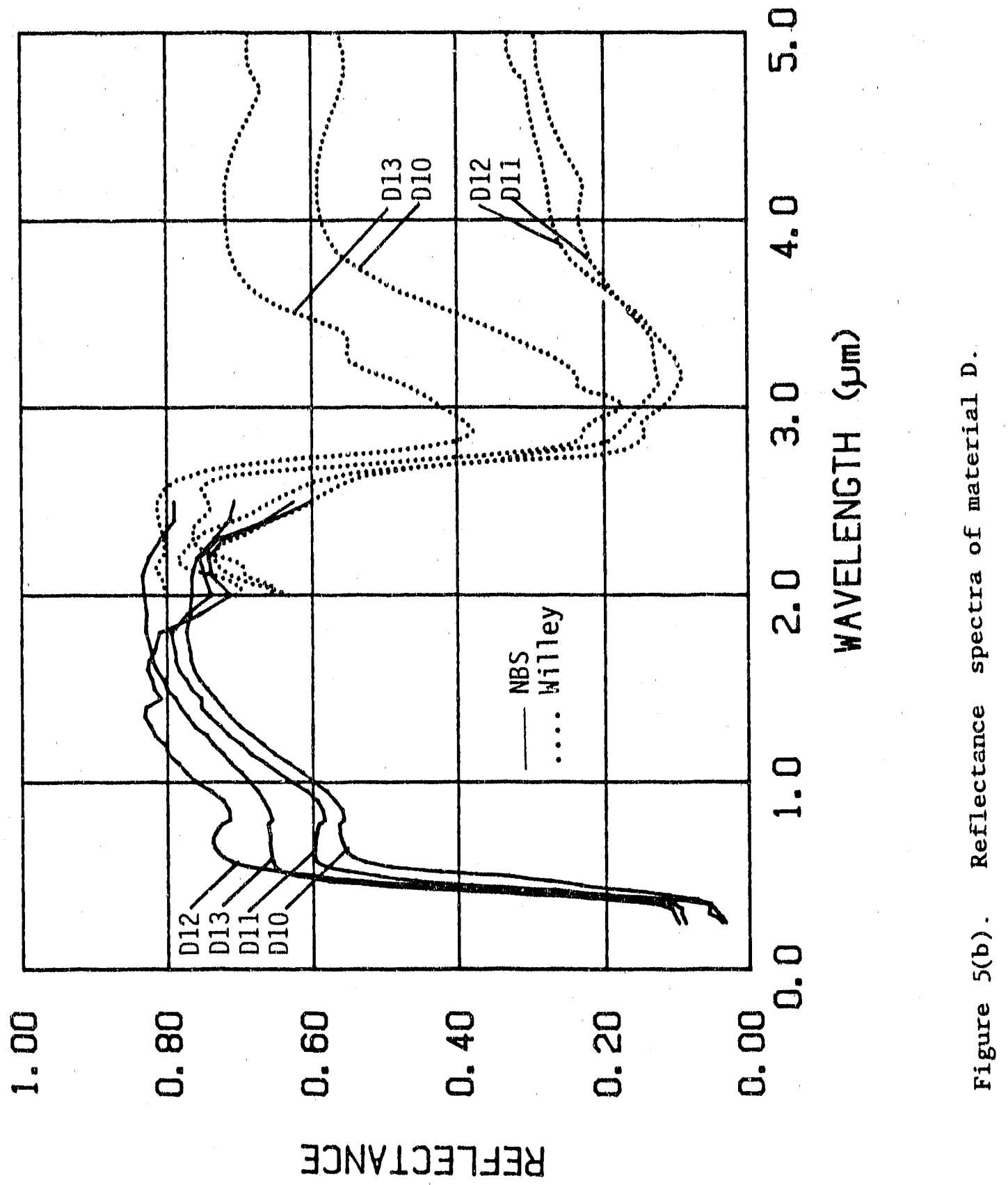




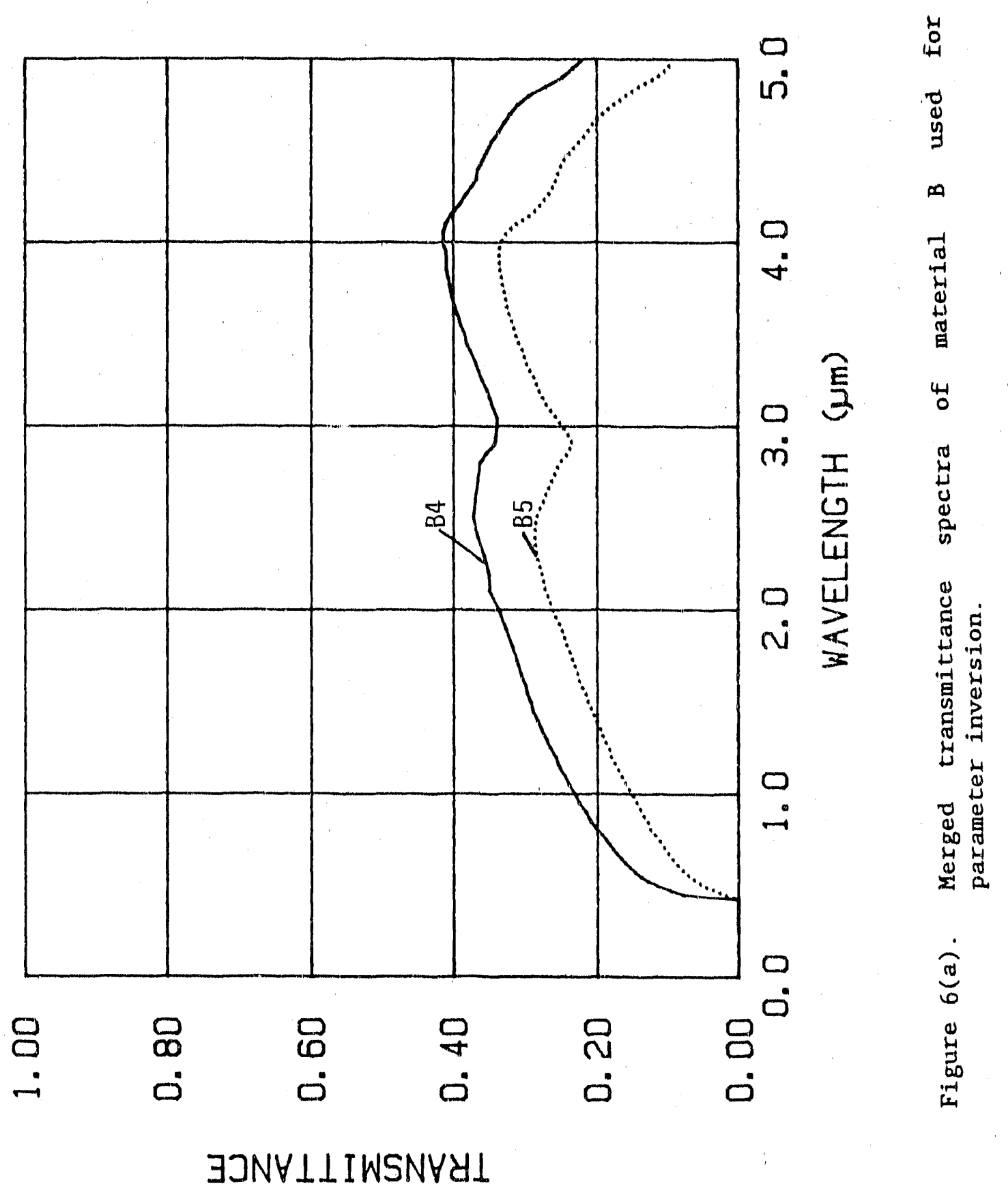




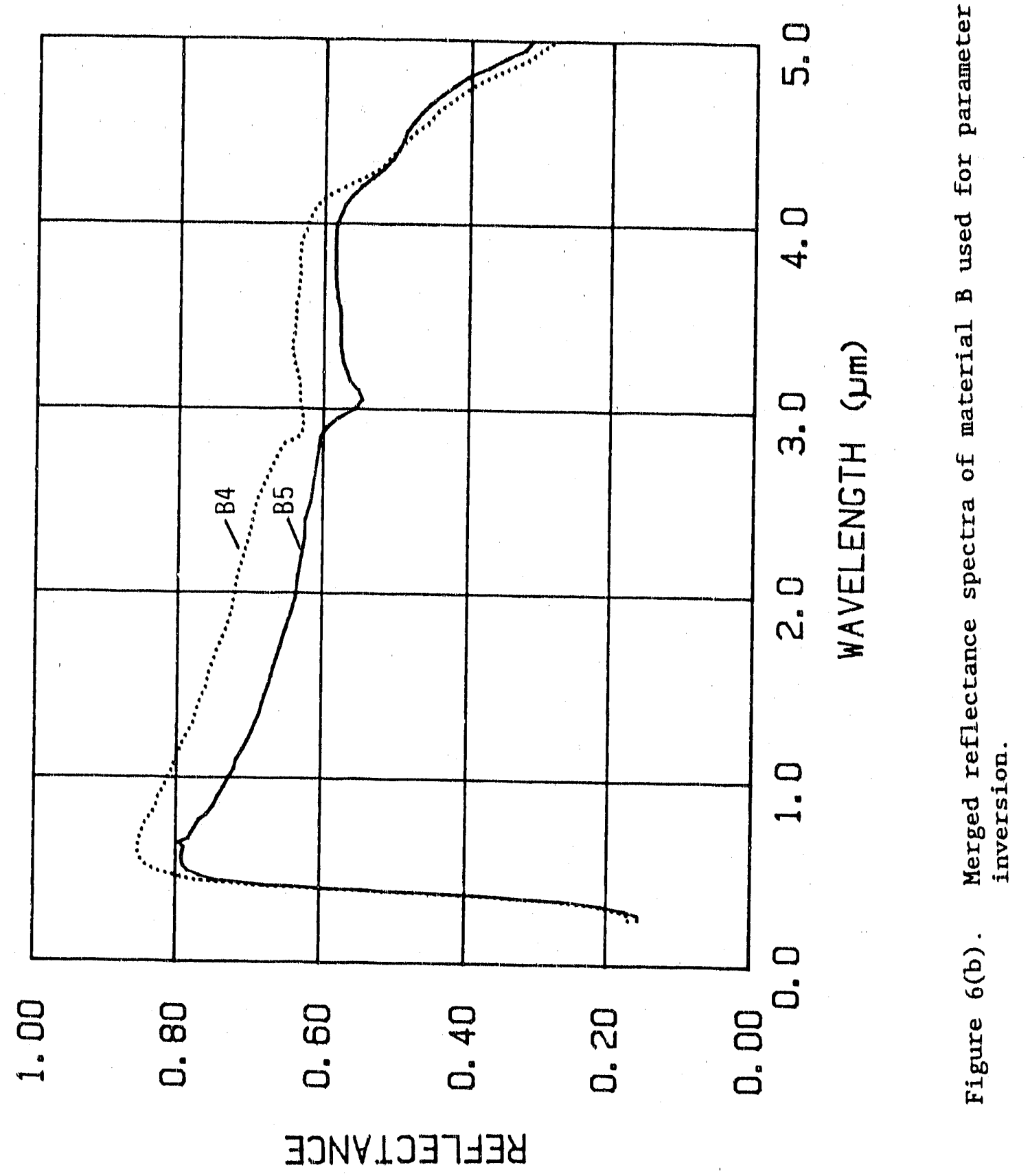









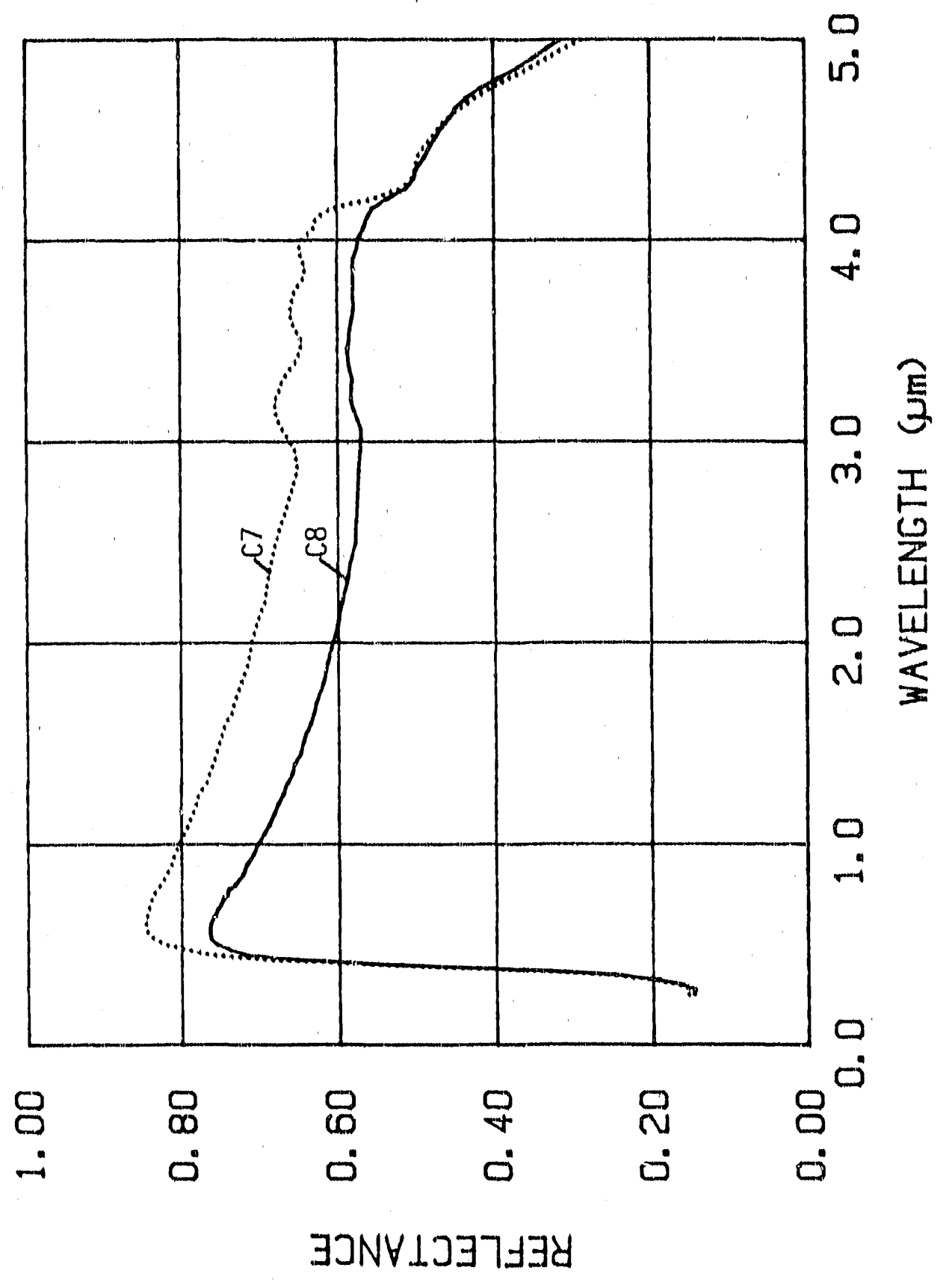

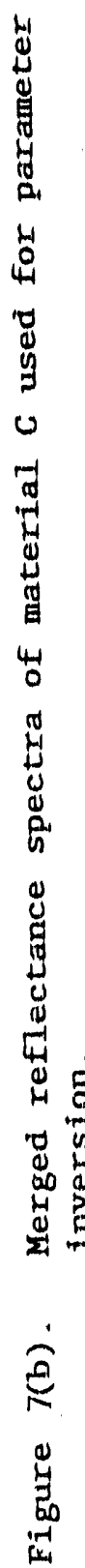




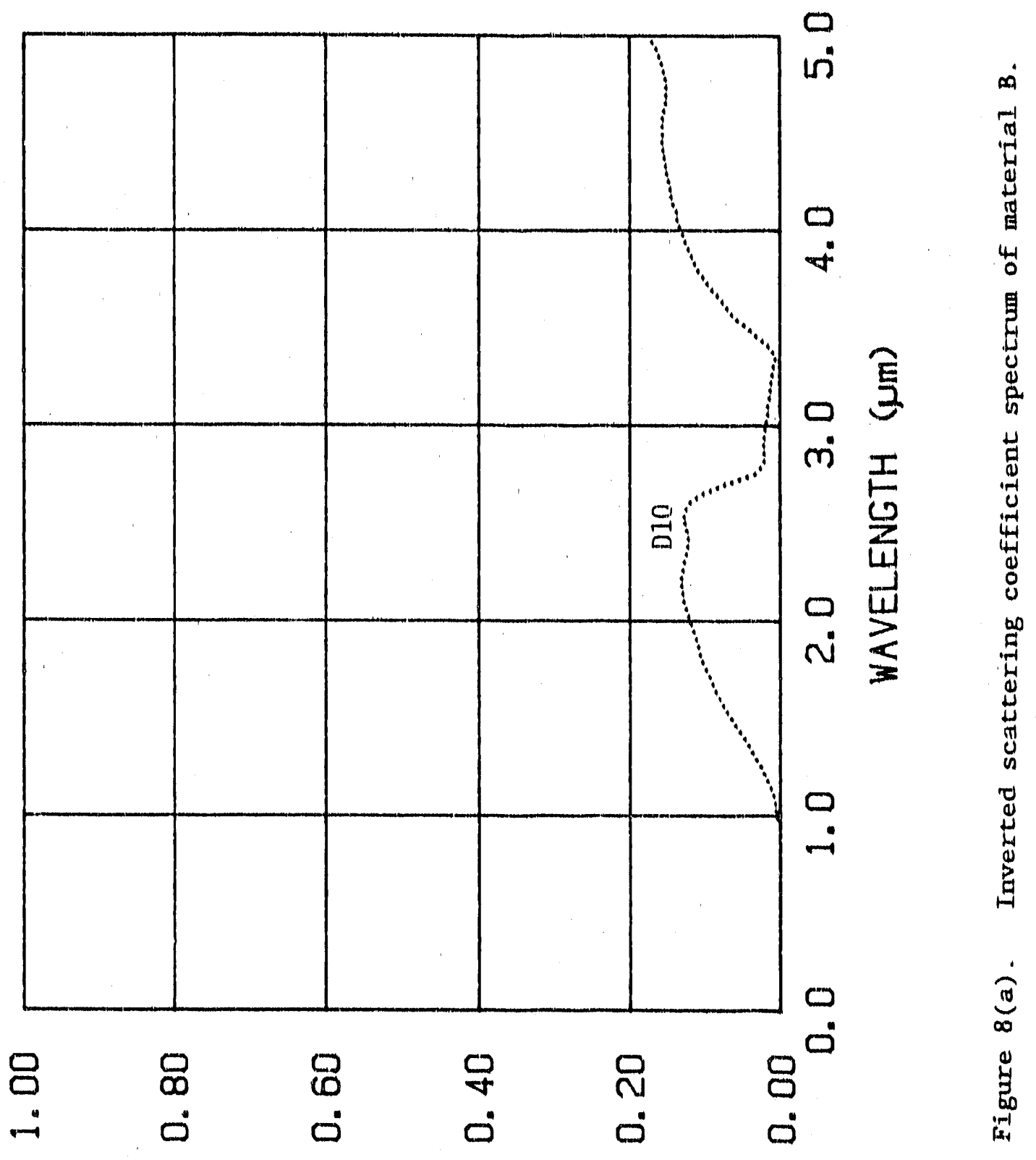

$\exists J N \forall \perp \perp I W S N \forall Y \perp$ 


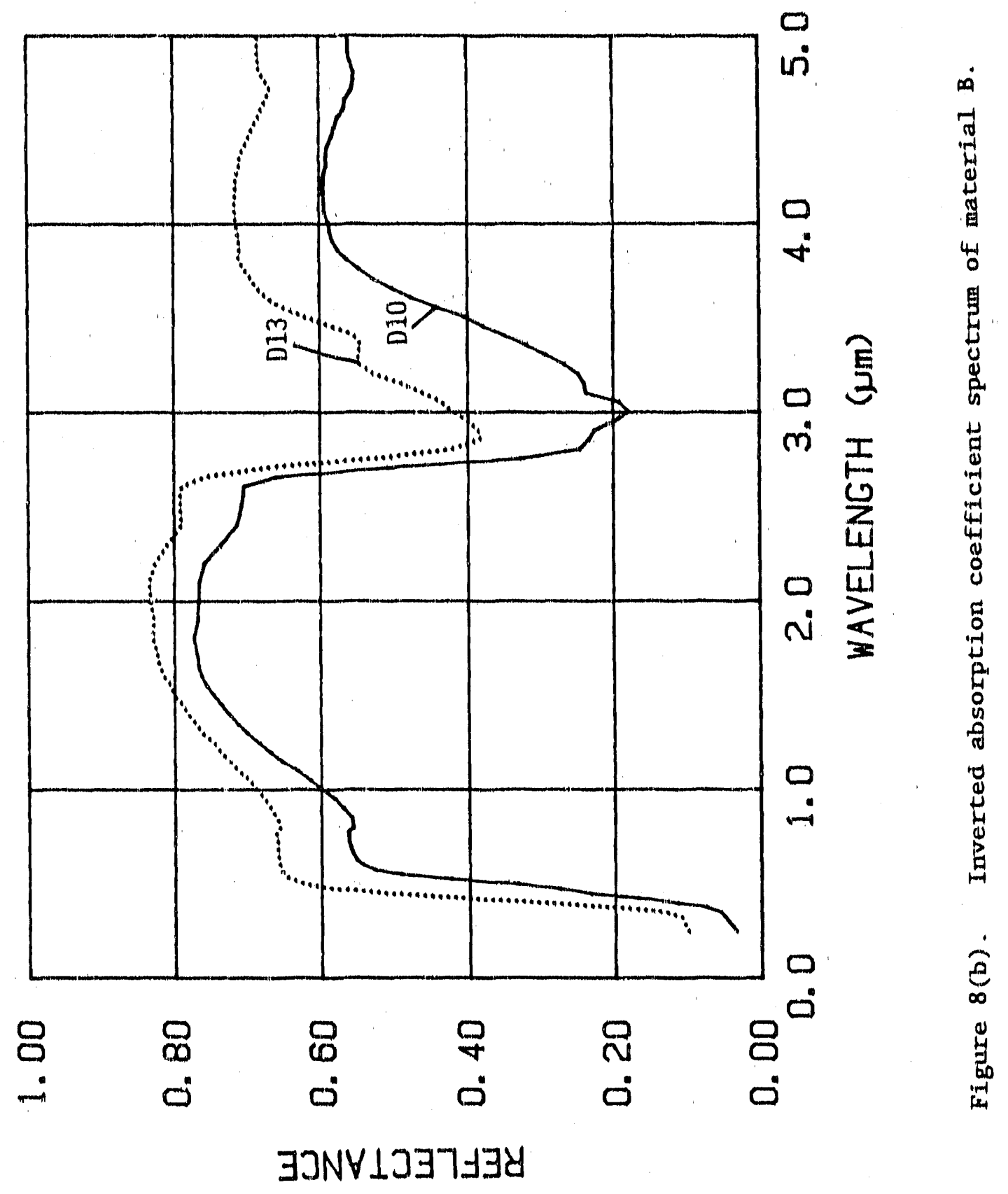




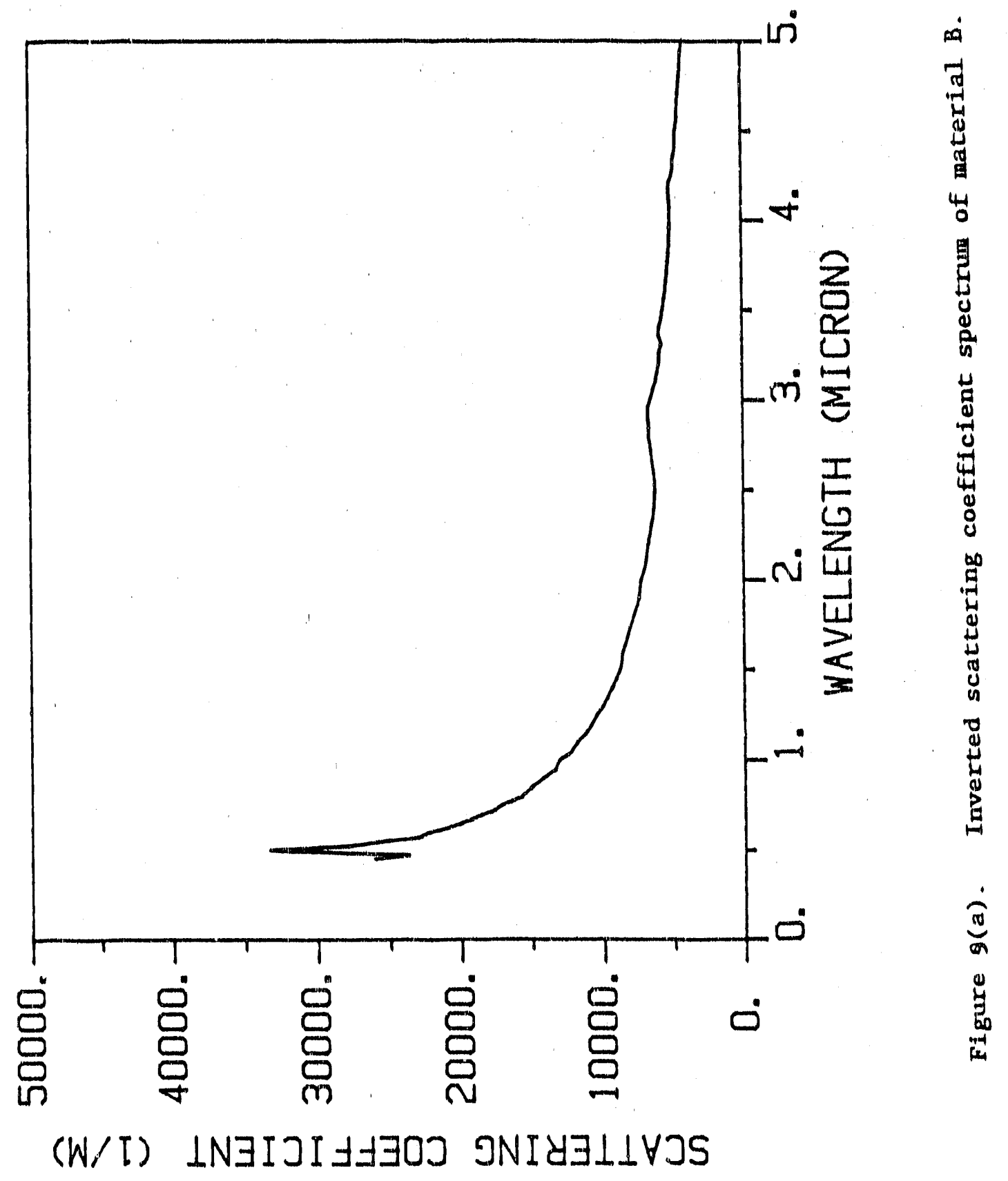




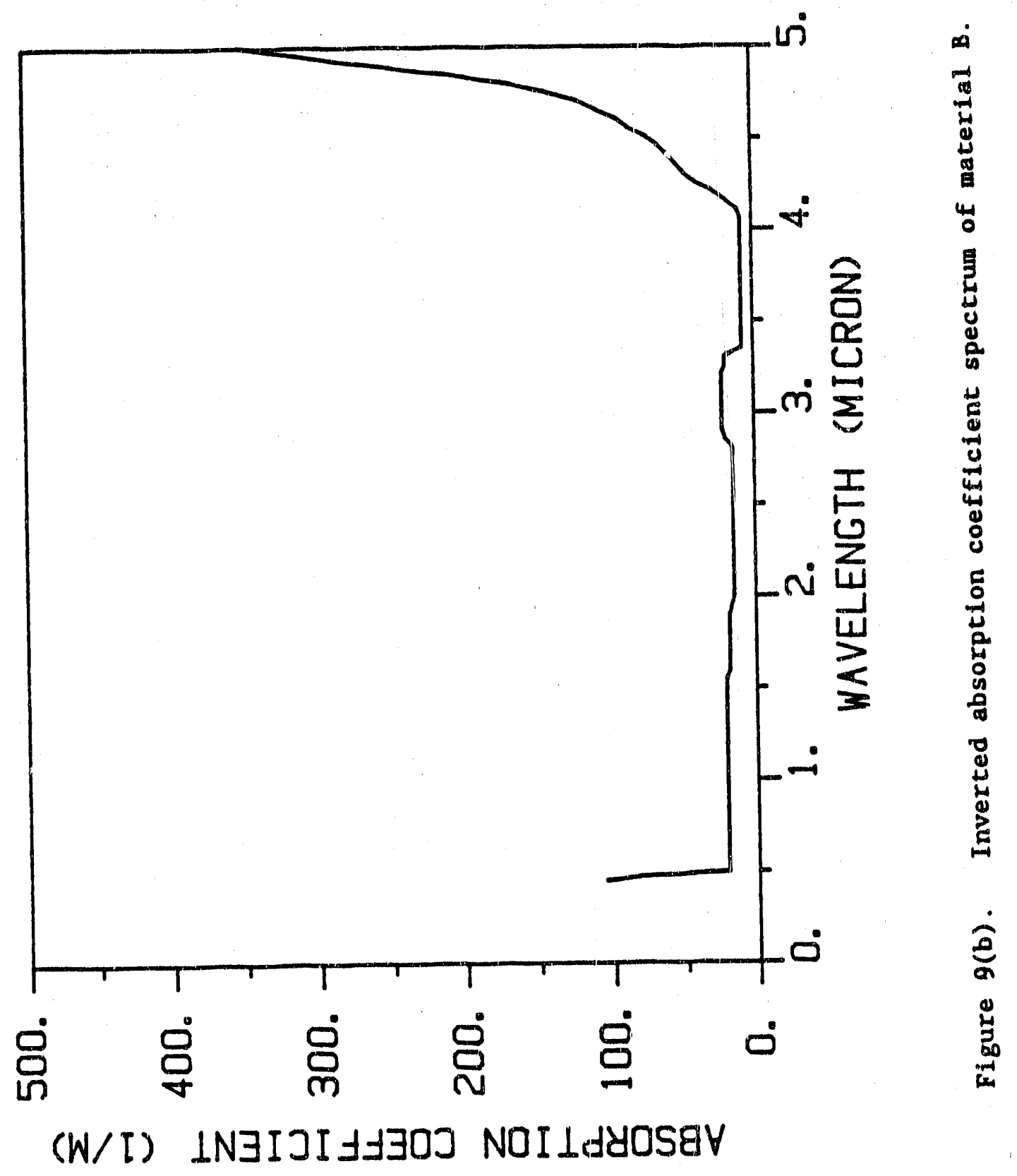




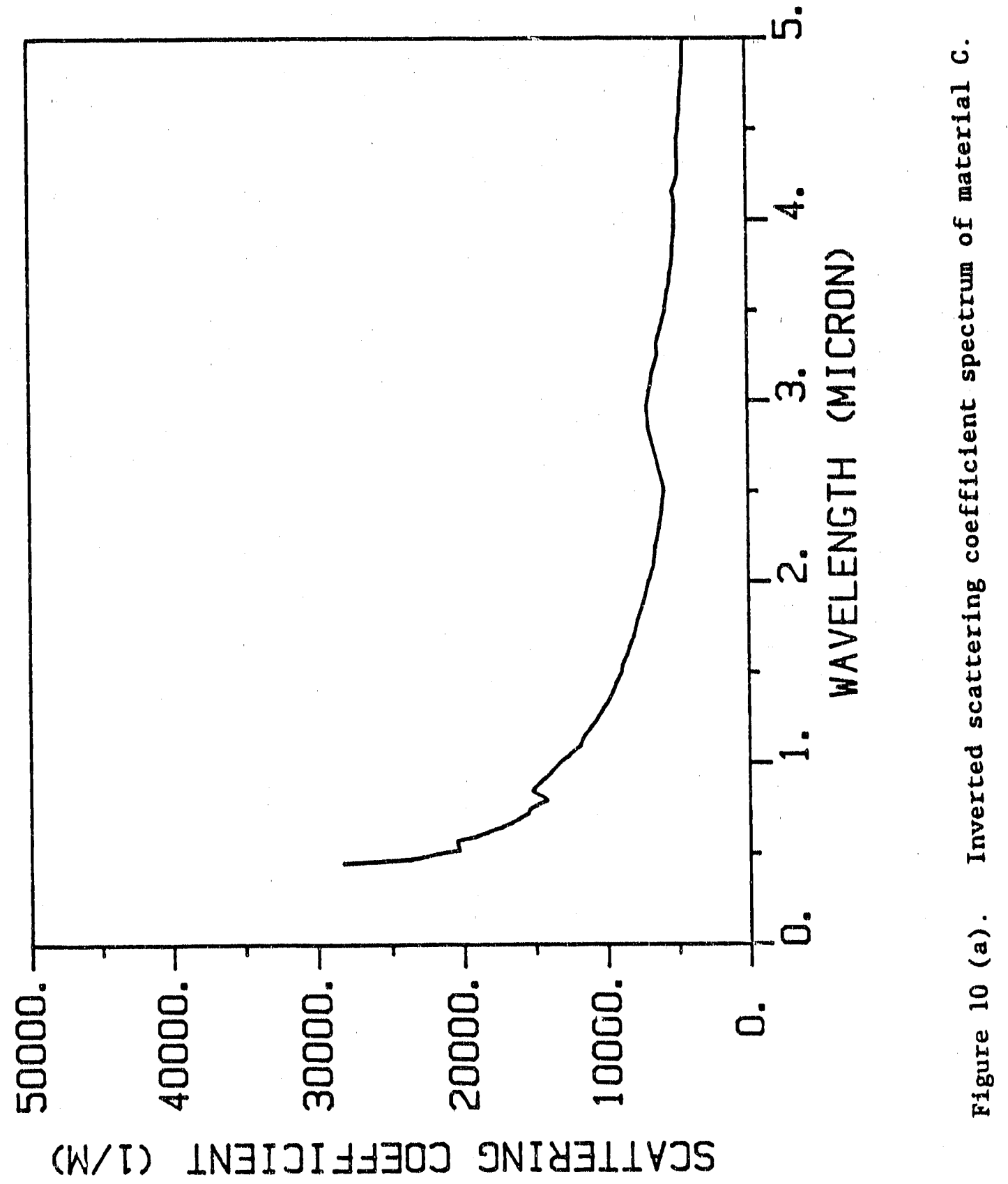




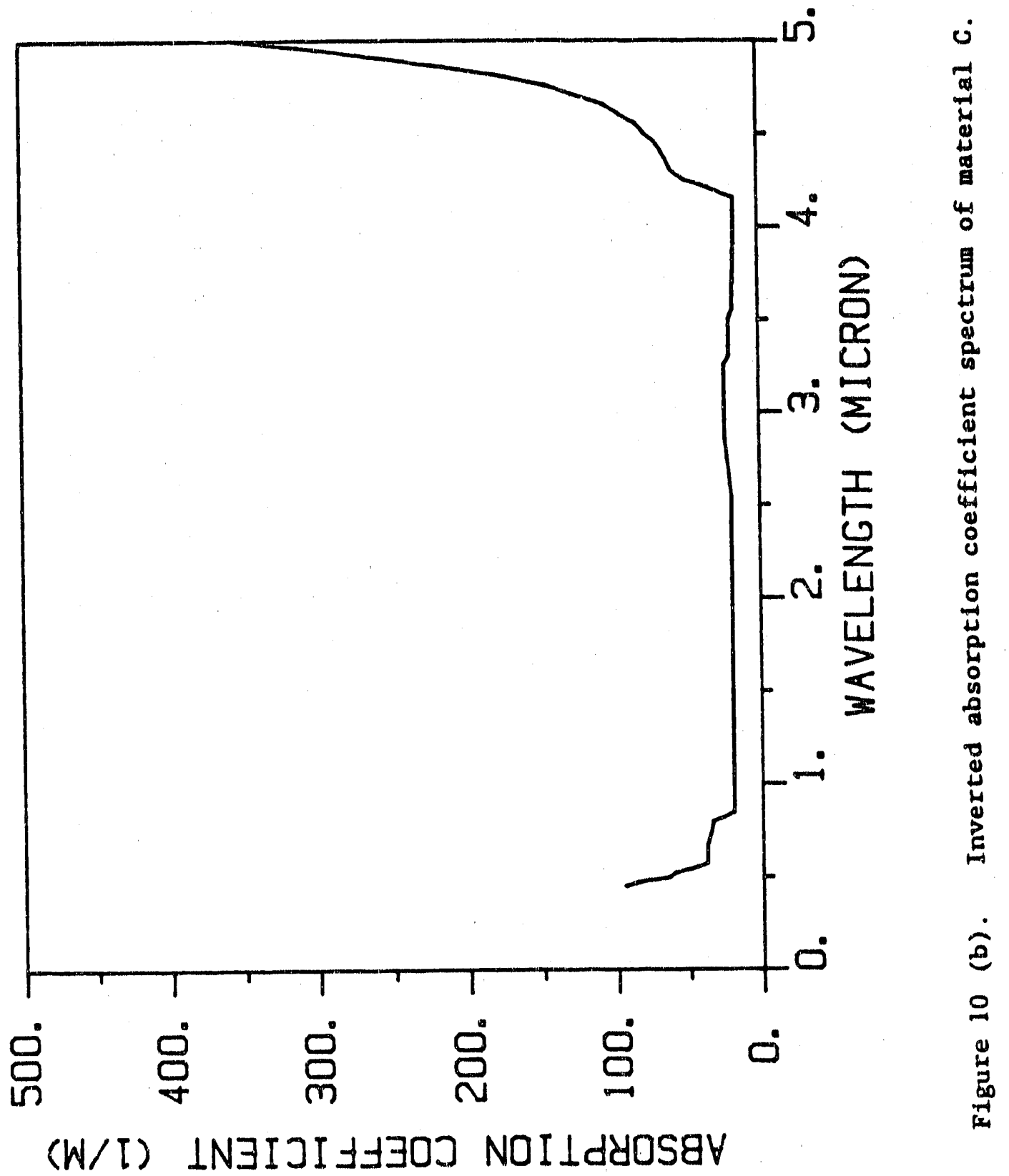




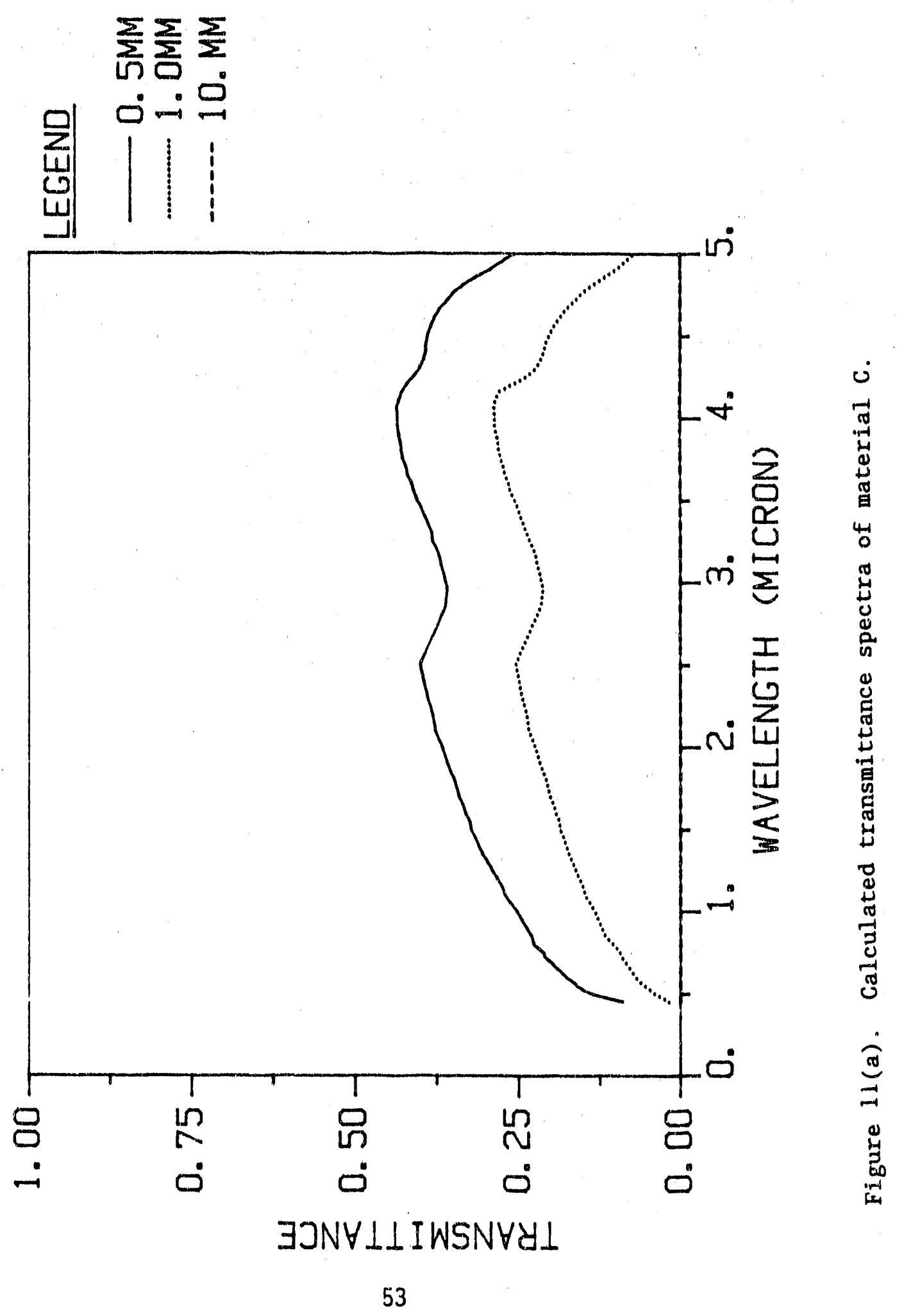




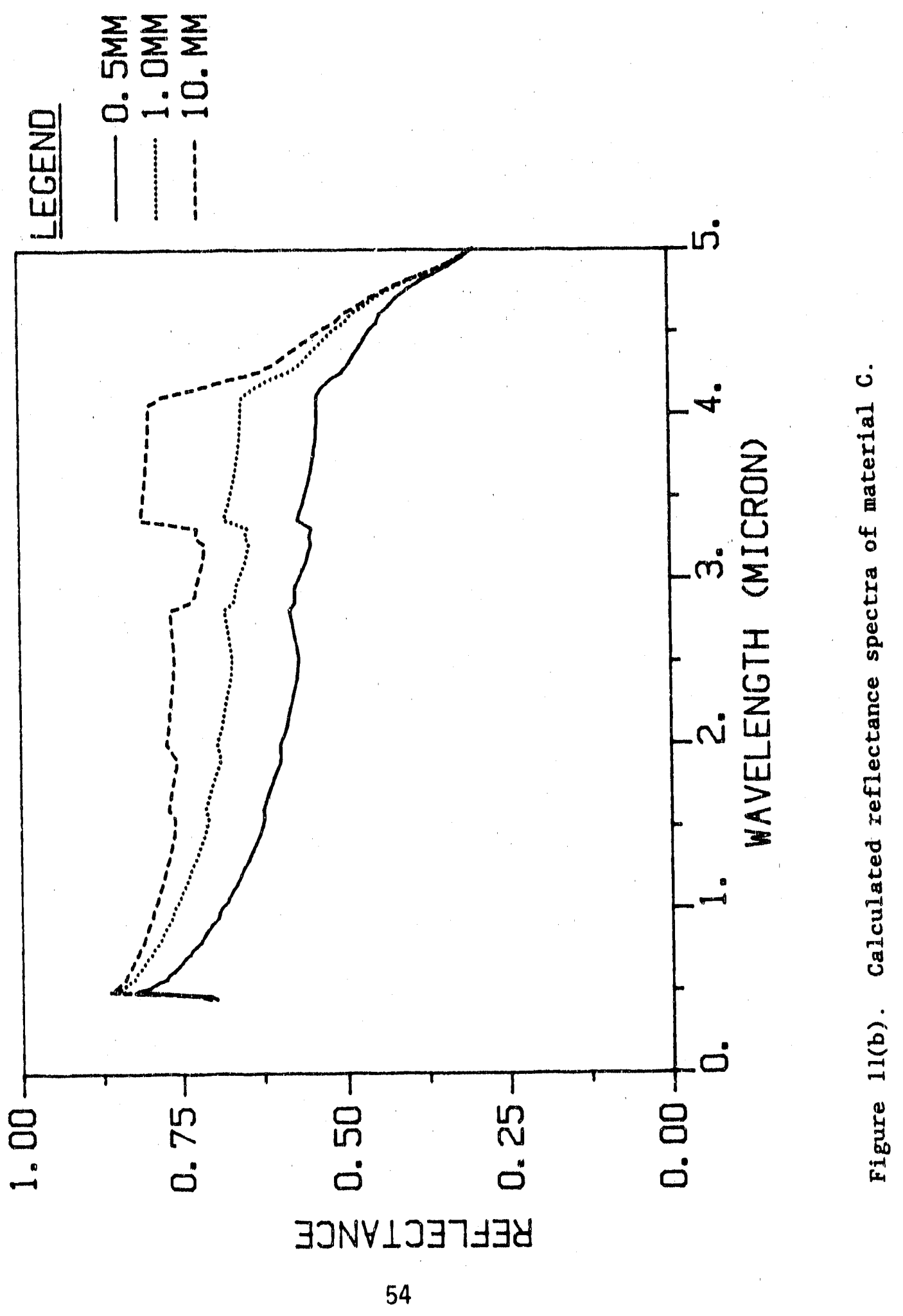




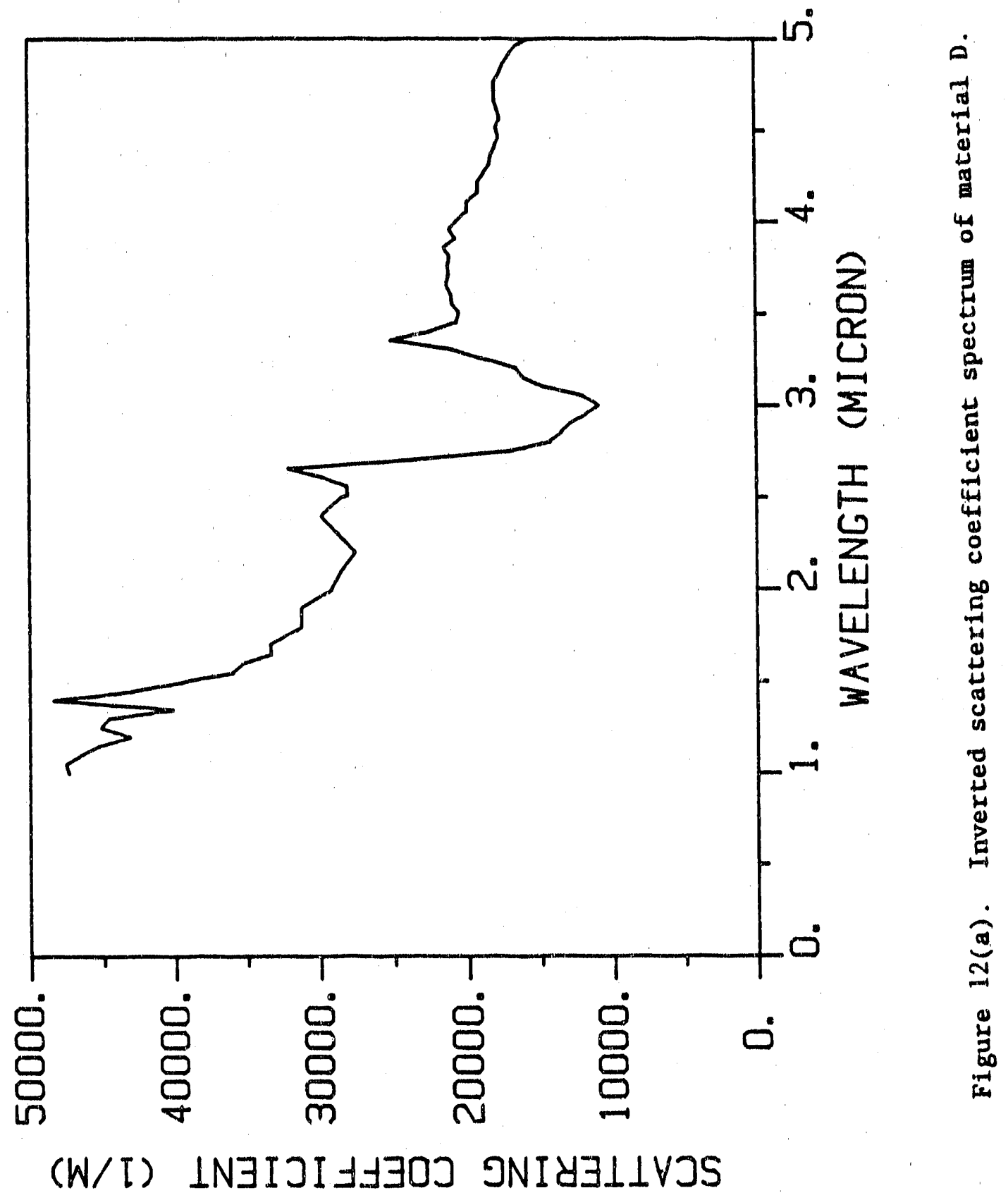




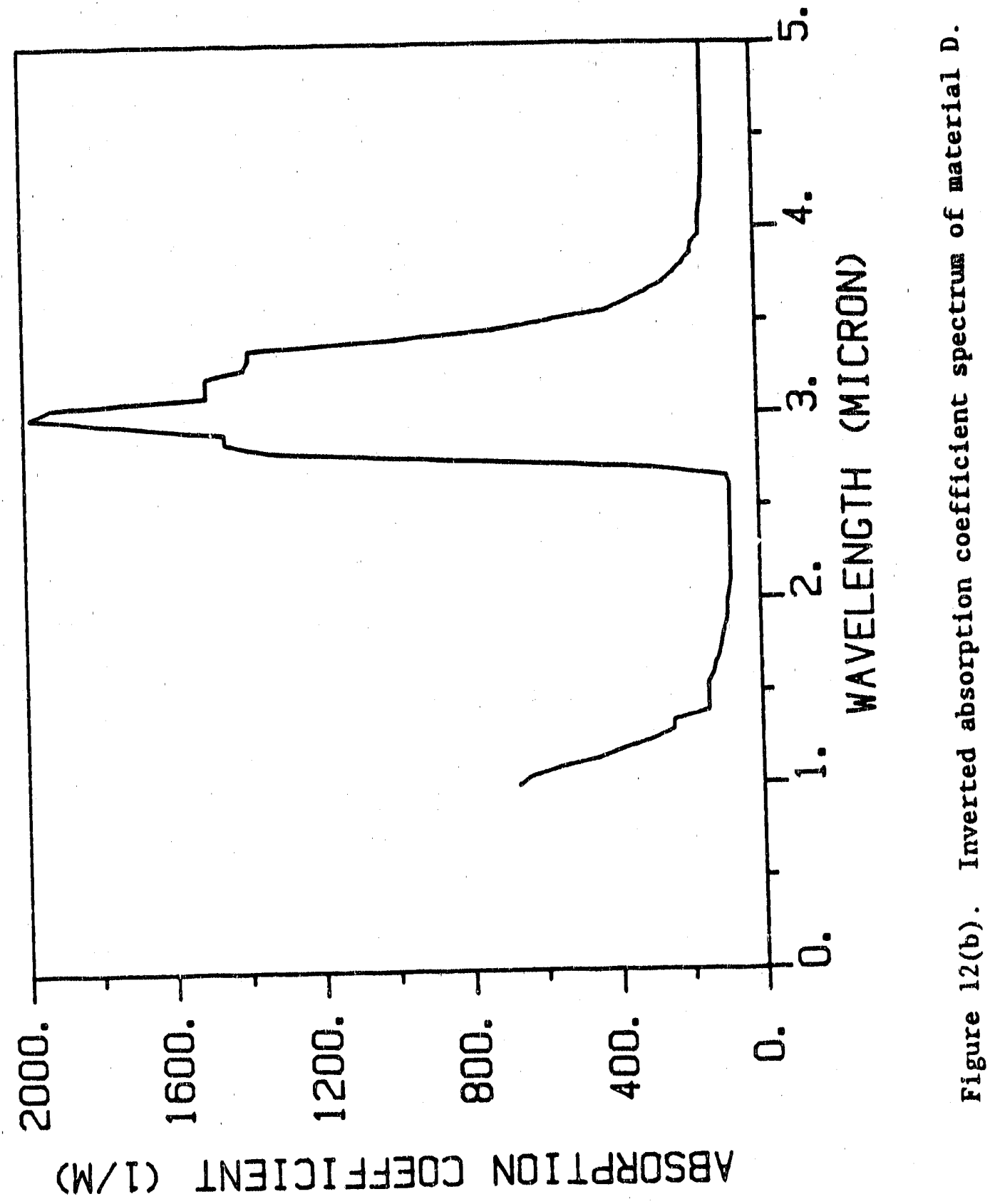




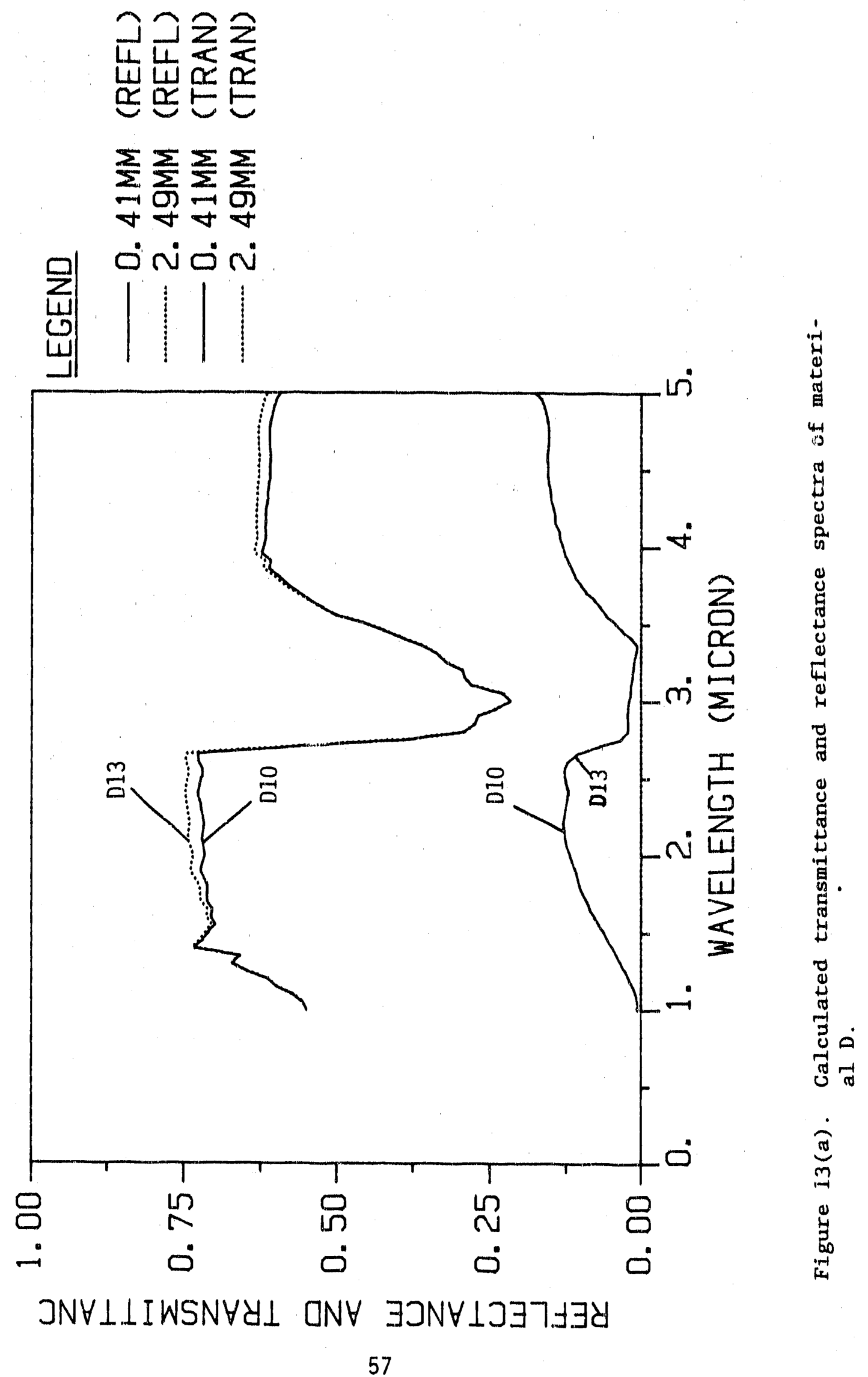




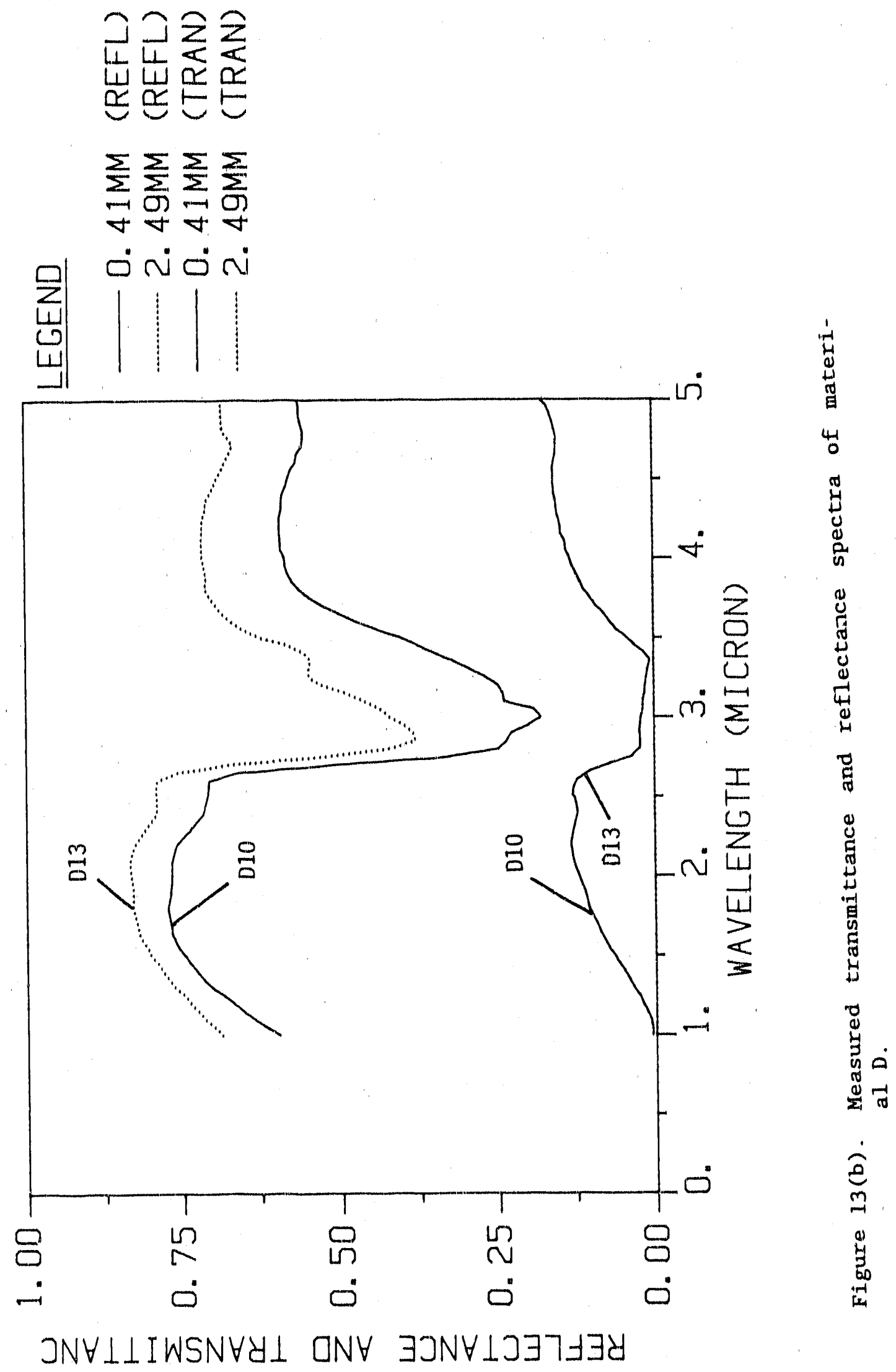




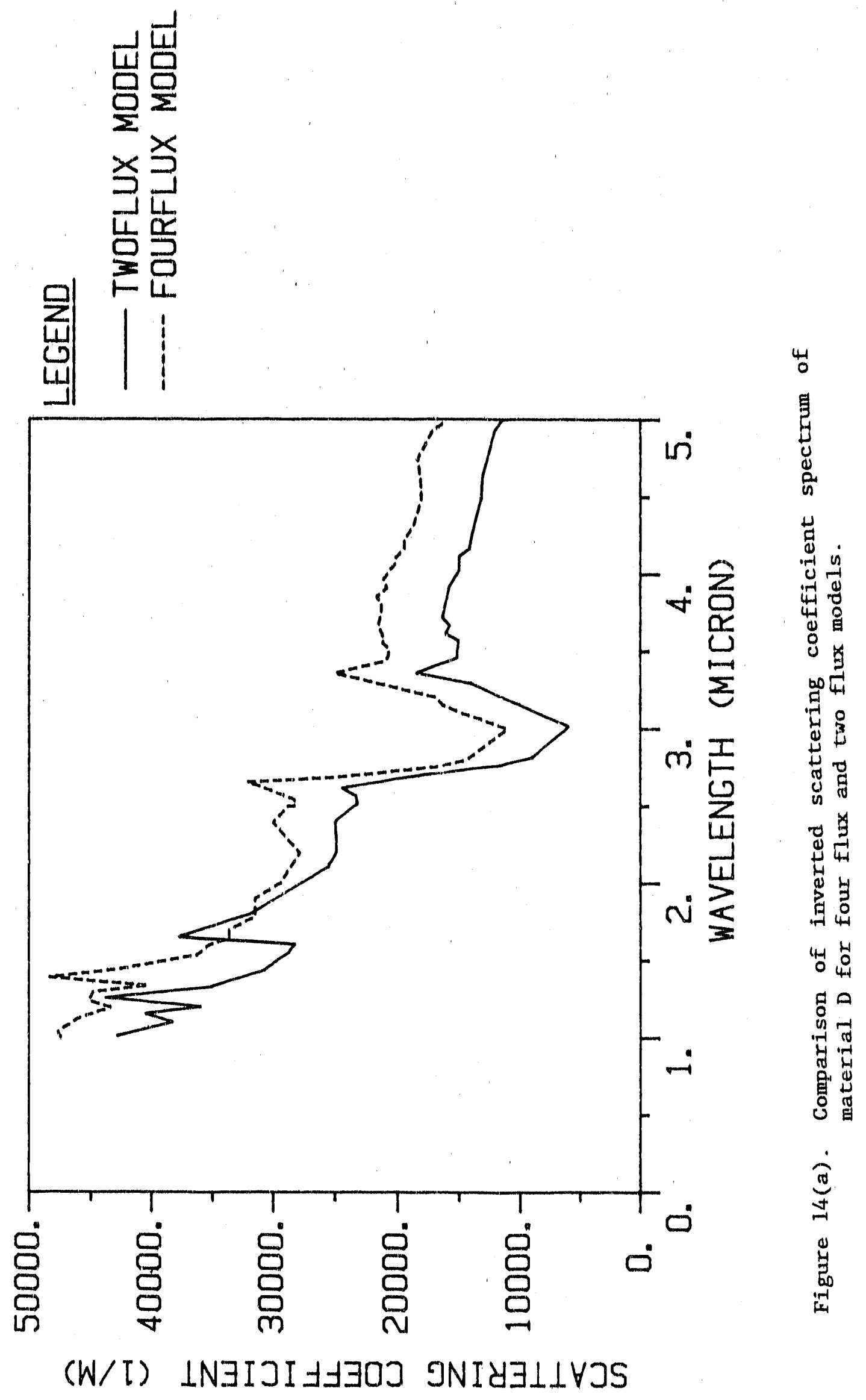




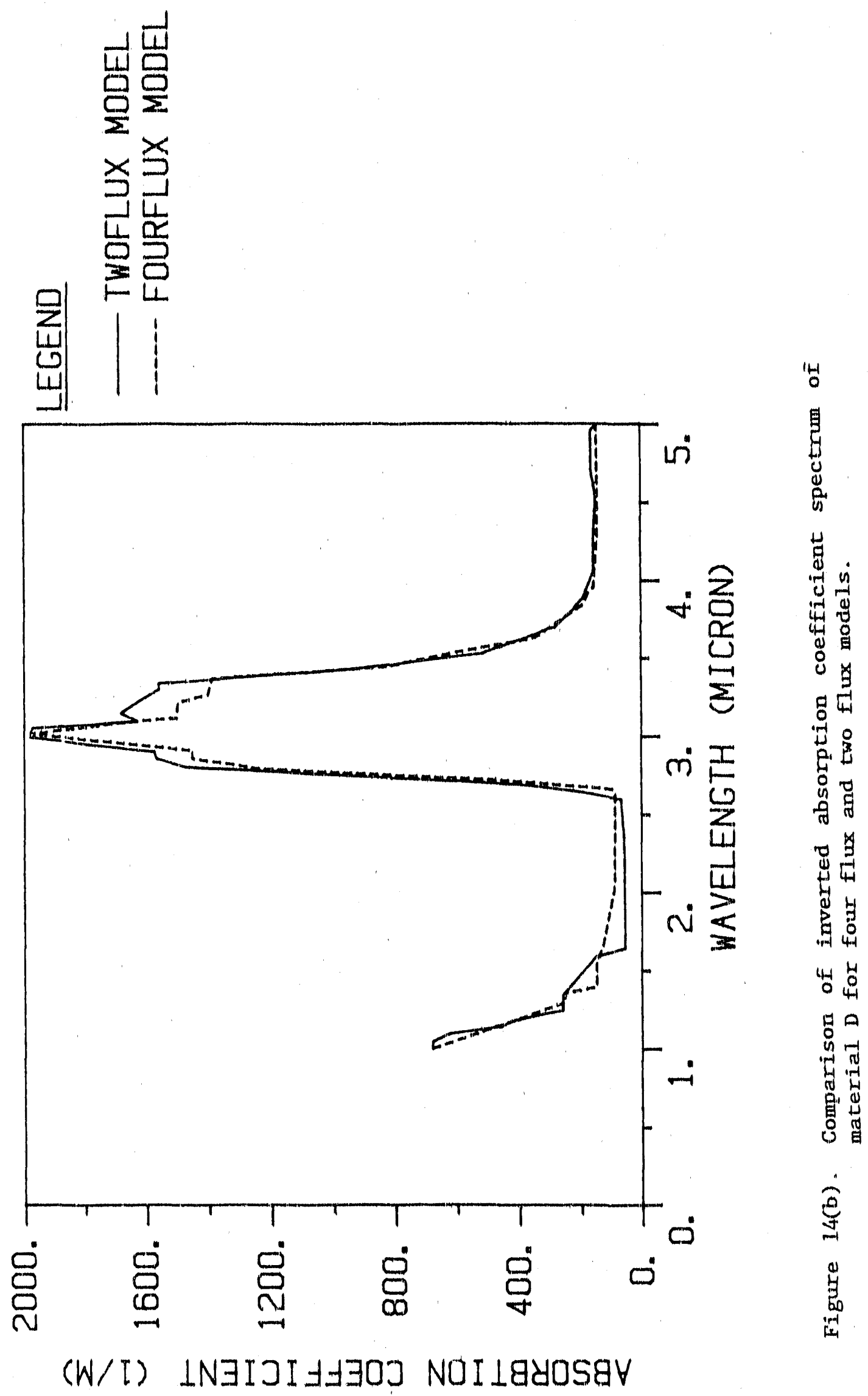




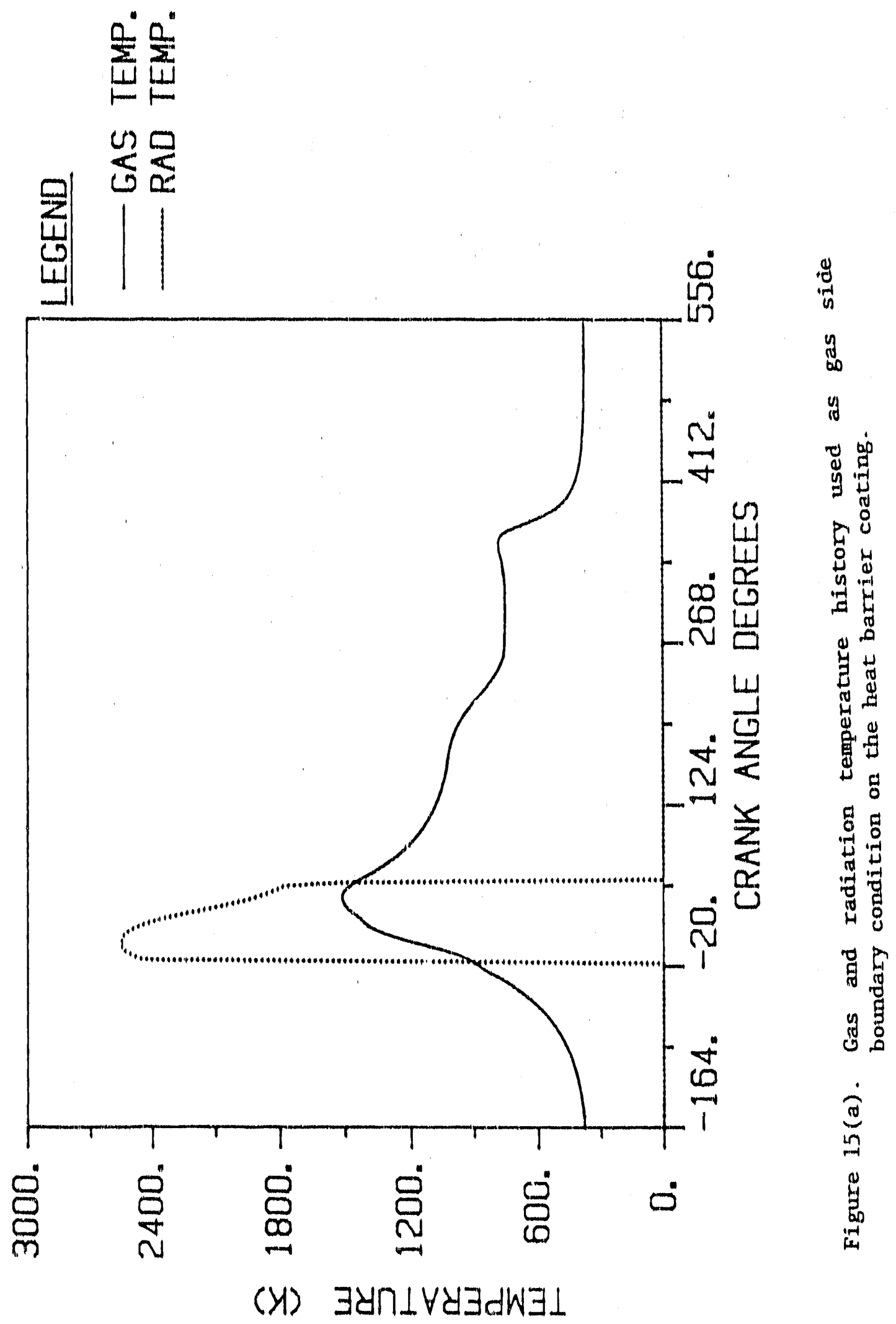




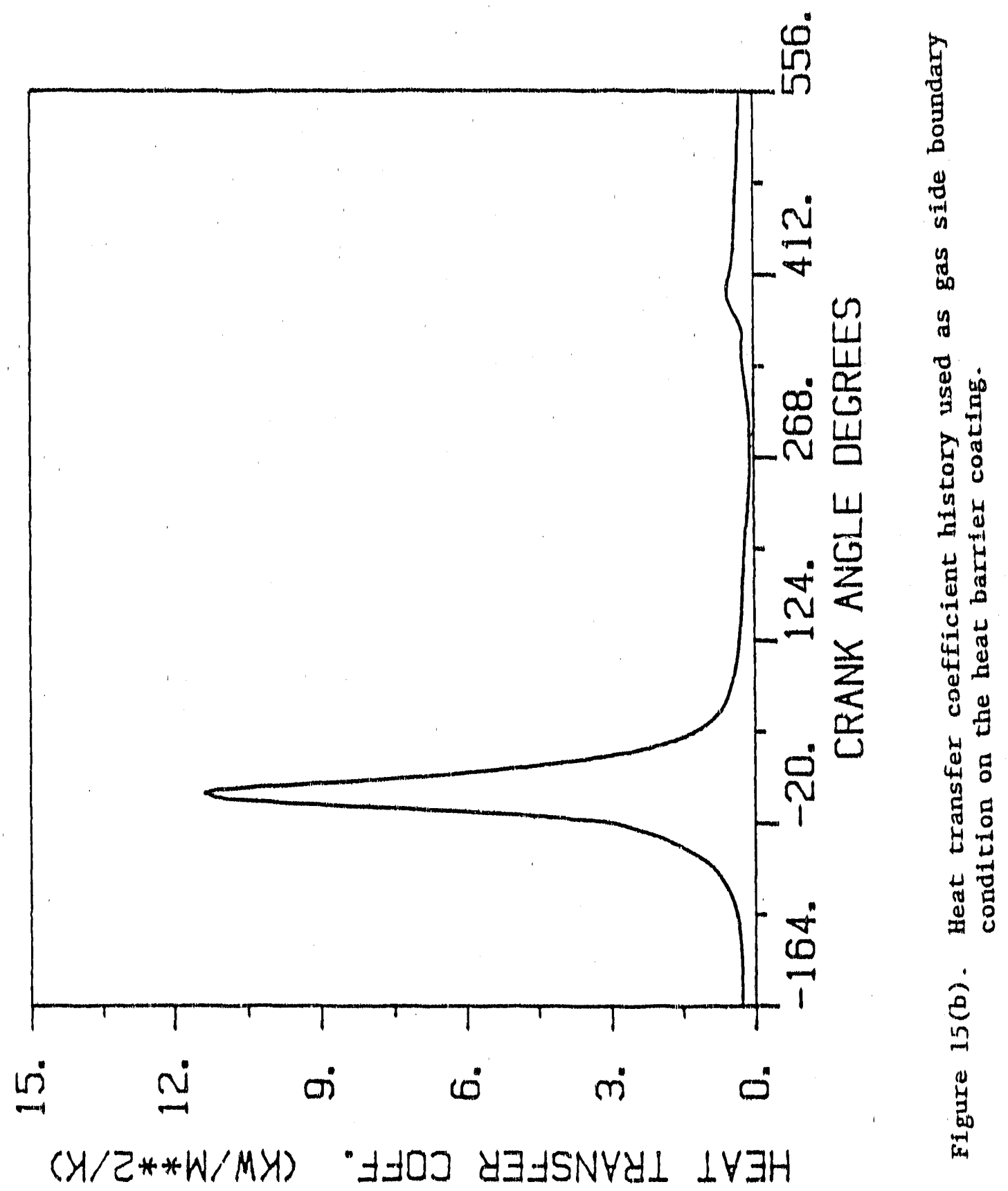




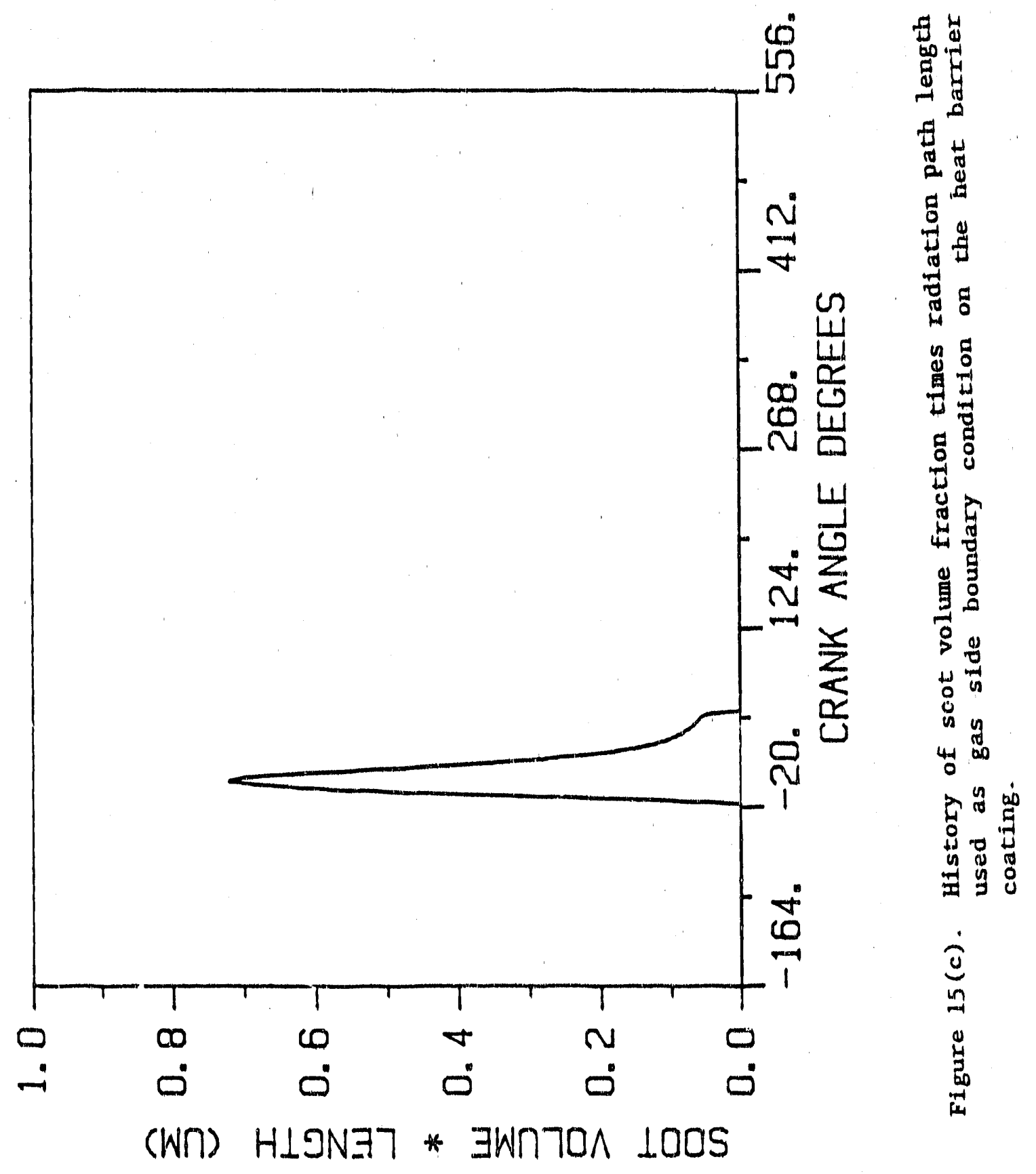




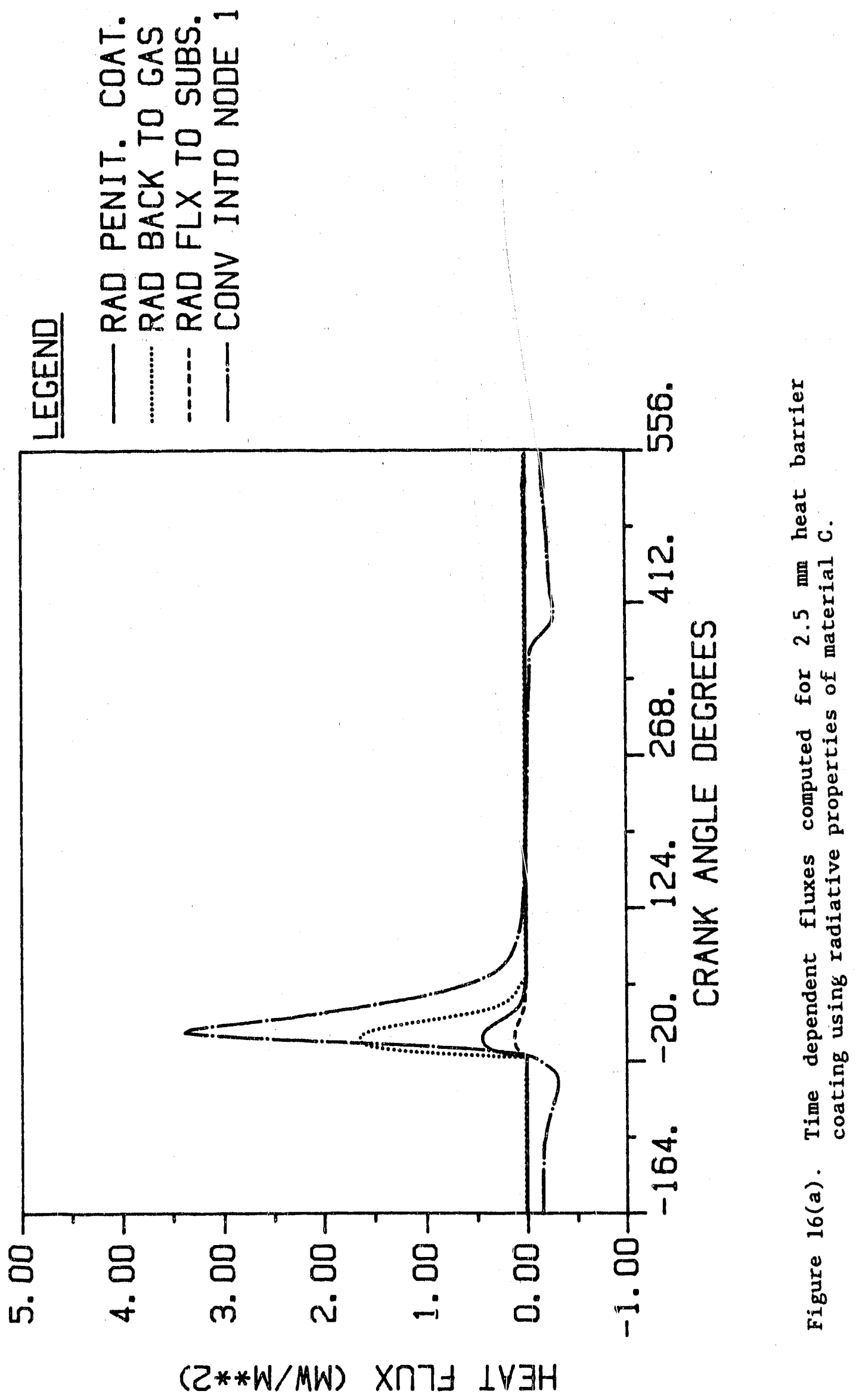




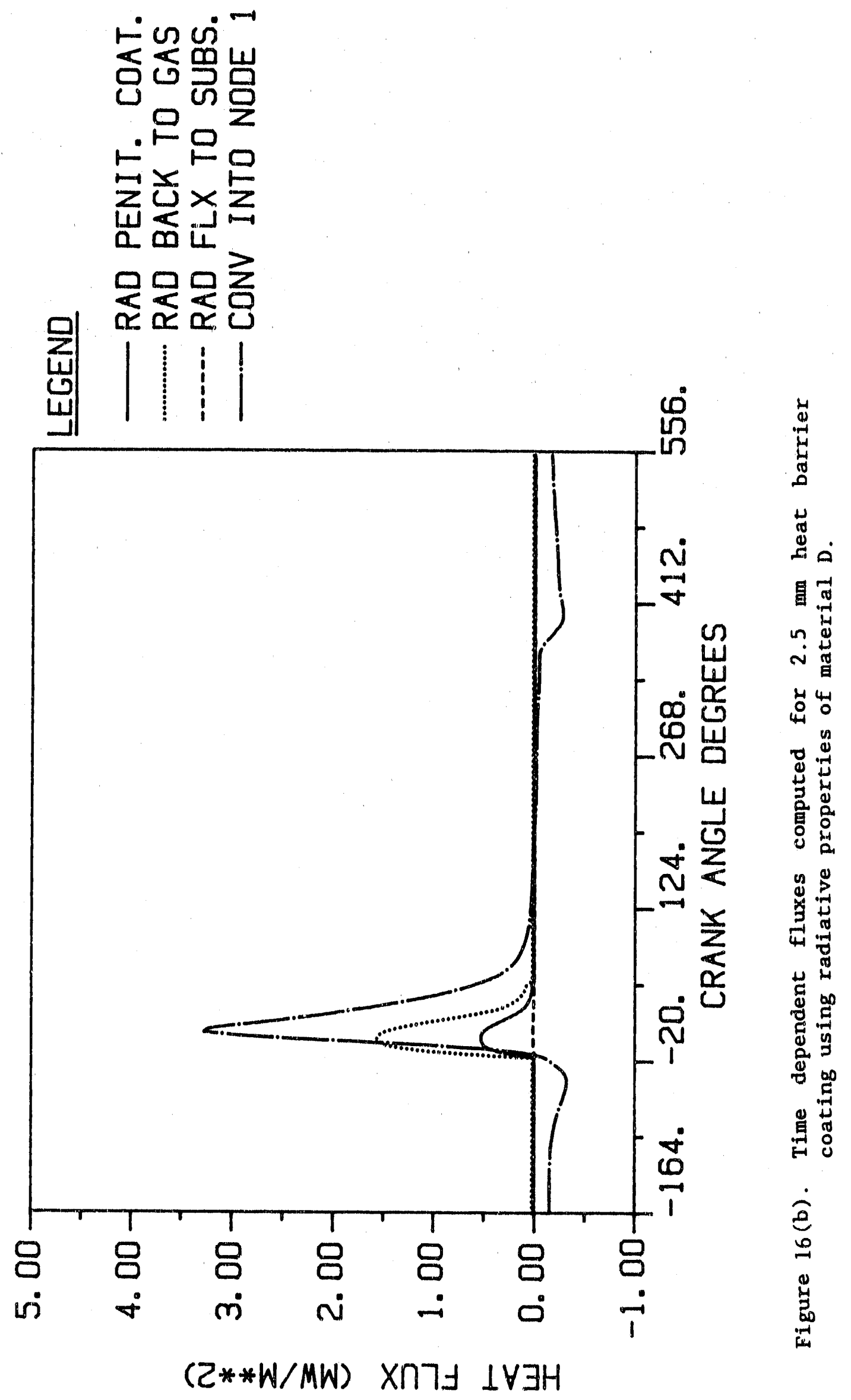




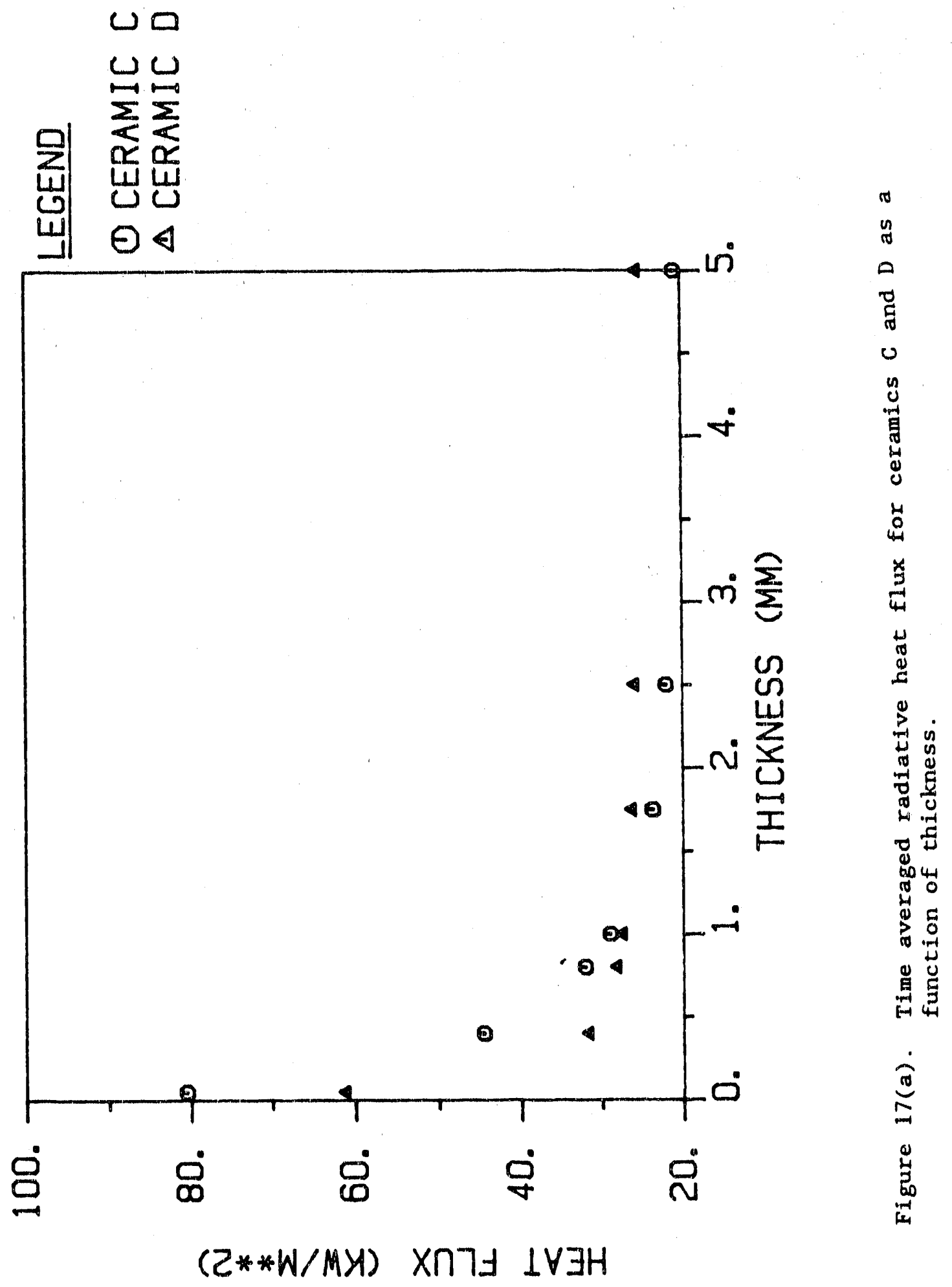




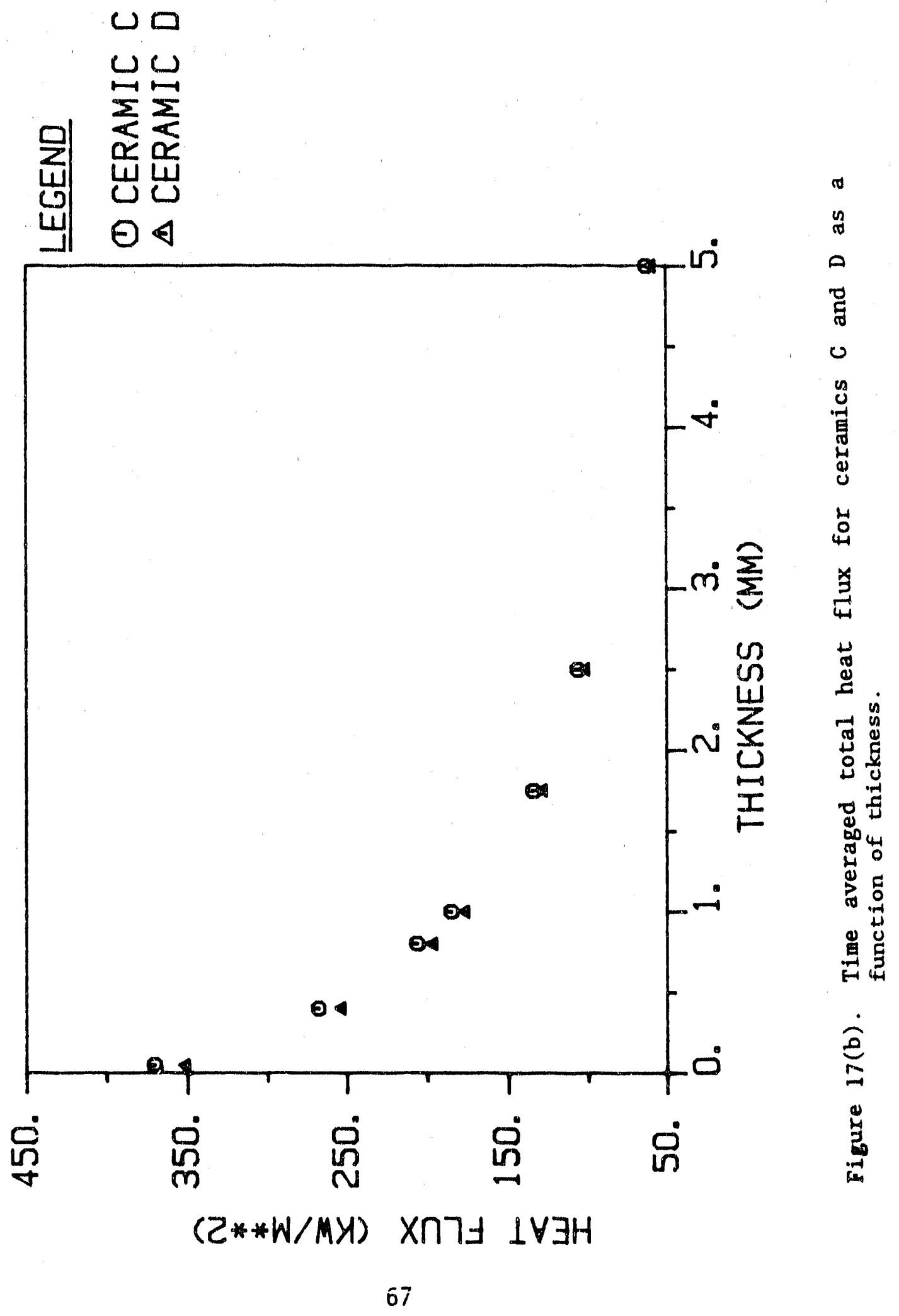




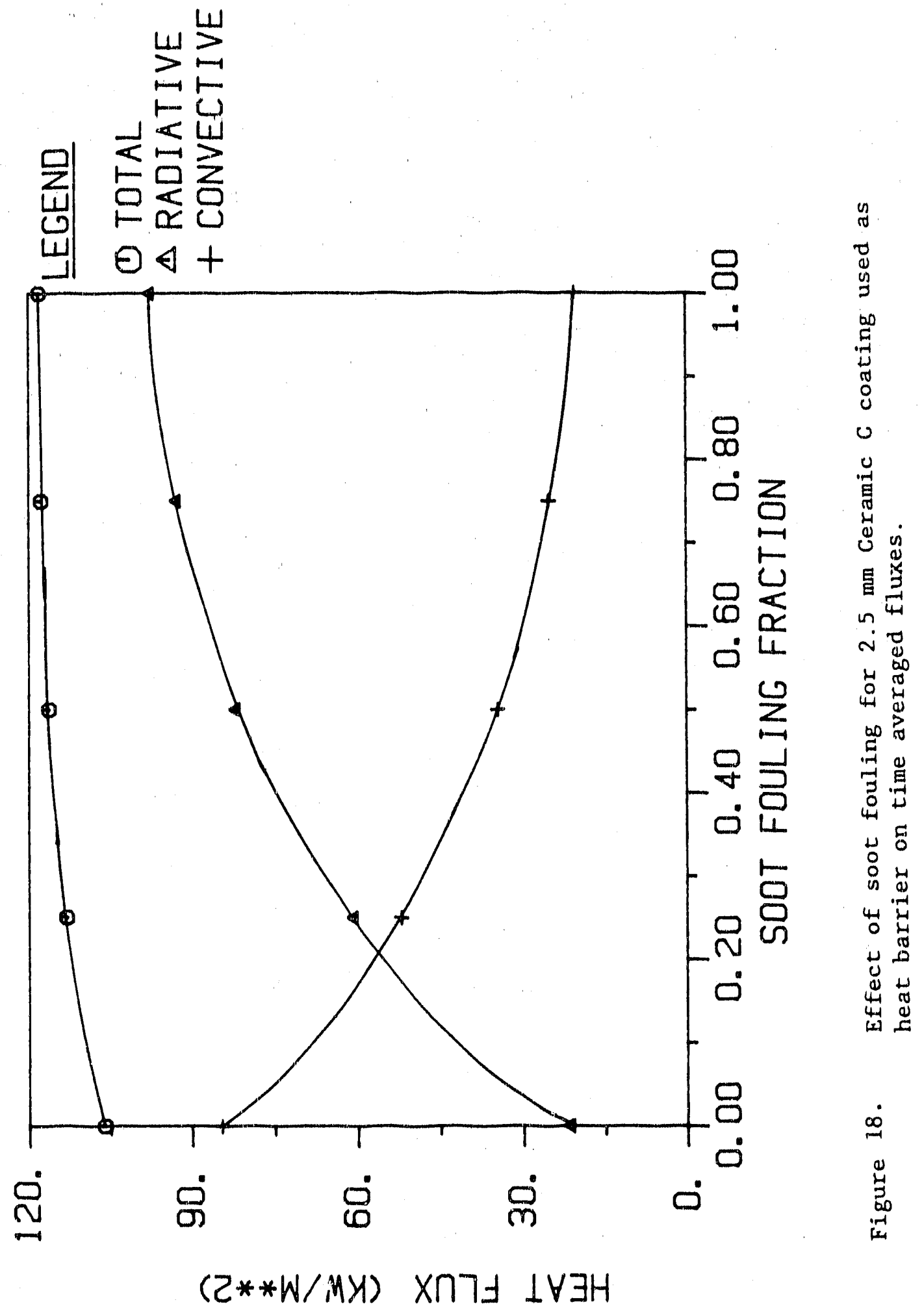




\section{APPENDIX}

The reflectance and transmittance measurements at short to long infrared regions $(2 \mu \mathrm{m}$ to $20 \mu \mathrm{m}$ were measured at the Willey Corporation. The data obtained were quite noisy at shorter wavelengths and necessitated smoothing. The smoothed profiles shown in the text have been used in the analysis. However, for reference purposes, the unsmoothed data is also presented in the following figures. (Note: Per instruction from the Willey Corporation the values in the reflectance spectra need to be divided by 0.95$)$. The corresponding NBS mesurements carried out in the range 0.25 $\mu \mathrm{m}$ to $2.5 \mu \mathrm{m}$ were furnished in tabular form and plots obtained from these tables are presented without modification in the general text of this report and will not be repeated here. 


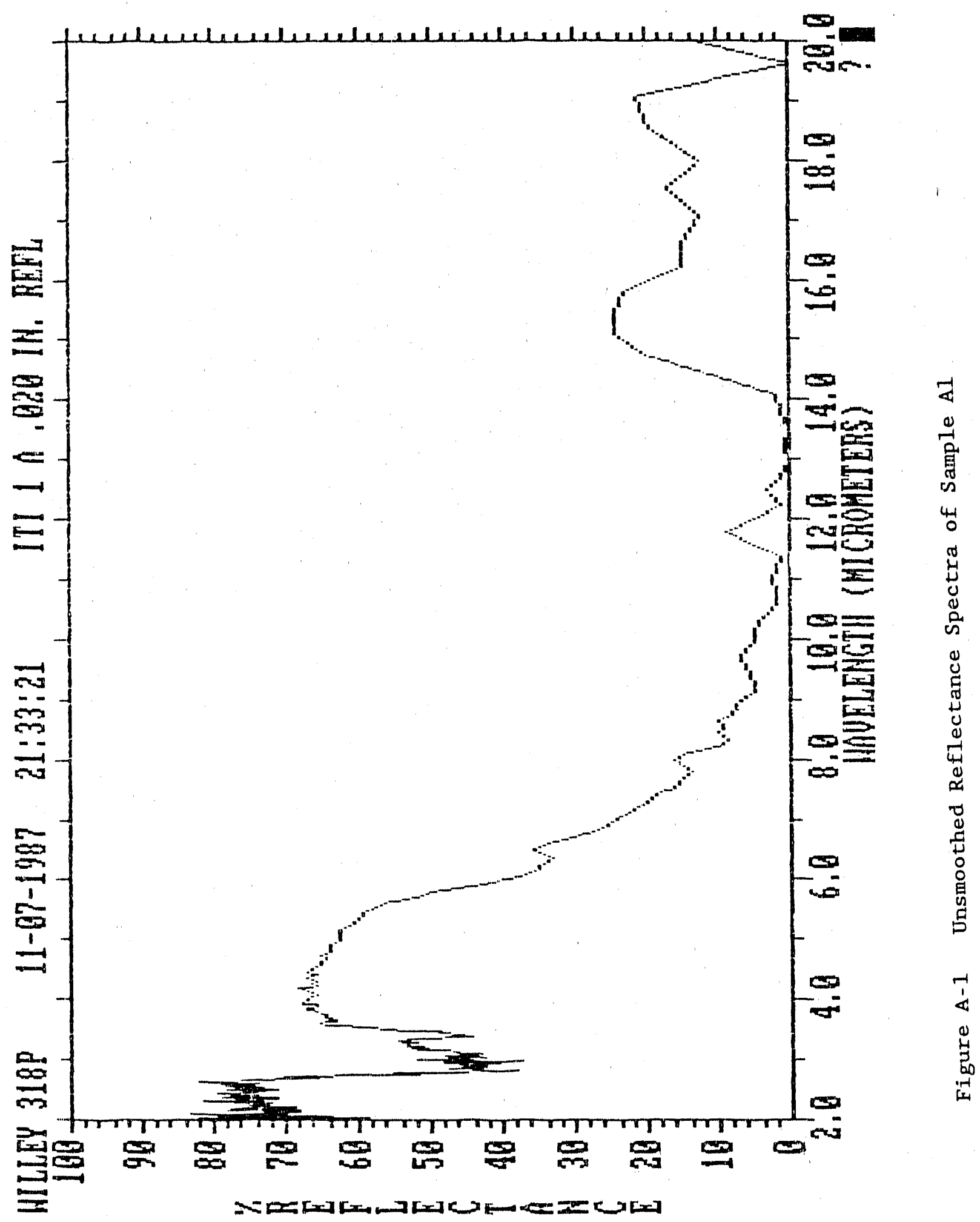




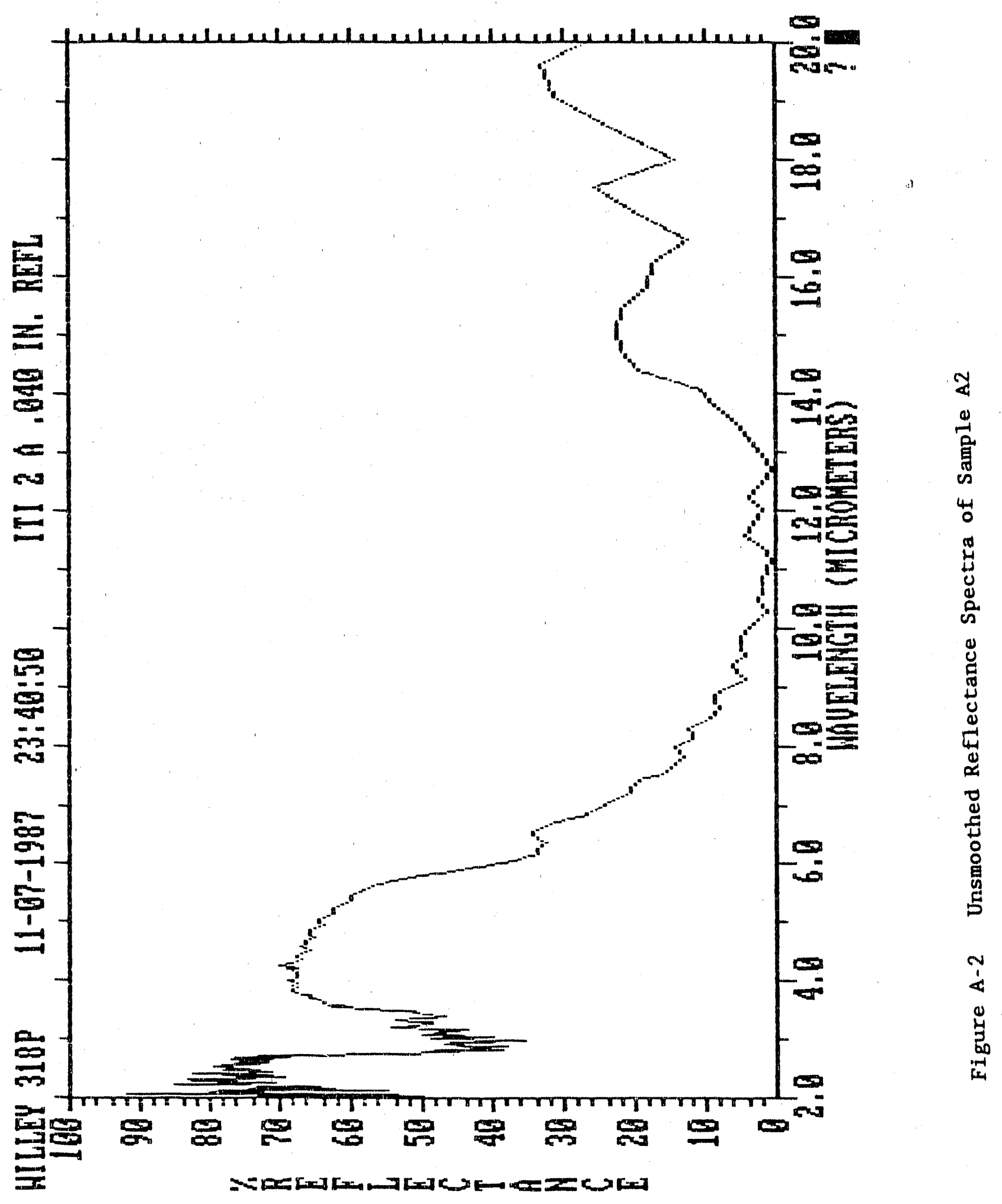




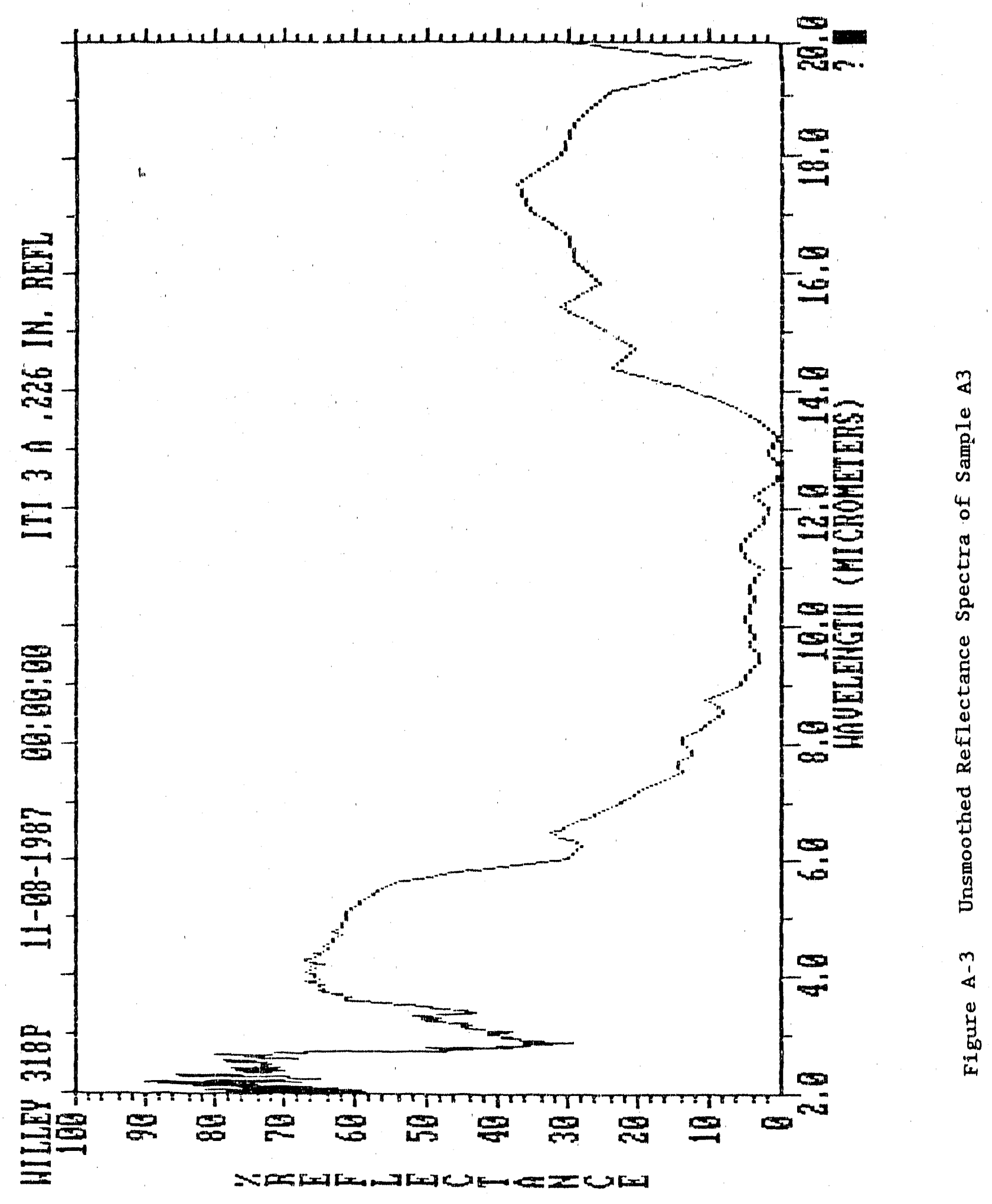




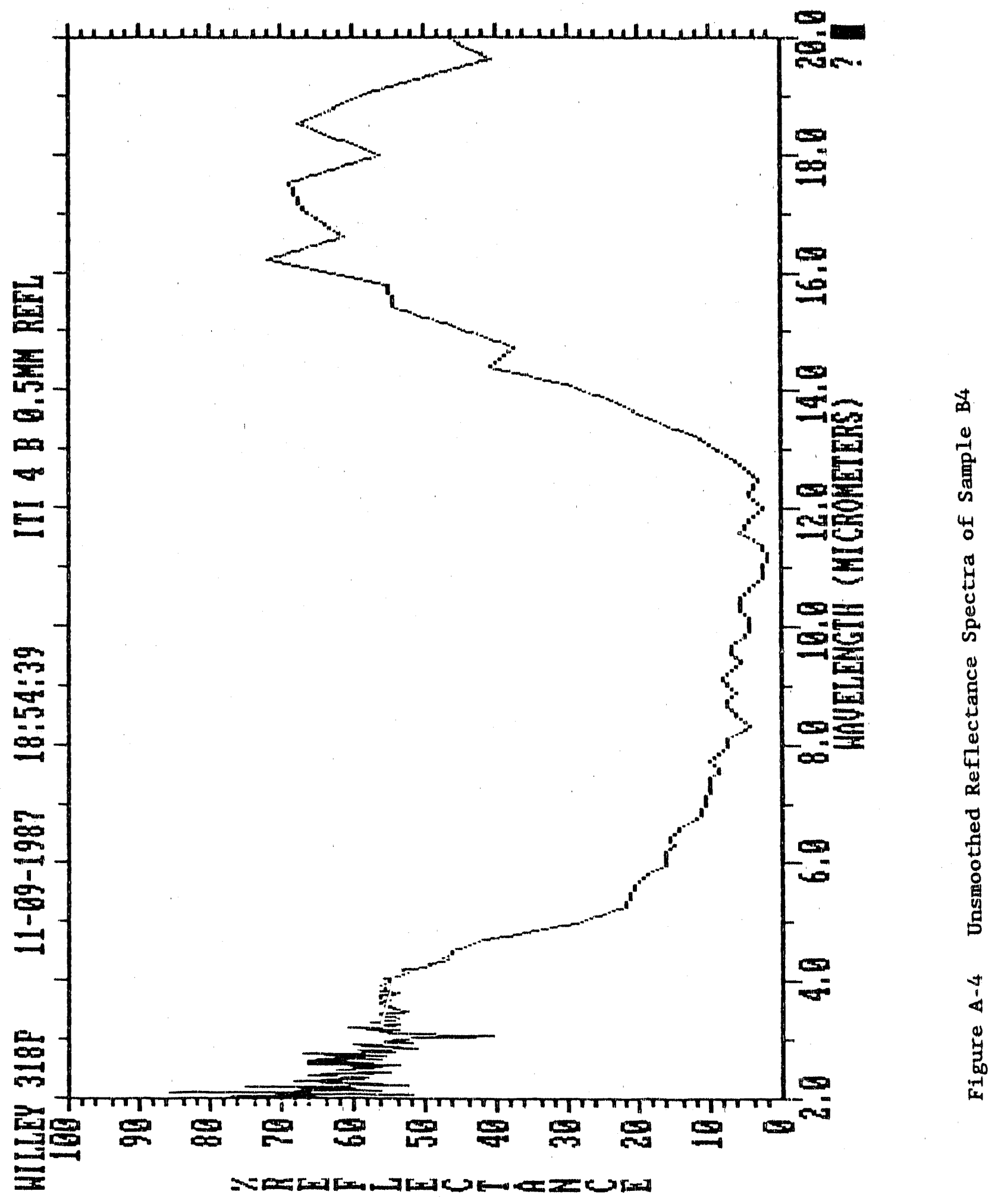




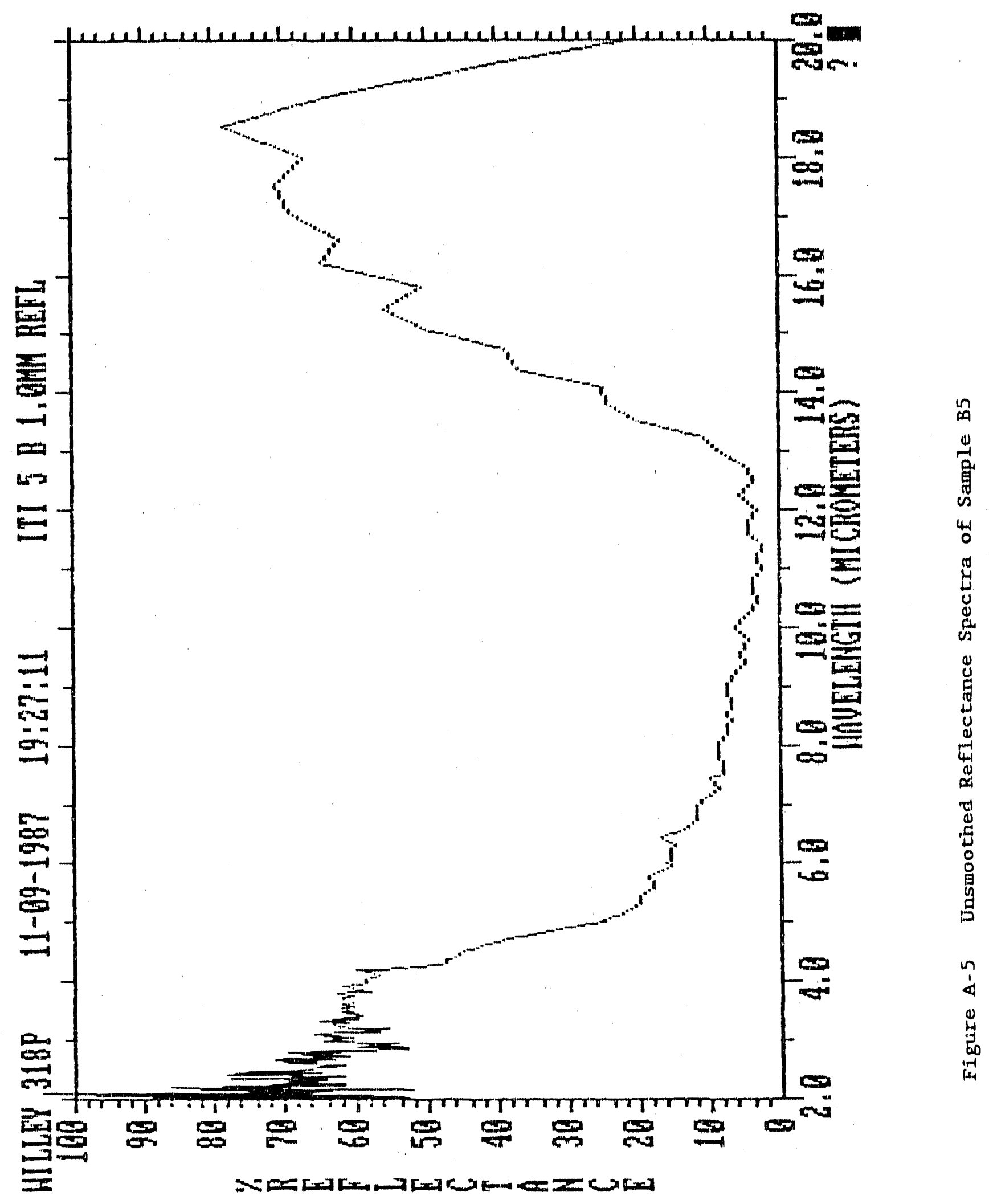




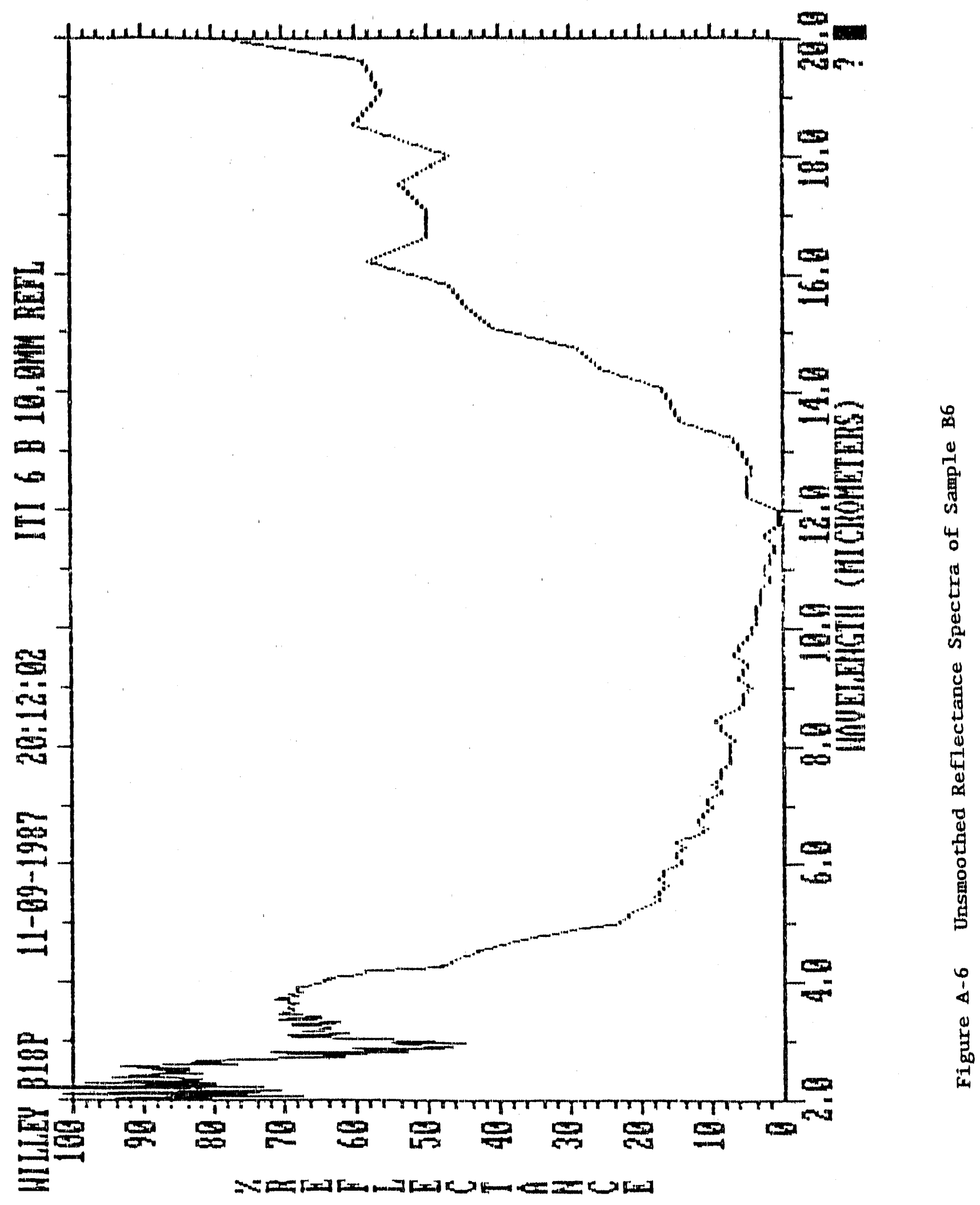




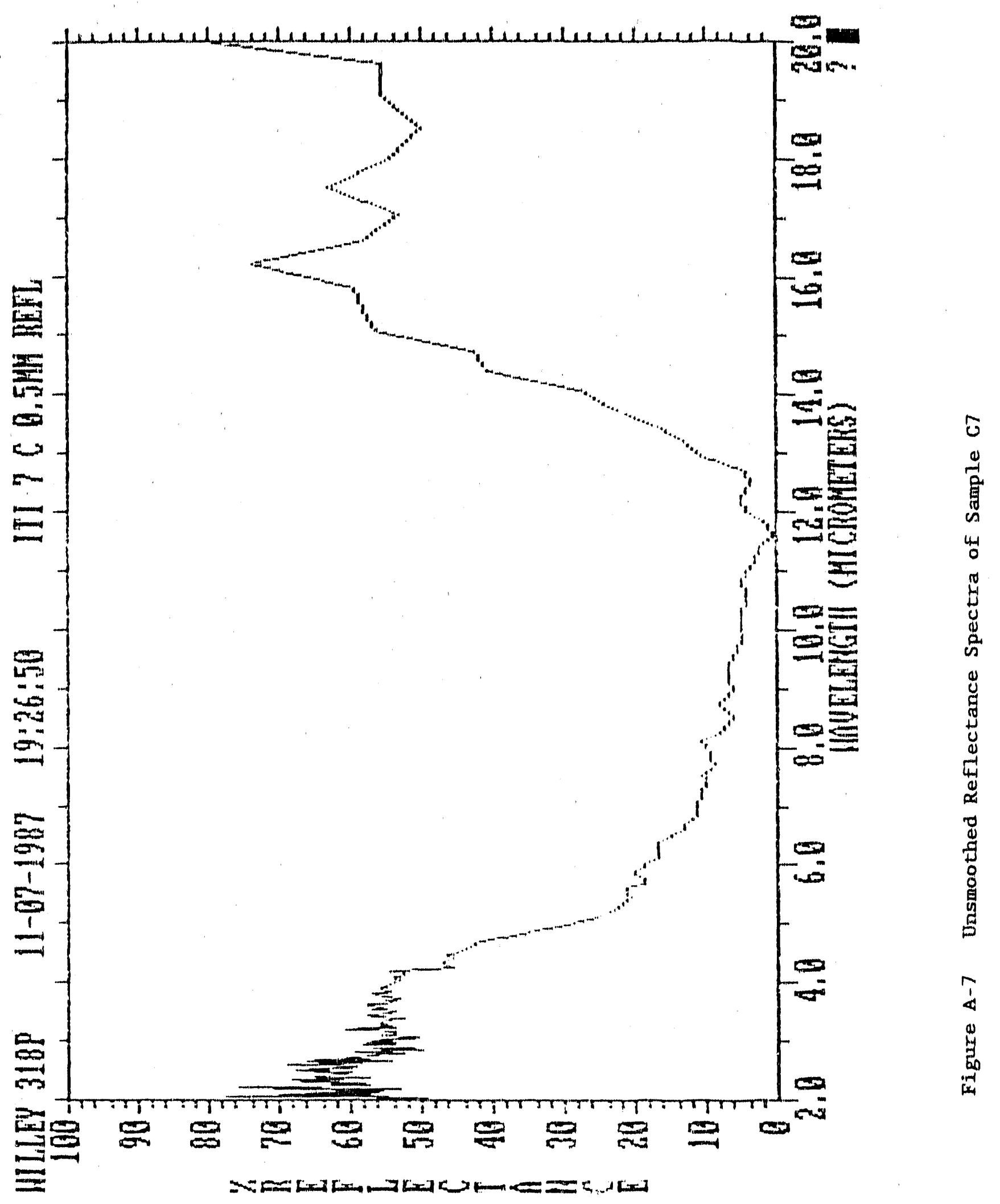




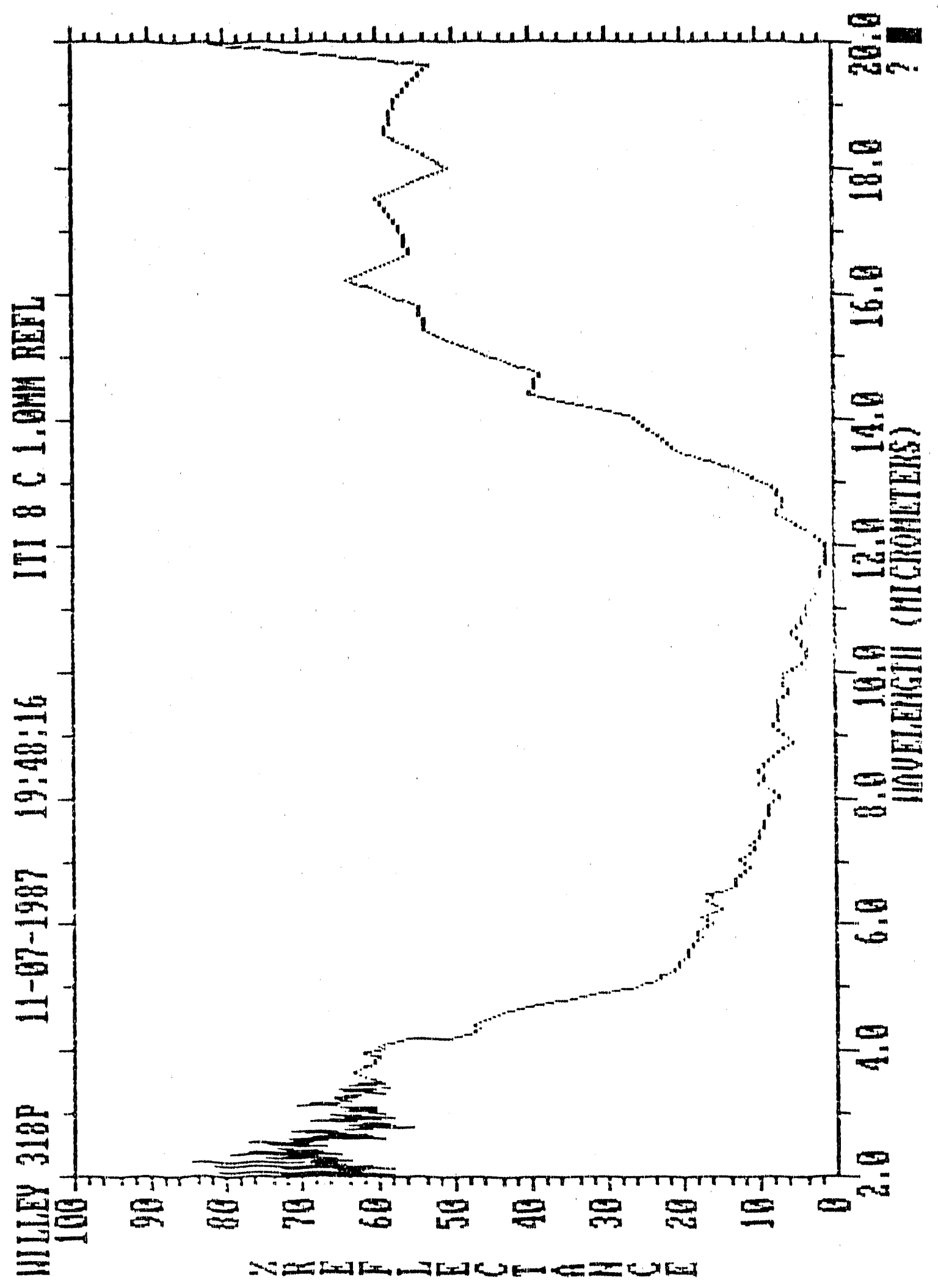

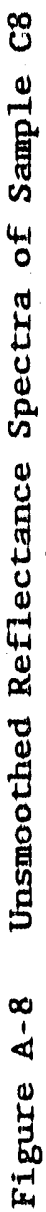




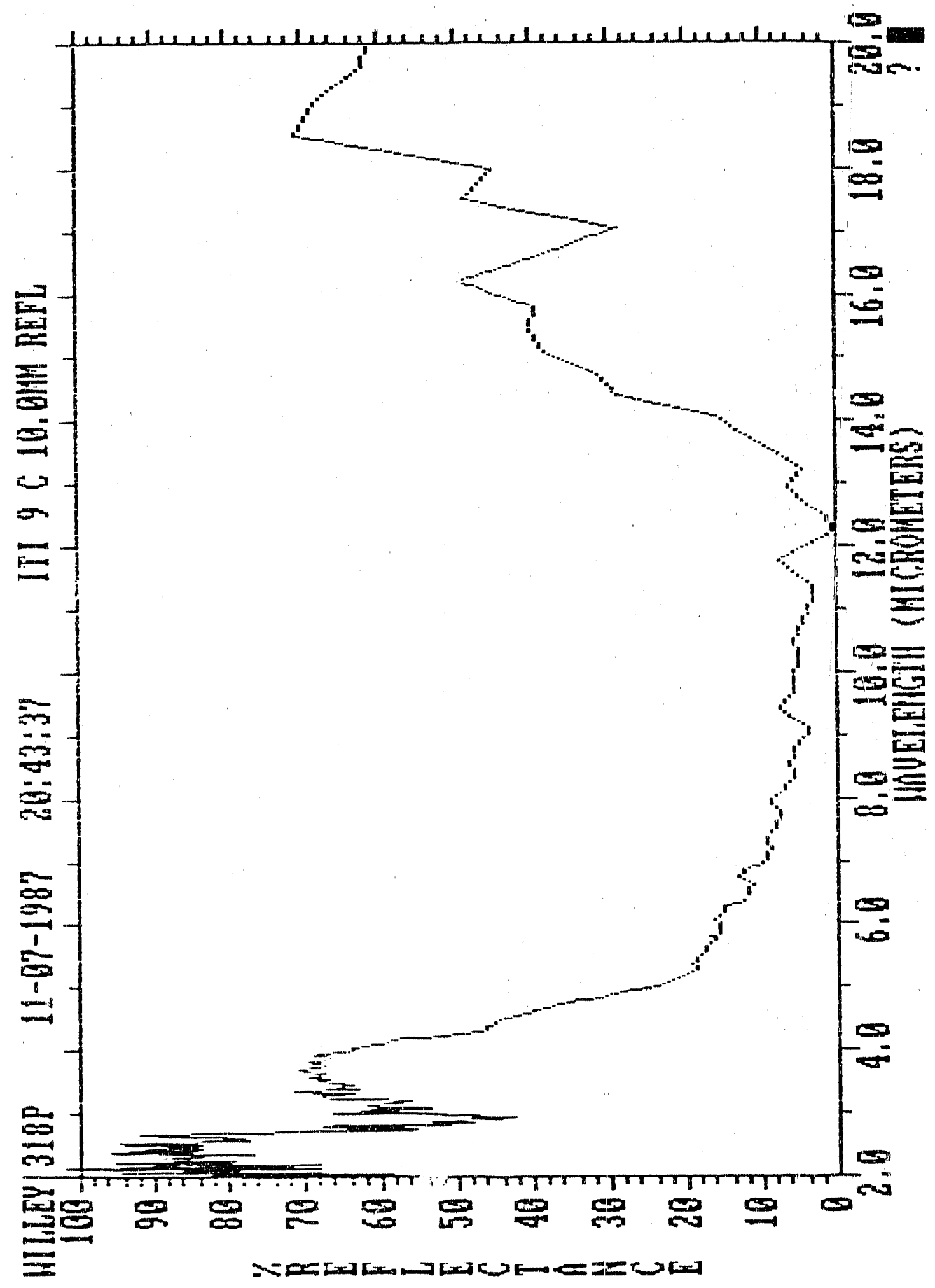

O 


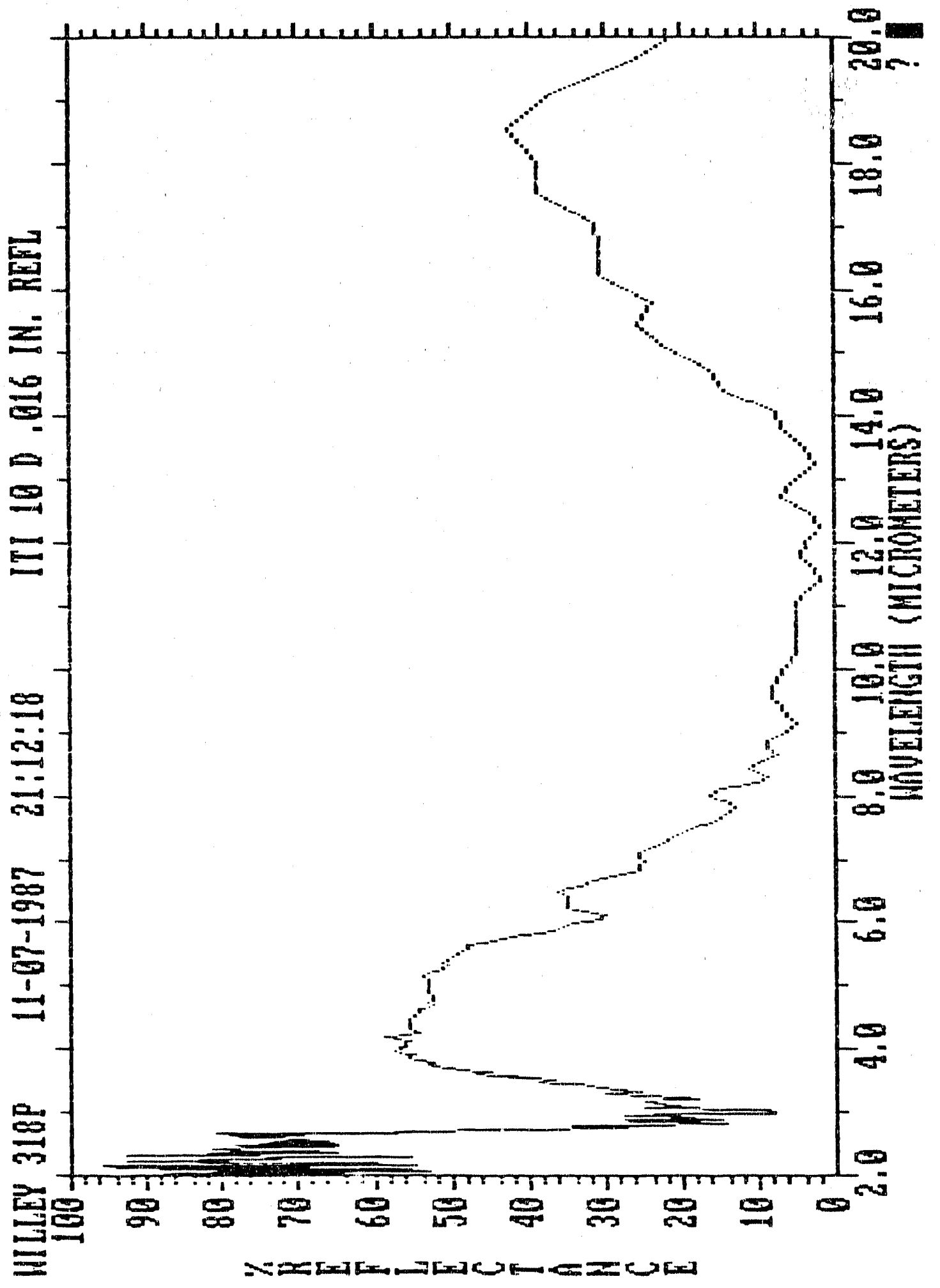

吕 


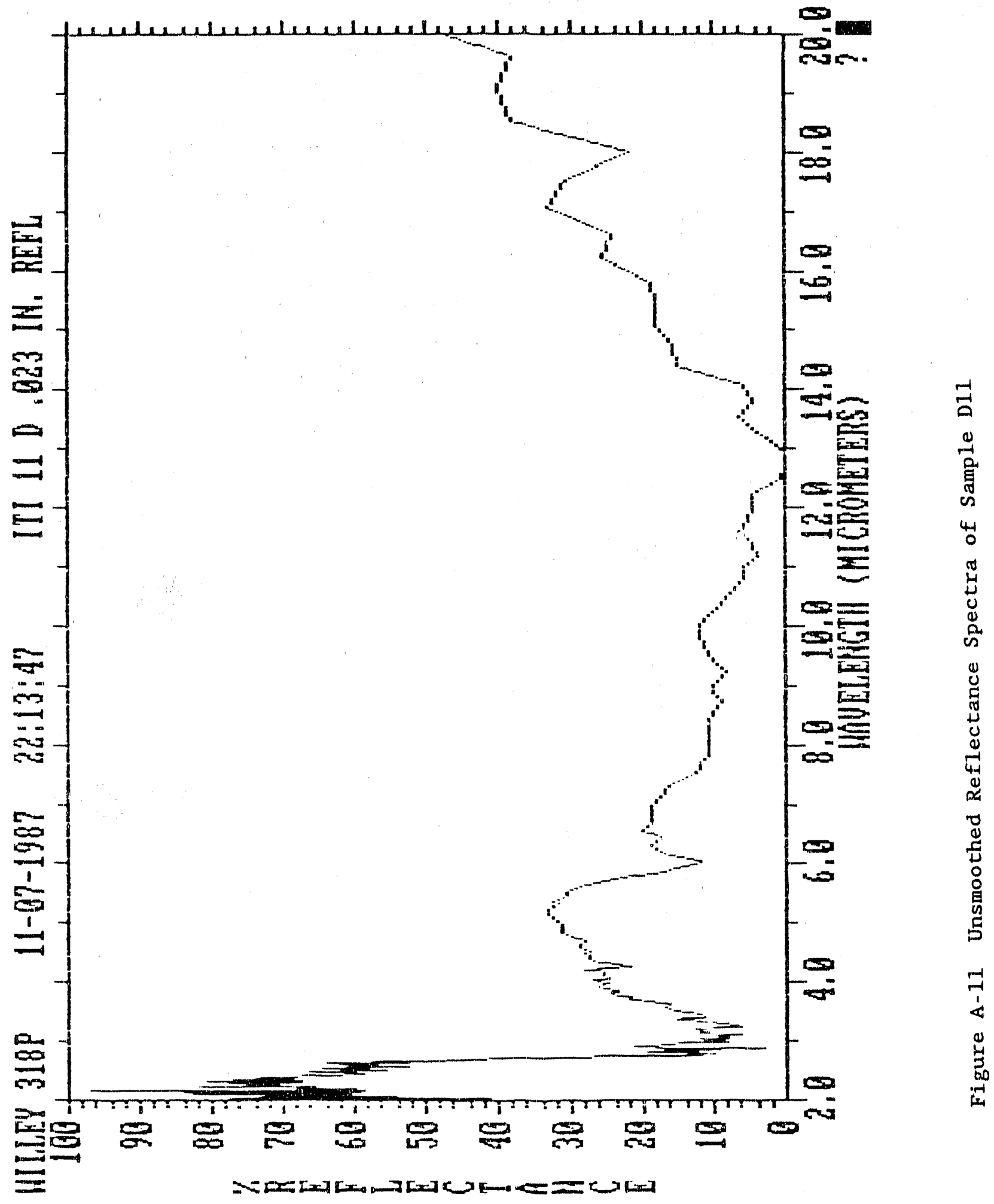




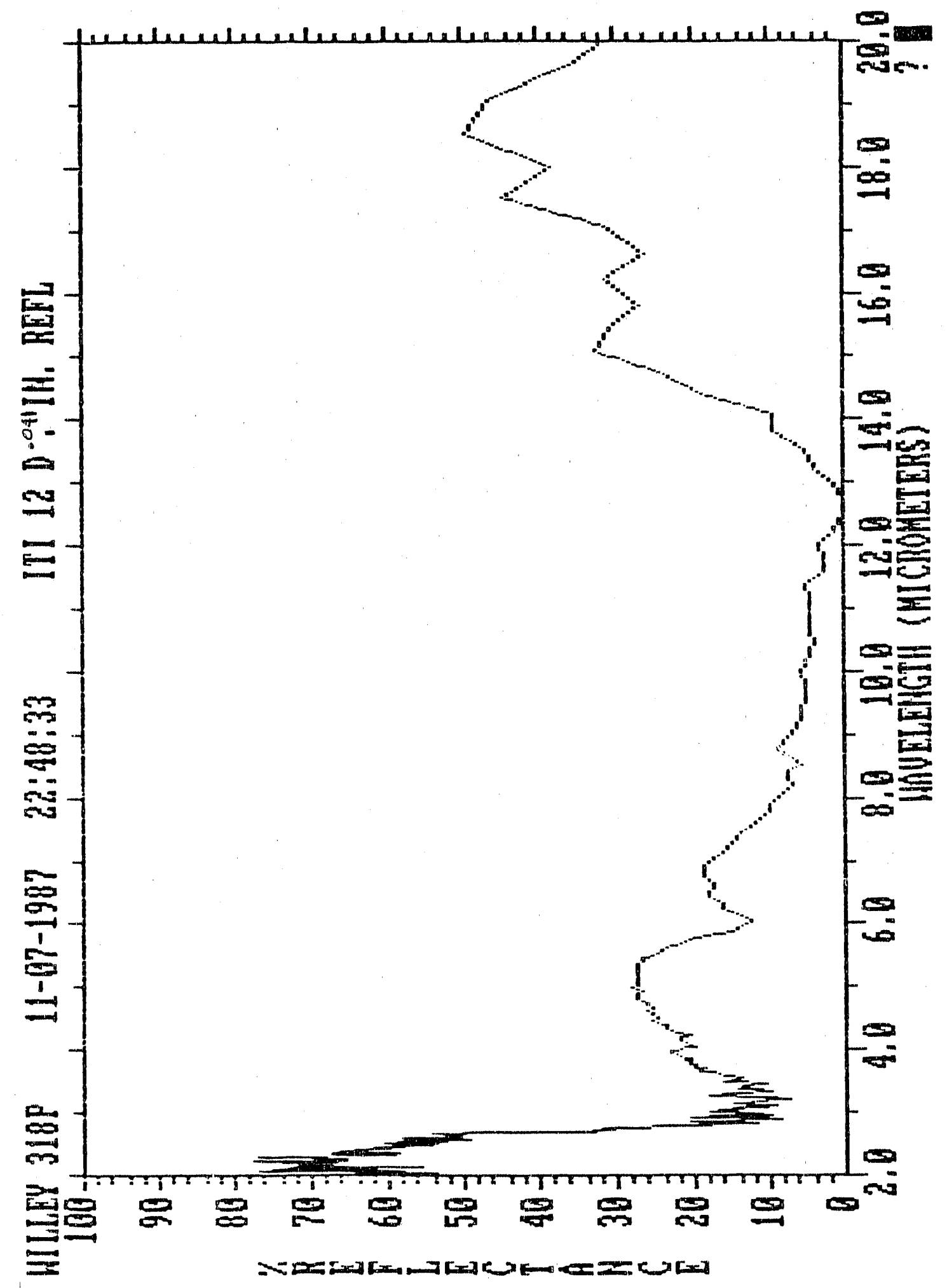

告 


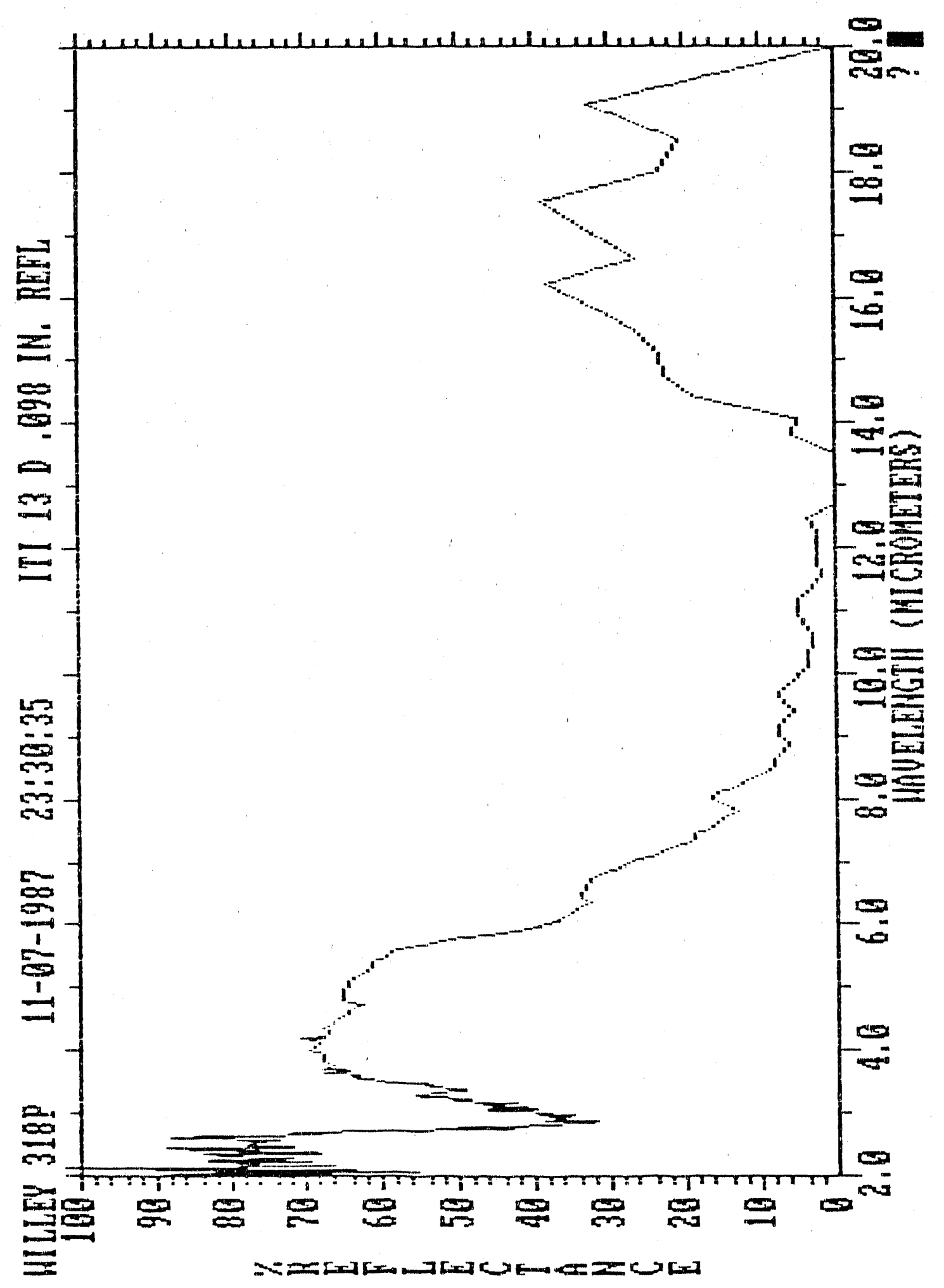

年是 


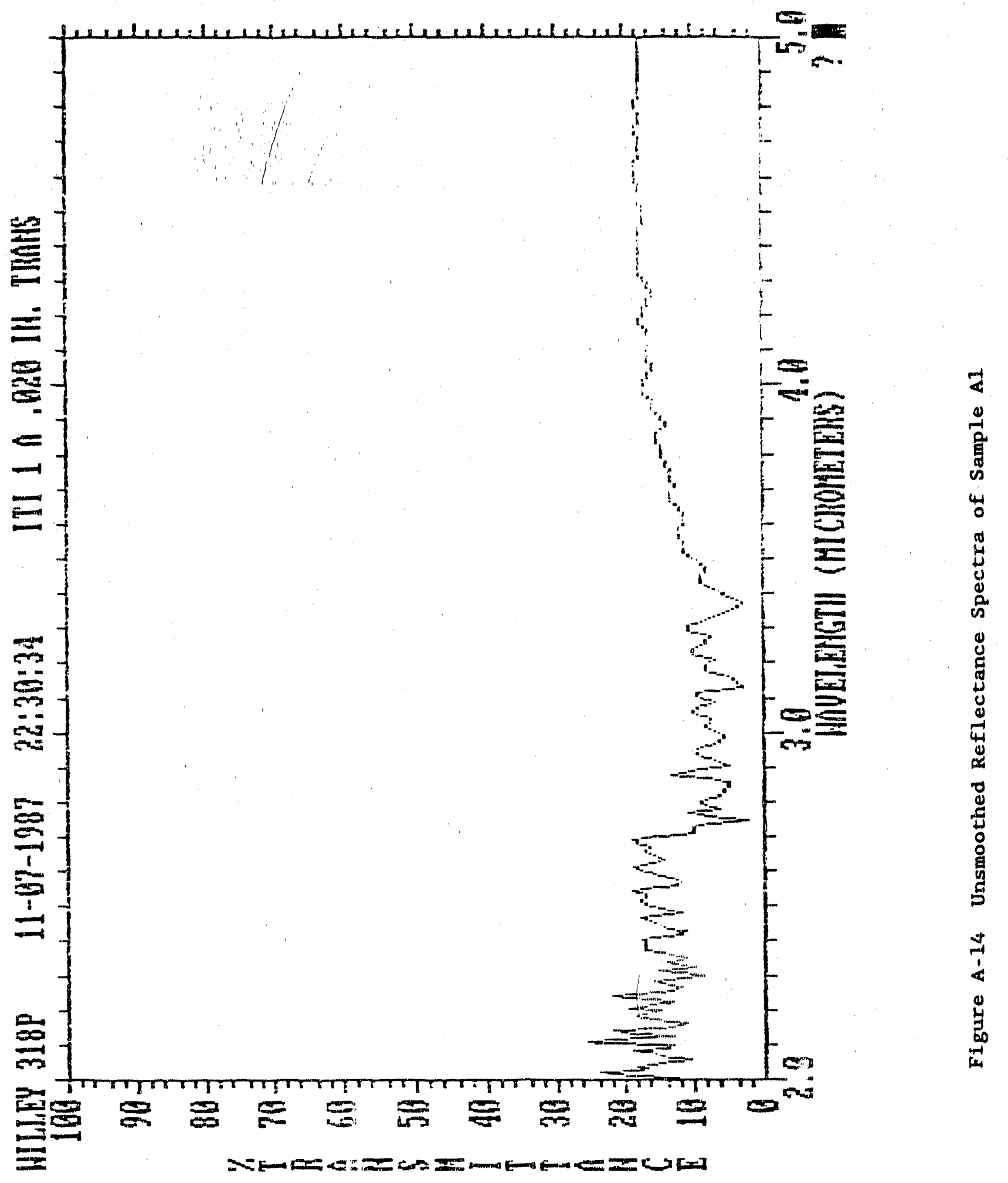




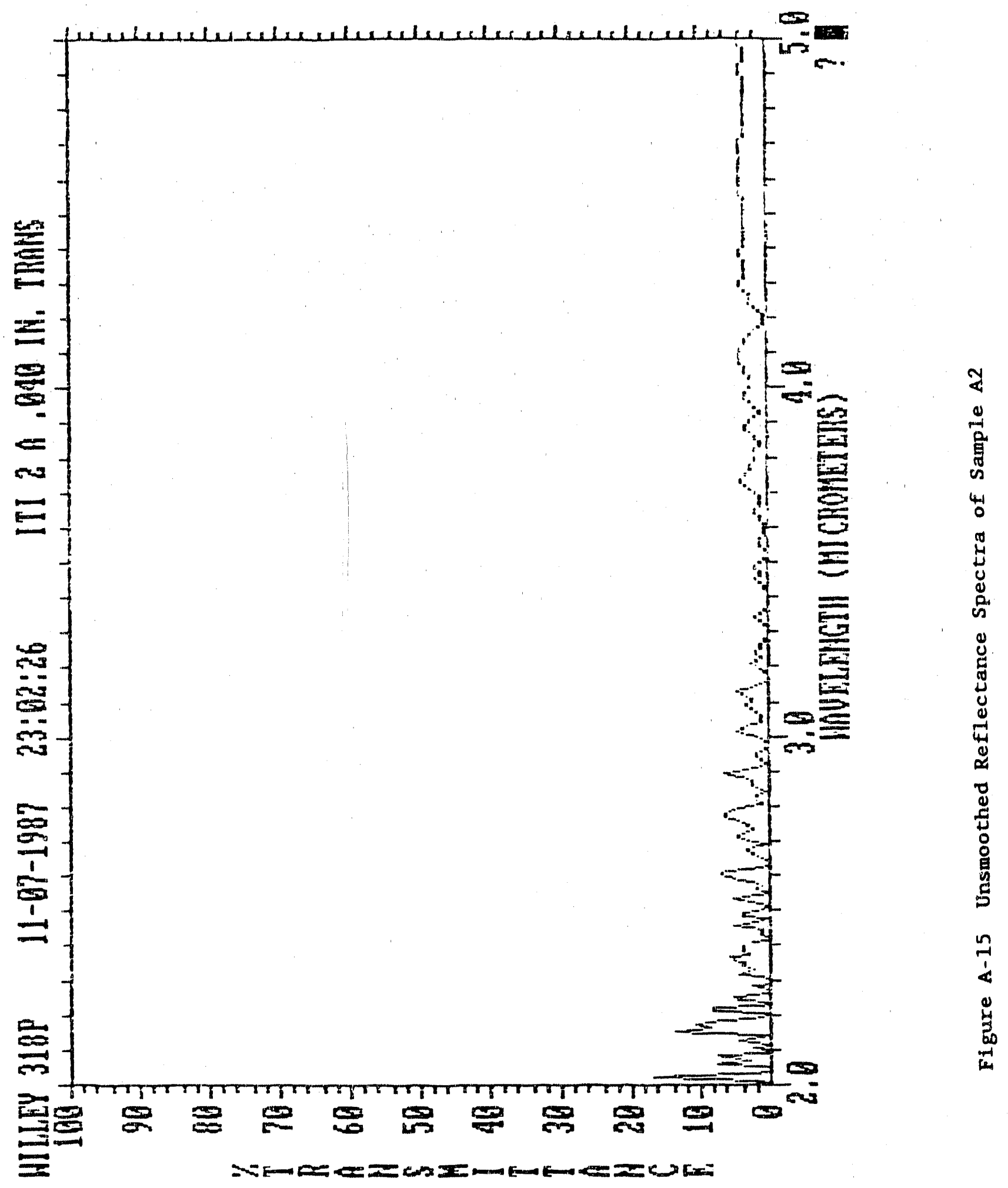




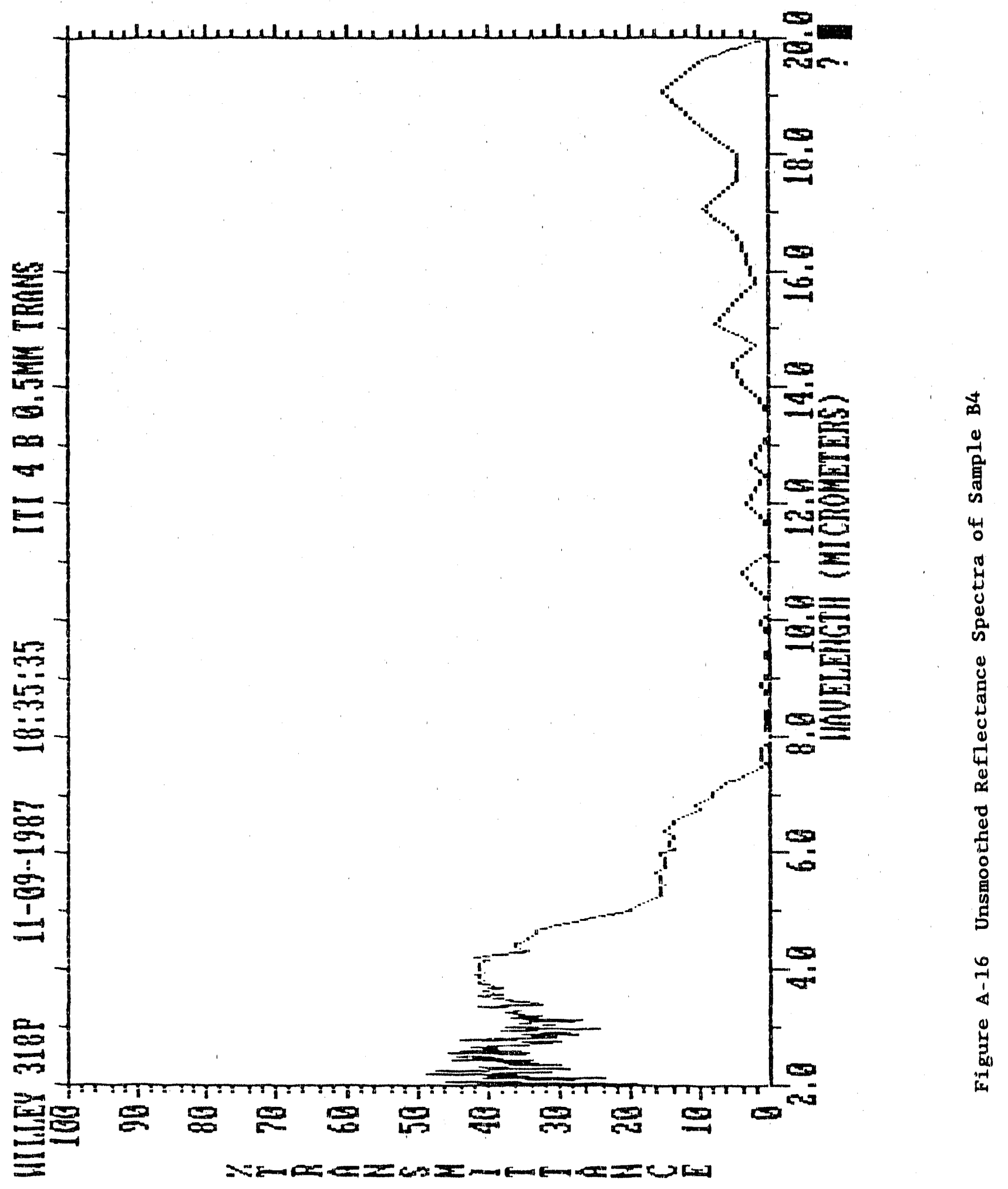




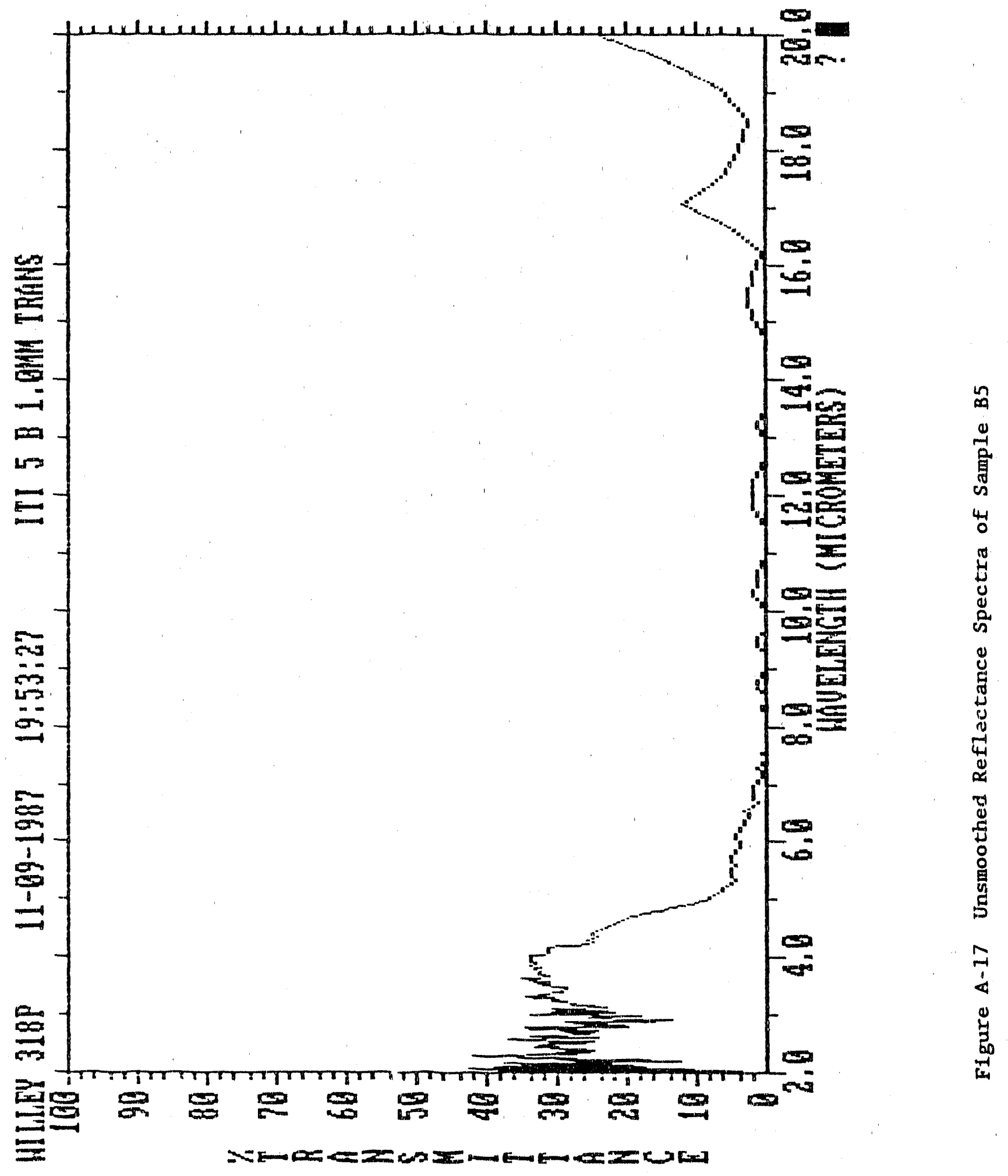




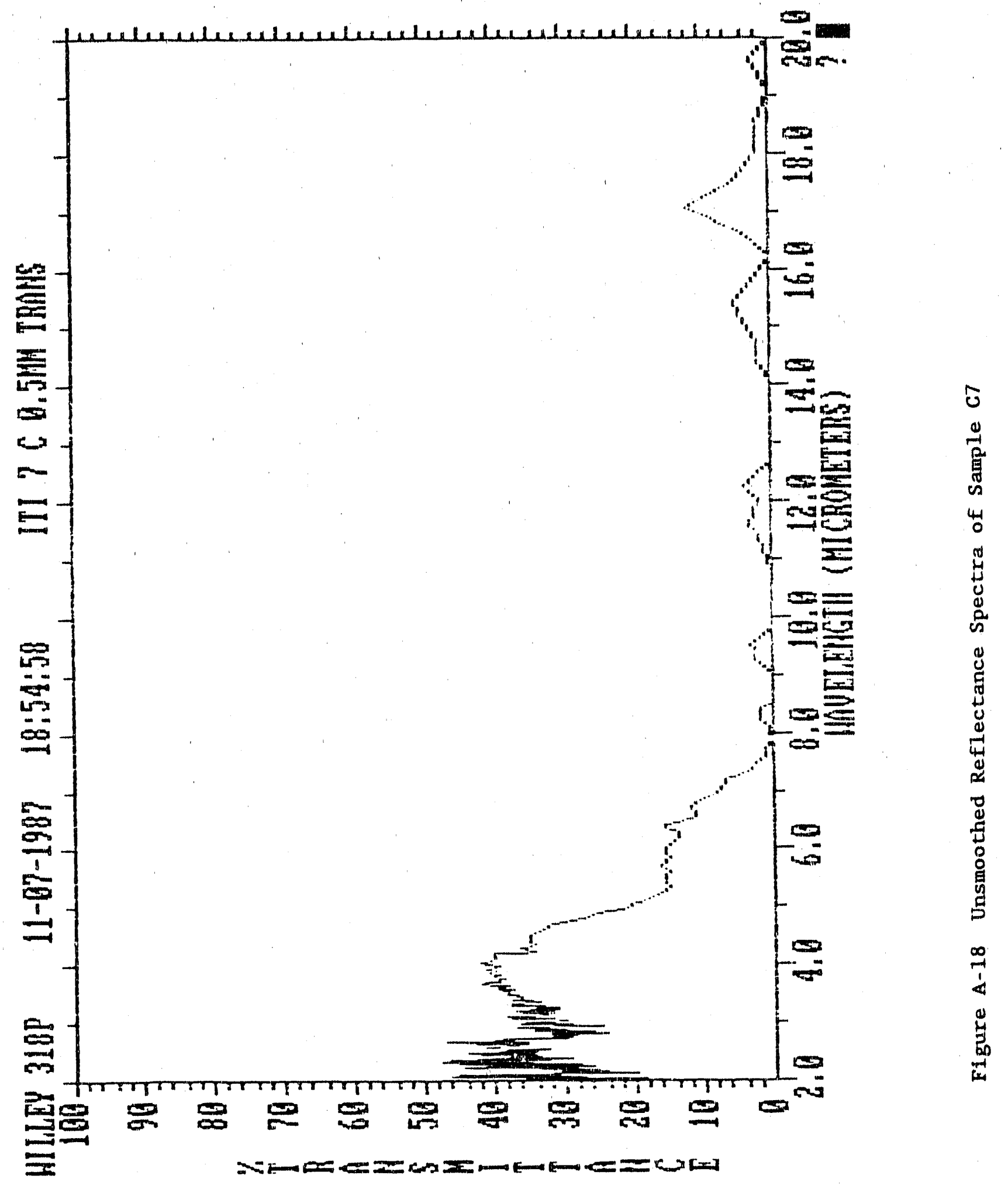




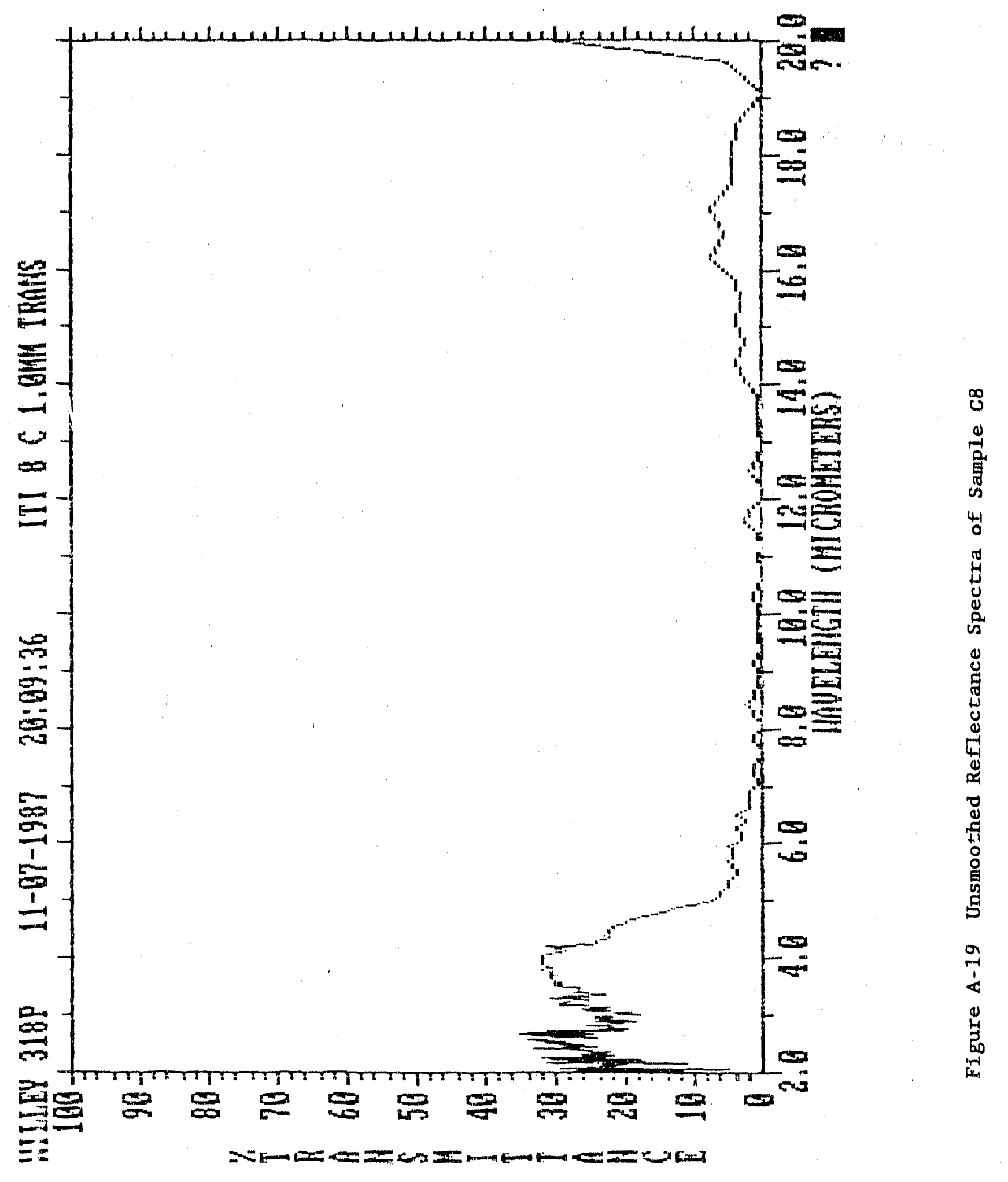




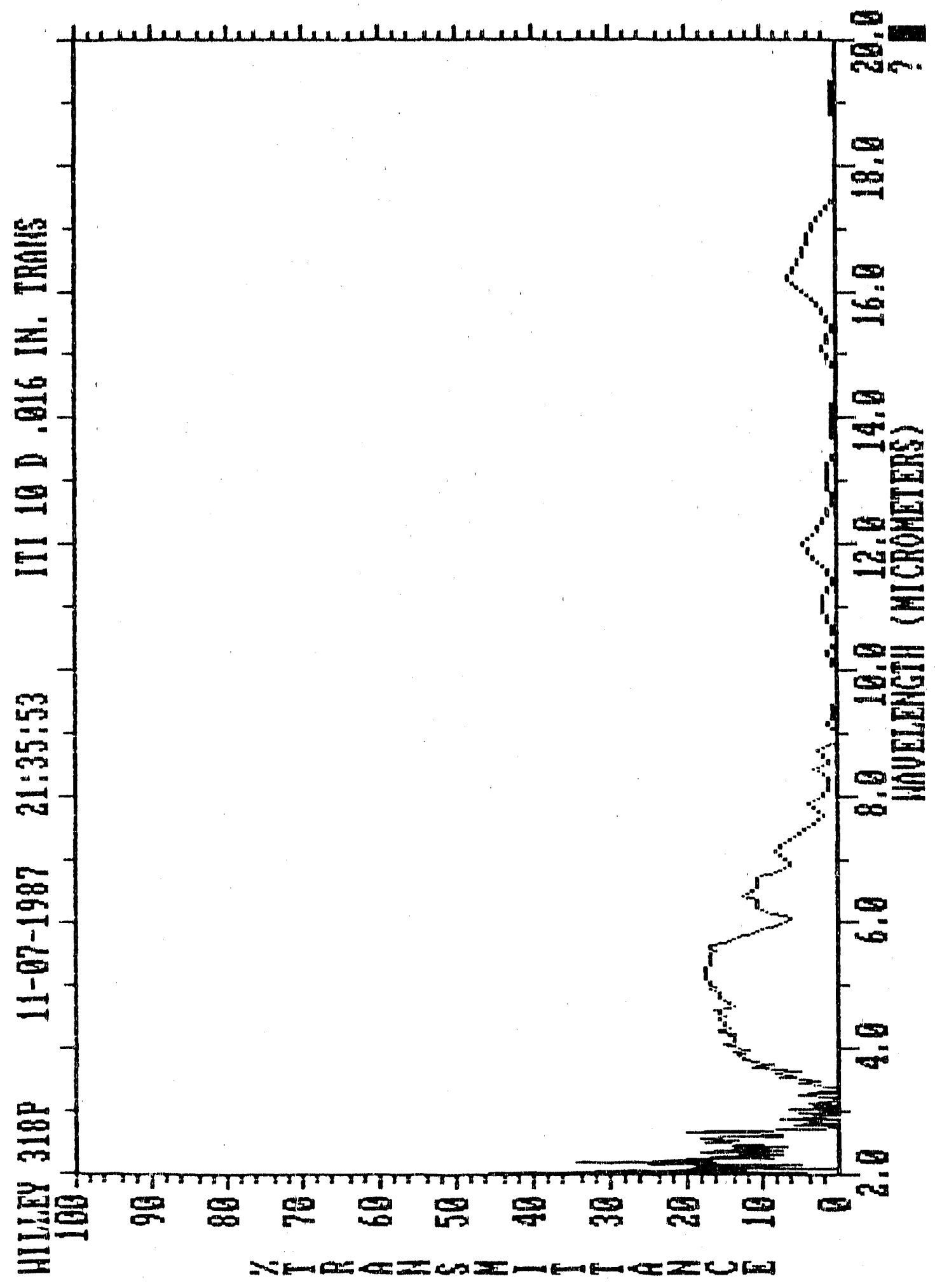

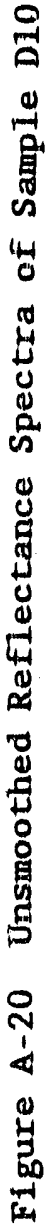




\section{INTERNAL DISTRIBUTION}

1-2. Central Research L Ibrary

3. Document Reference Section

4-5. Laboratory Records Department

6. Laboratory Records, ORNL RC

7. ORNL Patent Section

8-10. M\&C Records Office

11. L. F. Allard, Jr.

12. L. D. Armstrong

13. P. F. Becher

14. R. F. Bernal

15. T. M. Besmann

16. P. J. Biau

17. A. Bleter

18. E. E. Bloom

19. K. W. Boling

20. R. A. Bradley

21. C. R. Brinkman

22. V. R. Bullington

23. R. S. Carlsmith

24. P. T. Carlson

25. G. M. Caton

26. S. J. Chang

27. R. H. Cooper, Jr.

28. B. L. COX

29. D. F. Craig

30. S. A. David

31. J. H. DeVan

32. J. L. Ding

33. M. K. Ferber

34. F. M. Foust

35. W. Fulkerson

36. R. L. Graves

37. D. L. Greene

38. M. H. Harris

39. E. E. Hoffman

40. C. R. Hubbard

41. M. A. Janney
42. M. G. Jenkins

43. D. R. Johnson

44. W. F. Jones

45. D. Jositin

46. R. R. Judkins

47. M. A. Karnitz

48. M. R. Kass

49-53. B. L. P. Keyes

54. H. D. Kimrey, Jr.

55. T. G. Kollte

56. K. C. Liu

57. E. L. Long, Jr.

58. W. D. Manily

59. R. W. McClung

60. D. J. McGutre

61. J. R. Merriman

62. D. L. Moses

63. T. A. Nolan

64. A. E. Pasto

65. J. L. Rich

66. C. R. Richmond

67. J $M$ Robbins

68. M. L. Santella

69. A. C. Schaffhauser

70. S. Scott

71. G. M. Slaughter

72. E. J. Soderstrom

73. D. P. Stinton

74. R. W. Swindeman

75. V. J. Tennery

76. T. N. Tiegs

77. J. R. Weir, Jr.

78. B. H. West

79. F. W. Wiffen

90. S. G. Winslow

81. J. M. Wyrick

82. 


\section{EXTERNAL DISTRIBUTION}

83. James H. Adair

University of Florida

Materials Science and

Engineering

317 MAE Bidg.

Gainesville, FL 32611-2066

84. Donald F. Adams

University of Wyoming

Mechanical Engineering Department

P. 0. Box 3295

Laramie, WY 82071

85. Jalees Ahmad

AdTech Systems Research, Inc.

1342 North Fairfield Road

Dayton, $\mathrm{OH}$ 45432-2698

86. Yoshio Akimune

NISSAN Motor Co., Ltd.

Materials Research Laboratory

1 Natsushima-Cho

Yokosuka 237

JAPAN AIR MAIL

87. Mufit Akinc

Iowa State University

322 Spedding Hall

Ames, IA 50011

88. IThan A. Aksay

University of Washington

Materials Science and Engineering Department, FB-10

Seattle, WA 98195

89. R. G. Alexander

BASE

26 Malvern Close

Kettering Northants NN16 AJP

UNITED KINGDOM AIR MAIL

90. Richard L. Allor

Ford Motor Company

Material Systems

Reliability Department

20000 Rotunda Drive

P.0. Box 2053, Room S-2031

Dearborn, MI 48121-2053
91. Richard T. Alpaugh

U.S. Department of Energy

Advanced Propulsion Division

CE-322, Forrestal Building

Washington, DC 20585

92. Joseph E. Amaral

Instron Corporation

Corporate Engineering office

100 Royale Street

Canton, MA 02021

93. Edward M. Anderson

Aluminum Company of America

North American Industrial

Chemicals Division

P.0. Box 300

Bauxite, AR 72011

94. Norman C. Anderson

Ceradyne, Inc.

Ceramic-to-Metal Division

3169 Redhill Avenue

Costa Mesa, CA 92626

95. Don Anson

Battelle Columbus Laboratories

Thermal Power Systems

505 King Avenue

Columbus, $\mathrm{OH}$ 43201-2693

96. Thomas Arbanas

G.B.C. Materials Corporation

580 Monastery Drive

Latrobe, PA 15650-2698

97. Frank Armatis

3M Company

3M Center

Building 60-1N-01

St. Paut, MN 55144-1000

98. Everett B. Arnold

Detroit Diesel Corporation

Mechanical Systems Technology

13400 Outer Drive, West

Detroit, MI 48239-4001

99. Richard M. Arons

PA Consulting Group

279 Princeton Road

High stown, NJ 08550 
100. Bertil Aronsson

Sandvik $A B$

S- 12680

Stockholm Lerkrogsvagen 19

SWEDEN AIR MAIL

101. Dennis Assanis

University of Illinois

Department of Mechanical

Engineering

$1206 \mathrm{~W}$. Green Street

Urbana, IL 61801

102. William H. Atwell

Dow Corning Corporation

3901 South Saginaw Road

MS: 540

Midland, MI 48686-0995

103. V. S. Avva

North Carolina A\&T State University

Department of Mechanical

Engineering

Greensboro, NC 27411

104. Patrick Badgley

Adiabatics, Inc.

3385 Commerce Drive

Columbus, IN 47:201

105. Sunggi Baik

Pohang Institute of Science \& Technology

Department of Materials Science and Engineering

P.0. Box 125

Pohang 790-600

KOREA AIR MAIL

106. John M. Bailey

Caterpillar, Inc.

Technical Center

fuilding $L$

P.0. Box 1875

Peoria, IL 61656-1875

107. Bob Baker

Ceradyne, Inc.

3169 Redhill Avenue

Costa Mesa, CA 92626
108. Frank Baker

Aluminum Company of America

Alcoa Technical Center

Alcoa Center, PA 15069

109. J. G. Baldoni

GTE Laboratories Inc.

40 Sylvan Road

Waltham, MA 02254

110. Clifford P. Ballard

Allied-Signal, Inc.

Ceramics Program

P.0. Box 1021

Morristown, NJ 07962-1021

111. M. Balu

Amoco Performance Products Inc.

4500 McGinnis Ferry Road

Alpharetta, GA 30202

112. B. P. Bandyopadhyay

Toyohashi University of Technology

School of Productiun Systems Engineering

Tempaku-Cho Toyohashi 440

JAPAN AIR MAIL

113. P. M. Barnard

Ruston Gas Turbines Limited

Metallurgical Laboratory

P. 0. Box 1

Lincoln LN2 5DJ

ENGLAND AIR MAIL

114. Harold N. Barr

Hittman Corporation

9190 Red Branch Road

Columbia, MD 21045

115. Renald D. Bartoe

Vesuvius McDanel

510 Ninth Avenue

Box 560

Beaver Falls, PA 15010-0560

116. Donald M. Bartos

Dow Corning Corporation

Advanced Ceramics Program

Midl and, MI 48686-0995 
117. David L. Baty

Babcock \& Wilcox-LRC

P.0. Box 11165

Lynchburg, VA 24506-1165

118. Donald F. Baxter, Jr.

ASM International

Advanced Materials and

Processes

Materials Park, OH 44073-0002

119. M. Brad Beardsley

Caterpillar, Inc.

Advanced Materials Technology

Technical Center Bldg. E

P.O. Box 1875

Peoria, IL 61656-1875

120. Robert Beck

Teledyne CAE

Materials Engineering/Programs

1330 Laskey Road

P.0. Box 6971

Toledo, $\mathrm{OH} 43612$

121. John C. Bell

Shel1 Research Limited

Thornton Research Centre

P.0. Box 1

Chester, Chl 3SH

ENGLAND AIR MAIL

122. Albert H. Bel1, III

General Motors Technical Center 30200 Mound Road

Engineering Building/W3 Turbine

Warren, MI 48090-9010

123. M. Bente?e

Xamag, Inc.

259 Melville Avenue

Fairfield, CT 06430

124. Larry D. Bentsen

BF Goodrich Company

R\&D Center

9921 Brecksville Road

Brecksville, $\mathrm{OH} 44141$

125. Joseph C. Bentz

ENCERATEC

2525 Sandcrest Drive

Columbus, IN 47203
126. Louis Beregszazi

Defiance Precision Products

P.0. Drawer 428

Defiance, $\mathrm{OH} 43512$

127. Tom Bernecki

Northwestern University

BIRL

1801 Maple Avenue

Evanston, It 60201-3135

128. Charles F. Bersch

Institute for Defense Analyses

1801 North Beauregard Street

Alexandria, VA 22311

129. Ram Bhatt

NASA Lewis Research Center

21000 Brookpark Road

Cleveland, $\mathrm{OH} 44135$

130. Deane I. Biehler

Caterpillar, Inc.

Engineering and Research Materials

Technical Center, Building E

P.0. Box 1875

Peoria, IL 61656-1875

131. John. W. Bjerklie

Consolidated Natural Gas Service Co., Inc.

Research Department

CNG Tower

Pittsburgh, PA 15222-3199

132. Will iam D. Bjorndahl

TRW, Inc.

One Space Park

Building 01, Room 2040

Redondo Beach, CA 90278

133. Keith A. Blakely

Advanced Refractory

Technologies, Inc.

699 Hertel Avenue

Buffalo, NY 142.07

134. Edward G. B1 anchard

Netzsch Inc.

119 Pickering Way

Exton, PA 19341 
135. Keith $B 1$ andford

Boride Products, Inc.

2879 Aero Park Drive

Traverse City, MI 49684

136. Bruce Boardman

Deere and Company Technical

Center

3300 River Drive

Moline, IL 61265

137. Russe11 Bockstedt

Hoechst Celanese Corporation

150 JFK Parkway

Short Hills, NJ 07078

138. M. Boehmer

DLR German Aerospace Research Establi ishment

Postfach 906058

D-5000 Koln 90

GERMANY AIR MAIL

139. Lawrence P. Boesch

EER Systems Corp.

1593 Spring Hill Road

Vienna, $V A$ 22182-2239

140. Donald H. Boone

Boone \& Associates

2412 Cascade Drive

Wainut Creek, CA 94598-4313

141. Tom Booth

Allied-Signal Aerospace Company

AiResearch Los Angeles

Division

2525 West 190th Street

Torrance, CA 90509-2960

142. Tibor Bornemisza

Sundstrand Power Systems

4400 Ruffin Road

San Diego, CA 92186-5757

143. J.A.M. Boulet

University of Tennessee

Department of Engineering

Science and Mechanics

310 Perkins Hall

Knoxville, TN 37996-2030
144. H. Kent Bowen

Massachusetts Institute of Technology

77 Massachusetts Avenue

Room E40-434

Cambridge, MA 02139

145. Leslie J. Bowen

Materials Systems

53 Hillorest-Road

Concord, MA 01742

146. Steven C. Boyce

Air Furce Office of

Scientific Research

AFOSR/NA B1dg. 410

Bolling AFB DC 20332-6448

147. Gary L. Boyd

CEC

400 Howell Avenue, No. 4

Warland, WY 82401

148. Steve Bradley

UOP Research Center

50 East Algonquin Road

Des Plaines, IL 60017-6187

149. Michael C. Brands

Cummins Engine Company, Inc.

P.0. Box 3005

Mail Code 50179

Columbus, IN 47201

150. Raymond J. Bratton

Westinghouse Science and Technology Center

1310 Beulah Road

Pittsburgh, PA 15235

151. John J. Brennan

United Technologies Corporation

Research Center

Silver Lane, MS: 24

East Hartford, CT 06108

152. Jeff D. Bright

Ceramatec, Inc.

2425 South 900 West

Salt Lake City, UT 84108 
153. Terrence K. Brog

Coors Ceramics Company

Corporate Development and Technology

4545 McIntyre Street

Golden, CO 80403

154. Gunnar Broman

317 Fairlane Drive

Spartanburg, SC 29302

155. Al Brown

High-Tech Materials Alert

P.0. Box 882

Dayton, NJ 08810

156. Jesse Brown

Virginia Polytechnic Institute and State University

Center for Advanced Ceramic Materials

B1 acksburg, VA 24061-0256

157. Sherman D. Brown University of 117 inois

Materials Science and Engineering Department

105 South Goodwin Avenue

204 Ceramics Building

Urbana, IL 61801

158. S. L. Bruner

Ceramatec, Inc.

2425 South 900 West

Salt Lake City, UT 84119

159. Adolfo Brusaferro

Keramont Corporation

4231 South Fremont Avenue

Tucson, AZ 85714

160. W. Bryzik

U.S. Army Tank Automotive Command

R\&D Center

Propulsion Systems Division

Warren, MI 48397-5000

161. S. T. Buljan

GTE Laboratories, Inc.

40 Sylvan Road

Waltham, MA 02254
162. S. J. Burden

GTE Valenite

1711 Thunderbird

Troy, MI 48084

163. Curt V. Burkland

AMERCOM, Inc.

8928 Fullbright Avenue

Chatsworth, CA 91311

164. Bill Bustamante

AMERCOM, Inc.

8928 Fulloright Street

Chatsworth, CA 91311

165. Oral Buyukozturk

Massachusetts Institute of Technology

77 Massachusetts Avenue

Room 1-280

Cambridge, MA 02139

166. David A. Caillet

Ethyl Corporation

451 Florida Street

Baton Rouge, LA 70801

167. Frederick J. Calnan

Heany Industries, Inc.

249 Briarwood Lane

P.0. Box 38

Scottsville, NY 14546

168. Roger Cannon

Rutgers University

Ceramics Department

P.0. Box 909

Piscataway, NJ 08855-0909

169. Scott Cannon

P.0. Box 567254

Atlanta, GA 30356

170. Harry W. Carpenter

19945 Acre Street

Northridge, CA 91324

171. David Carruthers

Kyocera Industrial Ceramics Company

P.0. Box 2279

Vancouver, WA 98668-2279 
172. Calvin H. Carter, Jr. Cree Research, Inc. 2810 Meridian Parkway Durham, NC 27713

173. J. David Casey 35 Atlant is Street West Roxbury, MA 02132

174. Jere G. Castor J. C. Enterprise 5078 North 83rd Street Scottsdale, AZ 85250

175. James D. Cawley Case Western Reserve University Materials Science and Engineering Department Cleveland, $\mathrm{OH} 44106$

176. Thomas C. Chadwick Den-Mat Corporation P.0. Box 1729

Santa Maria, CA 93456

177. Roriald H. Chand Chand Kare Technical Ceramics 2 Coppage Drive Horcester, MA 01603

178. Robert E. Chaney EG\&G Idaho, Inc. Idaho National Engineering Laboratory

P.0. Box 1625

Idaho Falls, ID 83415-3525

179. Frank C. Chang

U.S. Army Materials Technology Laboratory. AMTL-EMM

405 Arsenal Street Watertown, MA 02172

180. Robert M. Chapman

Allied-Signal Aerospace Company

1530 Wilson Boulevard, 10th Floor

Arlington, VA 22209
181. Wil1iam Chapman

Williams International

Corporation

2280 West Maple Road

Walled Lake, MI 48390-0200

182. Charlie Chen

LECO Corporation

P.0. Box 211688

Augusta, GA 30917

183. Albert A. Chesnes

U.S. Department of Energy

Transportation Technologies

CE-30, Forrestal Building, 6B-094

Washington, DC 20585

184. Kaiyin Chia

Carborundum Company

P.0. Box 832

Niagara Falls, NY 14302

185. Frank Childs

EG\&G Idaho, Inc.

Idaho National Engineering Laboratory

P.0. Box 1625

Idaho Falls, ID 83415-3527

186. William J. Chmura

Torrington Company

59 Field Street

Torrington, CT 06790-4942

187. Tsu-Wei Chou

University of Delaware

Center for Composite Materials

201 Spencer Laboratory

Newark, DE 19716

188. R. J. Christopher

Ricardo Consulting Engineers Bridge Works

Shoreham-By-Sea West Sussex BN43 5FG

ENGLAND

AIR MAIL

189. Joel P. Clark

Massachusetts Institute of Technology

Room 8-409

Cambridge, MA 02139 
190. Giorgio Clarotti

Comnission of the European Communities

DGXII-C3, M075, 1-53; 200 Rue de la Lot

B.-1049 Brussels BELGIUM AIR MAIL

191. W. J. Clegg

ICI Advanced Materials

P.0. Box 11

The Heath, Runcorn Cheshire

WA7 4QE

ENGLAND AIR MAIL

192. Joseph Cleveland

GTE Products Corporation

Hawes Street

Towanda, PA 18848-0504

193. Gloria M. Collins

ASTM

1916 Race Street

Philadelphia, PA 19103

194. William C. Connors

Sundstrand Aviation Operations

Materials Science and

Engineering Department

4747 Harrison Avenue

P.0. Box 7002

Rockford, IL 61125-7002

195. John A. Coppola

Carborundum Company

P.0. Box 156

Niagara Falls, NY 14302

196. Normand D. Corbin

Norton Company

Advanced Ceramics

Goddard Road

Northboro, MA 01532-1545

197. Douglas Corey

All ied-Signal Aerospace

Company

2525 West 190th Street

MS : T52

Torrance, CA 90504-6099
198. Keith P. Coste110

Chand/Kare Technical Ceramics

2 Coppage Drive

Worcester, MA 01603-1252

199. Ed L. Courtright

Pacific Northwest Laboratory

MS: K3-59

Richland, WA 99352

200. Anna Cox

Mitchell Market Reports

P.0. Box 23

Monmouth Gwent NP5 4YG

UNITED KINGDOM AIR MAIL

201. Thomas Coyle

Unocal Corporation

Unocal Science \& Technology

Division

376 South Valencia Avenue

Brea, CA 92621

202. Art Cozens

Instron Corporation

3414 Snowden Ayenue

Long Beach, CA 90808

203. Robert C. Craft

American Ceramic

Society, Inc.

757 Brooksedge Plaza Drive

Westerville, $\mathrm{OH} 43081$

204. Mark Crawford

New Technology Week

4604 Monterey Drive

Annandale, VA 22003

205. Richard A. Cree

Markets \& Products, Inc.

P.0. Box 14328

Columbus, $\mathrm{OH}$ 43214-0328

206. Les Crittenden

Vesuvius McDanel

Box 560

Beaver Falls, PA 15010 
207. William J. Croft

U.S. Army Materials

Technology Laboratory

405 Arsenal Street

Watertown, MA 02372

208. M. J. Cronin

Mechanical Technology, Inc.

968 Albany-Shaker Road

Latham, NY 12110

209. Gary M. Crosbie

Ford Motor Company

1430 Culver Avenue

S-2079, SRL Building

Dearborn, MI 48121-4036

210. Floyd W. Crouse, Jr.

U.S. Department of Energy

Morgantown Energy

Technology Center

Collins Ferry Road

P.O. Box 880

Morgantown, WV 26505

211. John Cuccio

Allied-Signal Aerospace Company

Garrett Auxiliary Power Division

P.0. BOX 5227, MS: 1302-2Q

Phoenix, AZ 85010

212. Raymond Cutler

Ceramatec, Inc.

2425 South 900 West

Salt Lake City, UT 84119

213. Charles D'Angelo

GTE Laboratories, Inc.

40 Sylvan Road

Waltham, MA 02154

214. Stephen C. Danforth

Rutgers University

Ceramic Engineering Department

P.0. Box 909

Piscataway, NJ 08855-0909
215. Sankar Das Gupta

Electrofuel Manufacturing Co., Ltd.

9 Hanna Avenue

Toronto Ontario MGK - 1 W8

CANADA AIR MAIL

216. Charles Davis

Sverdrup Technology, Inc., MSFC

620 Discovery Drive

Huntsville, AL 35806

217. Frank Davis

Allied Signal Aerospace Co. 7550 Lucerne Dr., \#203

Middleburg Heights, $\mathrm{OH} 44130$

218. Robert F. Davis

North Carolina State University

Materials Engineering Department

229 Riddick Laboratory

P.0. Box 7907

Raleigh, NC 27695

219. Thomas DeAngel is

Carborundum Company

Niagara Falls R\&D Center

P.0. Box 832

Niagara Falls, NY 14302

220. George DeBell

Ford Motor Company

Material Systems Reliability Department

20000 Rotunda Drive

P.0. Box 2053, Room S-2023

Dearborn, MI 48121-2053

221. Michael Deluca

AMP-AKZO

West. Lane

Aquebogue, NY 11931

222. Gerald L. DePoorter

Colorado School of Mines

Metallurgical and Materials

Engineering Department

Golden, CO 80401 
223. J. F. DeRidder Omni Electro Motive, Inc., 12 Seely Hill Road Newfield, NY 14867

224. Nick C. Dellow Materials Technology Publications 40 Sotheron Road Watford Herts WDI 2QA UNITED KINGDOM AIR MAIL

225. L. R. Dharani University of Missouri-Rolla 224 M.E.

Rolla, MO 65401

226. Douglas A. Dickerson Union Carbide Specialty Powders

1555 Main Street Indianapolis, IN 46224

227. John Dodsworth

Vesuvius Research \& Development

Technical Ceramics Group

Box 560

Beaver Falls, PA 15010

228. B. Dogan

Institut fur Werkstofforschung GKSS-Forschungszentrum Geesthacht GmbH Max-Planck-Strasse D-2054 Geesthacht GERMANY AIR MAIL

229. Jean-Marie Drapier FN Moteurs S.A. Material and Processing B-4041 Milmort (Hersta1) BELGIUM AIR MAIL

230. Kenneth C. Dreitlein United Technologies Research Center Silver Lane East Hartford, CT 06108
231. Robin A.L. Drew McGill University Department of Mining and Metallurgical Engineering 3450 University Street Montreal Quebec H3A 2A7 CANADA AIR MAIL

232. Winston H. Duckworth

$\mathrm{BCL}$

Columbus Division 505 King Avenue Columbus, OH 43201-2693

233. Edmund M. Dunn Texel Company 6 Third Street Lexington, MA 02173

234. Bill Durako Sundstrand Aviation Operations Department 789-6

4747 Harrison Avenue P.0. Box 7002 Rockford, IL 61125-7002

235. Ernest J. Duwe11 212 Elm Street Hudson, WI 54016

236. Chuck J. Dziedzic Coors Ceramics Company Structural Products Group 17750 West 32nd Avenue Golden, CO 80401

237. Robert J. Eagan Sandia National Laboratories Engineered Materials \& Processes Center

Org 1700

P.0. Box 5800

Aibuquerque, NM 87185-5800

238. Jeffrey Eagleson Lanxide Corporation 1001 Connecticut Avenue, N.W. Washington, DC 20036 
239. Harry E. Eaton

United Technologies Corporation

Research Center

Silver Lane

East Hartford, CT 06108

240. Harvill C. Eaton

Louisiana State

University

Office of Research

and Economic Development

240 Thomas Boyd Hall

Baton Rouge, LA 70803

241. Christopher A. Ebel

Carborundum Company

Technology Division

P.0. Box 337

Niagara Fails, NY 14302

242. J. J. Eberhardt

U.S. Department of Energy

Office of Transportation

Materials

CE-34, Forrestal Building

Washington, DC 20585

243. Jim Edler

Eaton Corporation

26201 Northwestern Highway

P.0. Box 766

Southfield, MI 48037

244. William A. Ellingson

Argonne National Laboratory

Materials Science \& Technology

Division

9700 South Cass Avenue

Argonne, IL 60439

245. William S. Ellis

Machined Ceramics

629 N. Graham St.

N. Industrial Park

Bowling Green, KY 42101

246. Glen B. Engle

Nuclear \& Aerospace Materials Corporation

16716 Martincoit Road

Poway, CA 92064
247. Jeff Epstein

Ceramic Technologies, Inc.

2107 Jamara Lane

Houston, TX 77077

248. Kenneth A. Epstein

Dow Chemical U.S.A.

Ceramics and Advanced

Materials

800 Building

Midl and, MI 48667

249. Art Erdemir

Argonne National Laboratory

Materials and Components

Technology Division

9700 South Cass Avenue

Argonne, IL 60439

250. E. M. Erwin

Lubrizol Corporation

1819 East 225th Street

Euclid, OH 44117

251. Kenji Esaki

Toyota Technical Center U.S.A., Inc.

2000 Town Center, Suite 500

Southfie7d, MI 48075

252. Jose L. Escalante

Anglo-Mex-Tech. Inc.

3923 N.W. 24th Street

Miami, FL 33142

253. John N. Eustis

U.S. Department of Energy

Industrial Energy Efficiency Division

CE-221, Forrestal Building

Washington, DC 20585

254. Robert C. Evans

NASA Lewis Research Center.

Terrestrial Propulsion Office

21000 Brookpark Road, MS:86-6

Cleveland, OH 44135

255. W. L. Everitt

Kyocera International, Inc.

8611 Balboa Avenue

San Diego, CA 92123 
256. Gordon Q. Evison

332 South Michigan Avenue

Suite 1730

Chicago, IL 60604

257. John W. Fairbanks

U.S. Department of Energy

Advanced Propulsion Division

CE-322, Forrestal Building

Washington, DC 20585

258. Tim Fawcett

Dow Chemical Company

Central Research, Advanced

Ceramics Laboratory

1776 Building

Midl and, MI 48674

259. Robert W. Fawley

Sundstrand Power Systems

Division of Sundstrand Corporation

4400 Ruffin Road

P.0. Box 85757

San Diego, CA 92186-5757

260. John J. Fedorchak

GTE Products Corporation

Hawes Street

Towanda, PA 18848-0504

261. Jeff T. Fenton

Vista Chemical Company

900 Threadneedle

Houston, TX 77079

262. Larry Ferrell

Babcock \& Wilcox

01d Forest Road

Lynchburg, VA 24505

263. Raymond R. Fessier

BIRL

Industriai Research Lab

1801 Maple Avenue

Evanston, IL 60201

264. Michelle Finch

E. I. DuPont de Nemours \& Company, Inc.

Experimental Station

Information Center E302/301

Wilmington, DE 19898
265. Arthur D. Fine

United Technologies Corporation

Pratt \& Whitney Aircraft

400 Main Street

MS : $163-10$

East Hartford, CT 06108

266. Ross F. Firestone

Ross Firestone Company

188 Mary Street

Winnetka, IL 60093-1520

267. Sharon L. Fletcher

Arthur D. Little, Inc.

15 Acorn Park

Cambridge, MA 02140-2390

268. Thomas F. Foltz

Textron Specialty Materials

2 Industrial Avenue

Lowe 11, MA 01851

269. Renee G. Ford

Materials and Processing Report

P.0. Box 72

Harrison, NY 10528

270. John Formica

Supermaterials

2020 Lakeside Avenue

Cleveland, $\mathrm{OH} 44114$

271. Jennifer M. Fox

Dyson Refractories Limited

R\&D Laboratory

Owler Bar

Sheffield S17 3BJ

UNITED KINGDOM AIR MAIL

272. Edwin Frame

Southwest Research Institute

nivision 2

P.0. Drawer 28510

San Antonio, TX 78284

273. Armanet Francois

French Sctentific Mission

4101 Reservoir Road, N.W.

Washington DC 20007-2176

274. R. G. Frank

Technology Assessment Group

10793 Bentley Pass Lane

Lovel and, $\mathrm{OH} 45140$ 
275. David J. Franus

Forecast International

22 Commerce Road

Newtown, CT 06470

276. Marc R. Freedman

NASA Lewis Research Center

21000 Brookpark Road

MS : 49-3

Clevel and, $\mathrm{OH} 44135$

277. Douglas Freitag

LTV Missiles Division

P.0. Box 650003

MS:WT-21

Dallas, TX 75265

278. Brian R.T. Frost

Argonne National Laboratory

9700 South Cass Avenue

Building 900

Argonne, IL 60439

279. Lawrence R. Frost

Instron Corporation

100 Royall Street

Canton, MA 02021

280. George A. Fryburg

Norton/TRW Ceramics

7A-4 Raymond Avenue

Sa? em, NH 03079

281. Xiren $\mathrm{Fu}$

Shanghai Institute of Ceramics

Chinese Academy of Sciences

1295 Ding-xi Road

Shanghai 200050

CHINA AIR MAIL

282. John Gahimer

P.0. Box 1302

Dublin, $\mathrm{OH} 43017$

283. J. P. Gallagher

University of Dayton Researci Institute

300 College Park, JPC-250

Dayton, OH 45469-0120
284. Tom Garritano

University of Tennessee

Science Alliance

101 South College

Knoxville, TN 37996-1328

285. Joy A. Garwood

Norton Company

Advanced Ceramics

Goddard Road

Northboro, MA 01532-1545

286. H. Maury Gatewood

Reynolds Metals Company Corporate R\&D

Fourth and Canal Streets

P.0. Box 27003

Richmond, VA 23261

287. L. J. Gauckler

ETH-Zurich

Sonneggstrasse 5

CH-8092 Zurich 8092

SWITZERLAND AIR MAIL

288. Peter A. Gaydos

Battelle columbus Laboratories

505 King Avenue

Columbus, $\mathrm{OH} 43201$

289. George E. Gazza

U.S. Army Materials

Technology Laboratory

Ceramics Research Division

405 Arsenal Street

Watertown, MA 02172-0001

290. D. Gerster

CEA-DCOM

33 Rue De La Federation

Paris 75015

FRANCE AIR MAIL

291. John Ghinazzi

Coors Technical Ceramics Company

1100 Commerce Park Drive

Oak Ridge, TN 37830 
292. Robert Giddings

General Electric Company

Research Laboratory

P.0. Box 8

Schenectady, NY 12301

293. A. M. Glaeser

University of California

Materials Science and Mineral Engineering

Lawrence Berkeley Laboratory

Hearst Mining Building

Berkeley, CA 94720

294. Paul Glance

Concept Analysis

R\&D

950 Stephenson Highway

Dupont Automotive Development Building

Troy, MI 48007-7013

295. Joseph W. Glatz

Naval Air Propulsion Center

Systems Engineering Division

P.0. Box 7176, PE24

Trenton, NJ 08628

296. W. M. Goldberger

Superior Graphite Company

R\&D

2175 East Broad Street

Columbus, OH 43209

297. Allan E. Goldman

U.S. Graphite, Inc.

907 West Outer Drive

Oak Ridge, TN 37830

298. Stephen T. Gonczy

Allied Signal Research

P.0. Box 5016

Des Plaines, IL 60017

299. Jeffrey M. Gonzales

GTE Products Corporation

Hawes Street

Towanda, PA 18848-0504

300. Robert J. Gottschall

U.S. Department of Energy

ER-131, MS:G-236

Washington, DC 20545
301. Earl Graham

Cleveland State University

Department of Chemical

Engineering

Euclid Avenue at

East 24th Street

Cleveland, $\mathrm{OH} 44115$

302. William A. Graham Lanxide Corporation P.0. Box 6077

Newark, DE 19714-6077

303. Robert E. Green, Jr.

Johns Hopkins University

Materials Science and

Engineering Department

Baltimore, MD 21218

304. Lance Groseclose

General Motors Corporation

Allison Gas Turbine Division

P.0. Box 420, MS:W-5

Indianapolis, IN 46206

305. Mark F. Gruninger

Union Carbide Corporation

Specialty Powder Business

1555 Main Street

Indianapol is, IN 46224

306. Ernst Gugel

Cremer Forschungsinstitut GmbH\&CO.KG

Oeslauer Strasse 35

D-8633 Roedental 8633

GERMANY AIR MAIL

307. Donald L. Guile

Corning Glass Works

SP-DV-1-9

Corning, NY 14831

308. Bimleshwar P. Gupta

Solar Energy Research Institute

Mechanical and Industrial

Technology Division

1617 Cole Boulevard

Golden, CO 80401 
309. John P. Gyekenyesi

NASA Lewis Research Center 21000 Brookpark Road, MS:6-1 Cleveland, $\mathrm{OH} 44135$

310. Nabil S. Hakim Detroit Diesel Corporation 13400 West Outer Drive Detroit, MI 48239

311. Philip J. Haley General Motors corporation Vehicular Engineering P.0. Box 420, MS:T12A Indianapolis, IN 46236

312. Judith Hall

Fiber Materials, Inc. Biddeford Industrial Park 5 Morin Street Biddeford, ME 04005

313. Y. Harada

IIT Research Institute Nometallic Materials and Composites

10 West 35th Street

Chicago, IL 60616

314. R. A. Harmon

25 Schalren Drive Latham, NY 12110

315. Amy Harmon-Barrett Martin Marietta Laboratories 1450 South Rolling Road Baltimore, MD 21227

316. Norman H. Harri: Hughes Aircraft Company P.0. Box 800520 Saugus, CA 91380-0520

317. Alan Hart Dow Chemical Company Advanced Ceramics Laboratory 1776 Building

Midland, MI 48674
318. Pat E. Hart

Battelle Pacific Northwest Laboratories

Ceramics and Polymers Development Jection

P.O. Box 999

Richland, WA 99352

319. Siephen D. Hart line

Norton Company

Advanced Ceramics

Goddard Road

Northboro, MA 01532-1545

320. Michael H. Haselkorn

Caterpillar, Inc.

Engineering Research Materials

Technical Center, Building E

P.0. Box 1875

Peoria, IL 61656-1875

321. N. B. Havewala

Corning, Inc.

SP-PR-11

Corning, NY 14831

322. John Haygarth

Teledyne WAA Chang Albany

P.0. Box 460

Albany, OR 97321

323. Norman L. Hecht

University of Dayton Research Institute

300 College Park

Dayton, OH 45469-017?

324. Peter W. Heitman

General Motors Corporation

Allison Gas Turbine Division

P.0. Box 420, MS:W-5

Indianapol is, IN 46206-0420

325. Robert W. Hendricks

Virginia Polytechnic Institute and State University

Materials Engineering Department

210 Holden Hall

B1acksburg, VA 24061-0237 
326. Wynne Henley

Hertel Cutting Technologies, Inc. 1000 Clearview Court

Oak Ridge, TN 37830

327. Thomas L. Henson

GTE Products Corporation

Chemical \& Metallurgical

Division

Hawes Street

Towanda, PA 18848

328. Thomas P. Herbel1

NASA Lewis Research Center

21000 Brookpark Road

MS: 49-3

Clevel and, $\mathrm{OH} 44135$

329. Marlene Heroux

Rolls-Royce, Inc.

2849 Paces Ferry Road

Suite 450

Atlania, GA 30339-3769

330. Robert L. Hershey

Science Management Corporation

1255 New Hampshire Ave., N.W.

Suite 1033

Washington, DC 20036

331. Hendrik Heystek

Bureau of Mines

Tuscaloosa Research Center

P.0. Box L

University, AL 35486

332. Wallace C. Higgins

Norwal Unt imited

P.0. Box 1258

Alfred, NY 14802

333. Robert V. Hillery

GE Aircraft Engines

One Neumann Way, M.D. H85

Cincinnati, OH 45215

334. Arthur Hindman

Instron Corporation

100 Royal1 Street

Canton, MA 02021
335. Jon Hines

American Ceramic Society, Inc.

757 Brooksedge Plaza Drive

Westerville, $\mathrm{OH}$ 43081-6136

336. Hans Erich Hintermann

CSEM

Materials and Micromechanics

Division

Rue Breguet- 2

Neuchatel 2000

SWITZERLAND AIR MAIL

337. Shinichi Hirano

Mazda R\&D of North America, Inc.

1203 Woodridge Avenue

Ann Arbor, MI 48105

338. Tommy Hiraoka

NGK Locke, Inc.

1000 Town Center

Southfield, MI 48075

339. John M. Hobday

U.S. Department of Energy

Morgantown Energy Te:hnology Center

Collins Ferry Road

P.0. Box 880

Morgantown, WV 26507

340. Greg Hoenes

Vista Chemical Company

900 Threadneedle

P.0. Box 19029

Houston, TX 77079-2990

341. Clarence Hoenig

Lawrence Livermore National Laboratory

P.0. Box 808, Mail Code L-369

Livermore, CA 94550

342. Thomas Hollstein

Fraunhofer-Institut fur Werkst of fmechanik IWM

Wohlerstrabe 11

D-7800 Freiburg

GERMANY AIR MAIL 
343. Richard Holt

National Research Council of Canada

Structures and Materials Laboratory

Ottawa Ontario K1A OR6

CANADA AIR MAIL

344. Joseph Homeny

University of Illinois

Department of Materials Science and Engineering

105 South Goodwin Avenue

Ceramics Building

Urbana, IL. 616.

345. A. T. Hopper

Battelle Columbus

Laboratories

Metals and Ceramics Department

505 King Avenue

Columbus, $\mathrm{OH} 43201-2693$

346. Michael Horgan

Materials Engineering Magazine

1100 Superior Avenue

Cleveland, $\mathrm{OH} 44114$

347. Woodie Howe

Coors Technical Ceramics

Company

1100 Commerce Park Drive

Oak Ridge, TN 37830

348. Stephen M. Hsu

National Institute of

Standards and Technology

Gaithersburg, MD 20899

349. Hann S. Huang

Argonne National Laboratory

9700 South Cass Avenue

Argonne, $\because L 60439-4815$

350. Gene Huber

Precision Ferrites \& Ceramics

5576 Corpisrate Drive

Cypress, CA 90630

351. M. L. Hucliabee

GTE Laboratories, Inc.

40 Sylvan Road

Waltham, MA 02254
352. Harold A. Huckins

Princeton Advanced

Technology, Inc.

56 Finley Road

Princeton, NJ 08540

353. Fred R. Huettic

Advanced Magnetics, Inc.

45 Corey Lane

Mendham, NJ-07945

354. Biil Huffman

Zircar

110 North Main Street

Florida, NY 10921

355. Brian K. Humphrey

Lubrizol Petroleum

Chemicals Co.

3000 Town Center, Suite 1340

Southfield, MI 48075-1201

356. Robert M. Humrick

Dylon Ceramic Technologies

3100 Edgehill Road

Cleveland Heights, $\mathrm{OH} 44118$

357. Lorretta Inglehart

National Science Foundation

Division of Materials Research

1800 "G" Street, N.W.,

Room 408

Washington, DC 20550

358. Michael S. Inoue

Kyocera International, Inc.

KII Library

8611 Balboa Avenue

San Diego, CA 92123-1580

359. Osama Jadaan

University of WisconsinPlatteville

General Engineering Division

1 University $\mathrm{Plaza}$

Platteville, WI 53818

360. Curtis $A$. Johnson

General Electric Company

Corporate R\&D

Room MB-187

P.0. Box 8

Schenectady, NY 12301 
361. Sylvia Johnson

SRI Intirnational

333 Ravenswood Avenue

Menlo Park, CA 94025

362. Thomas A. Johnson

Lanxide Corporation

1300 Marrows Road

P. O. Box 6077

Newark, DE 19714-6077

363. W. S. Johnson

Indiana University

One City Centre, Suite 200

Bloomington, IN 47405

364. Jill E. Jonkouski

U.S. Department of Energy

9800 South Cass Avenue

Argonne, IL 60439-4899

365. L. A. Joo

Great Lakes Research

Corporation

P.0. Box 1031

Elizabethton, TN 37643

366. A. D. Joseph

SPX Corporation

700 Terrace Point

Muskegon, MI 49443

367. Adam Jostsons

Australian Nuclear Science \& Technology Organization

Lucas Heights Research Laboratories

New IIl awarra Road

Lucas Heights New South Wales

AUSTRALIA AIR MAIL

368. Matthew $K$, Juneau

Ethyl Corporation

451 Florida Street

Baton Rouge, LA 70801

369. Hartmut Kainer

Didier-Werke AG

Anlagentechnik Wiesbaden

Abraham-Lincoln-Str. 16

D-62 Wiesbaden

GERMANY

AIR MAIL
370. Tom Kalamasz

Norton/TRW Ceramics

7A-4 Raymond Avenue

Salem, NH 03079

371. Lyle R. Kallenbach

Phillips Petroleum Company

R\&D

Mail Drop:123AL

Bartlesvitie, OK 74004

372. Nick Kamiya

Kyocera Industrial Ceramics Corporation

2700 River Road

Des Plaines, IL 60018

373. Roy Kamo

Adiabatics, Inc.

3385 Commerce Park Drive

Columbus, IN 47201

374. S. Kang

GTE Laboratories, Inc.

40 Sylvan Road

Waltham, MA 02254

375. Chih-Chun Kao

Industrial Technology Research Institute

Materials Research

Laboratories

195 Chung-Hsing Road, Sec. 4

Chutung Hsinchu 31015 R.O.C.

TAIWAN AIR MAIL

376. Keith R. Karasek

Allied-Signal, Inc.

Engineered Materials Research Center

50 East Algonquin Road

P.0. Box 5016

Des Plaines, IL 60017-5016

377. Robert E. Kasse1

Ceradyne, Inc.

3169 Redhill Avenue

Costa Mesa, CA 92626

378. Allan Katz

Wright Laboratory

Metals and Ceramics Division

WL/MLLM

Wright-Patterson AFB, OH 45433 
379. R. Nathan Katz

Worcester Polytechnic

Institute

Dept. of Mechanical

Engineering

100 Institute Road

Worcester, MA 01609

380. Ted Kawaguchi

Tokai Carbon America, Inc.

375 Park Avenue, Suite 3802

New York, NY 10152

381. Noritsugu Kawashima

TOSHIBA Corporation

Mechanical Engineering Laboratory

4-1 Ukishima-Cho

Kawasaki-Ku Kawasaki 210

JAPAN AIR MAIL

382. Lisa Kempfer

Penton Publishing

Materials Engineering

1100 Superior Avenue

Cleveland, $\mathrm{OH}$ 44114-2543

383. Frederick L. Kennard, II I

General Motors Corporation

AC Rochester

Department 32-24, EB

1300 North Dort Highway

Flint, MI 48556

384. David 0. Kennedy

Lester B. Knight Cast

Metals Inc.

549 West Randolph Street

Chicago, IL 60661

385. George Keros

Photon Physics

3175 Penobscot Building

Detroit, MI 48226

386. Pramod K. Khandelwal

General Motors Corporation

Alli son Gas Turbine

Division

P.O. Box 420, MS:W05

Indi anapolis, IN 46206
387. Jim R. Kidwell

Allied-Signal Aerospace

Company

Garrett Auxiliary Power

Division

P.0. Box 5227

Phoenix, AZ 85010

388. Han J. Kim

GTE Laboratories, Inc.

40 Sylvan Road

Wal tham, MA 02254

389. Shin Kim.

Korea Institute of Machinery \& Metals

66 Sangnam-dong, Changwon

Kyungnam 641-010

KOREA AIR MAIL

390. W. C. King

Mack Truck, Z-41

1999 Pennsylvania Avenue

Hagerstown, MD 21740

391. Carol Kirkpatrick

MSE, Inc.

CDIF Technical Library

P.0. Box 3767

Butte, MT 59702

392. Tony Kirn

Caterpillar, Inc.

Defense Products Department, JB7

Peoria, IL. 61629

393. James D. Kiser

NASA Lewis Research Center

21000 Brookpark Road, MS:49-3

Cleveland, $\mathrm{OH} 44135$

394. Max Klein

Gas Research Institute

Thermodynamics

8600 West Bryn Mawr Avenue

Chicago, IL 60631

395. Richard N. Kleiner

Coors Ceramics Company

4545 McIntyre Street

Golden, CO 80403 
396. Stanley J. Klima

NASA Lewis Research Center 21000 Brookpark Road

MS : 6 - 1

Cleveland, $\mathrm{OH} 44135$

397. Chris E. Knapp

Norton Advanced Ceramics of Canada Ltd.

8001 Daly Street

Niagara Falls, Ontario L2G 6 S2

CANADA AIR MAIL

398. Albert S. Kobayashi

University of Washington

Mechanical Engineering Department

MS:FU10

Seattle, WA 98195

399. Shigeki Kobayashi

Toyota Central Research Labs, Inc.

Nagakute Aichi 480-11

JAPAN AIR MAIL.

400. Richard A. Kole

Z-Tech Corporation

8 Dow Road

Bow, NH 03304

401. E. Kostiner

University of Connecticut

Chemistry Department, U-60

Storrs, CT 06269-3060

402. Kenneth A. Kovaly

Technical Insights, Inc.

P.0. Box 1304

Fort Lee, NJ 07024-9967

403. Ralph G. Kraft

Spraying Systems Company North Avenue at Schmale Road Wheaton, IL 60189-7900

404. Saunders B. Kramer

U.S. Department of Energy Advanced Propulsion Division CE-322, Forrestal Building Washington, DC 20585
405. Arthur Kranish

Trends Publishing, Inc.

1079 National Press Building

Washington, DC 20045

406. A. S. Krieger

Radiation Science, Inc.

P.0. Box 293

Belmont, MA 02178

407. Pieter Krijgsman

Ceramic Design International Holding B.V.

P.0. Box 68

Hattem 8050-AB

THE NETHERLANDS AIR MAIL

408. Waltraud M. Kriven

University of Illinois

Materials Science and

Engineering Department

105 South Goodwin Avenue

Urbana, IL 61801

409. Edward J. Kubel, Jr.

ASM International Advanced Materials \& Processes

Materials Park, OH 44073

410. Dave Kupperman

Argonne National Laborator

9700 South Cass Avenue

Argonne, IL 60439

411. Oh-Hun Kwon

Norton Company

Advanced Ceramics

Goddard Road

Northboro, MA 01532-1545

412. W. J. Lackey

Georgia Institute of Technology

Materials Science and

Technology

At lanta, GA 30332

413. Jai Lala

Tenmat Ltd.

40 Somers Road

Rugby Warwickshire CV22 70H

ENGLAND AIR MAIL 
414. Hari S. Lamba

General Motors Corporation

Electro-Motive Division

9301 West 55th Street

LaGrange, IL 60525

415. Richard L. Landingham

Lawrence Livermore National Laboratory

Ceramics, Corrosion, and Thermochemistry

P.0. Box 808, L-369

Livermore, CA 94550

416. Charles J. Landry

Chand Kare Technical Ceramics

712 Flat Hill Road

Lumenburg, MA 01462

417. Manfred W. Langer

Volkswagen $A G$

Material Technology

3180 Wolfsburg 1

GERMANY AIR MAIL.

418. James Lankford

Southwest Research Institute.

Department of Materials Sciences

6220 Culebra Road

San Antonio, TX 78228-0510

419. Stantey B. Lasday

Business News Publishing Co. Manor Oak One

1910 Cochran Road, Suite 630

Pittsburgh, PA 15220

420. Mark S. Laser

Solar Turbines, Inc.

2211 Erie Street.

San Diego, CA 92110

421. S. K. Lau

Carborundum Company

Technology Division

P.0. Box 832, B-100

Niagara Falls, NY 14302

422. Edward A. Lauder

Advanced Composite Materials Corporation

1525 South Buncombe Road

Greer, SC 29651-9208
423. J. Lawrence Lauderdale Babcock \& Wilcox Contract Research Division 1850 "K" Street, Suite 950 Washington, DC 20006

424. Harry A. Lawler

Carborundum Company

Technology Division

P.0. Box 832

Niagara Falls, NY 14302

425. Jean F. LeCostaouec

Textron Speciality Materials

2 Industrial Avenue

lowe 11, MA 01851

426. Benson P. Lee

Interscience, Inc.

9718 Lake Shore Boulevard

Clevel and, $\mathrm{OH} 44108$

427. Burtrand I. Lee

Clemson University

Department of Ceramic Engineering

01 in Hall

Clemson, SC 29634-0907

428. June-Gunn Lee

KIST

Structural Ceramic Lab

P.0. Box 131, Cheong-Ryang

Seout 130-650

KOREA AIR MAIL.

429. Ran-Rong Lee

Ceramics Process Systems Corporation

155 Fortune Boulevard

Milford, MA 01757

430. Stan Levine

NASA Lewis Research Center

21000 Brookpark Road

MS : 49 - 3

Cleveland, $\mathrm{OH} 44135$

431. Alan V. Levy

Lawrence Berkeley Laboratory

One Cyclotron Road, MS:62-203

Berkeley, CA 94720 
432. Ai-Kang Li

Materials Research Laboratories, ITRI 195-5 Chung-Hsing Road, Sec. 4 Chutung Hs inchu 31015 R.O.C.

TAIWAN AIR MAIL

433. Winston W. Liang

Hong Kong Industrial

Technology Centre Co. Ltd.

78 Tat Chee Avenue

4/F, HKPC Building

Howloon

HONG KONG AIR MAIL

434. Robert Licht

Norton Company

Advanced Ceramics

Goddard Road

Northboro, MA 01532-1545

435. E. Lilley

Norton Company

Advanced Ceramics

Goddard Road

Northboro, MA 01532-1545

436. Laura J. Lindberg

Allied-Signal Aerospace Company

Garrett Fluid Systems Division 1300 West Warner

MS: 93-901-1207-4TT

P.0. Box 22200

Tempe, AZ 85284-2200

437. Leonard C. Lindgren

General Motors Corporation

Allison Gas Turbine Division

P.0. Box 420, Speed Code:T-20A

Indianapolis, IN 46206-0420

438. Hans A. Lindner

Cremer Forschungs institut GmbH\&CO.KG

Oeslauer Strasse 35

D-8633 Rodental 8866

GERMANY AIR MAIL
439. Ronald E. Loehman

Sandia National Laboratories

Chemistry \& Ceramics

Department 1840

P.0. Box 5800

Albuquerque, NM 87185

440. Jeffrey C. Logas

Winona State University

Composite Materials

Engineering

115 Pasteur Hall

Winona, MN 55987

441. Bill Long

Babcock \& Wilcox

P.0. Box 11165

Lynchburg, VA 24506

442. William D. Long

Wacker Chemicals (USA), Inc.

ESK Engineered Ceramics

50 Locust Avenue

New Canaan, CT 06840

443. L. A. Lott

EG\&G Idaho, Inc.

Idaho National Engineering Laboratory

P.0. Box 1625

Idaho Falls, ID 83415-2209

444. Raouf 0. Loutfy

MER Corporation

7960 South Kolb Road

Tucson, AZ 85706

445. Gordon R. Love

Aluminum Company of America

Alcoa Technical Center

Alcoa Center, PA 15069

446. Lydia Luckevich

Ortech International

2395 Speakman Drive

Mississauga Ontario L.5K 183

CANADA AIR MAIL 
447. James W. MacBeth

Carborundum Company

Structural Ceramics Division

P.0. Box 1054

Niagara Falls, NY 14302

448. H. Maclaren

General Electric Company

Thomson Laboratory, Materials

Engineering 36807

1000 Western Avenue

Lynn, MA 01910

449. George Maczura

Aluminum Company of America

Industrial Chemicals Division

670 One Allegheny Square

Pittsburgh, PA 15212

450. David Maginnis

Tinker AFB

OC-ALC/LIIRE

Tinker AFB OK 73145-5989

451. Frank Maginnis

Aspen Research, Inc.

220 Industrial Boulevard

Moore, OK 73160

452. Tai-i1 Mah

Universal Energy Systems, Inc.

Ceramics and Composites

Research

4401 Dayton-Xenia Road

Dayton, $\mathrm{OH} 45432$

453. Kenneth M. Maillar

Barbour Stockwell Company

83 Linskey Way

Cambridge, MA 02142

454. Lorenzo Majno

Instron Corporation

100 Royall Street

Canton, MA 02021

455. S. G. Malghan

National Institute of Standards and Technology

I-270 \& Clopper Road

Gaithersburg, MD 20899
456. Lars Malmrup

United Turbine $A B$

Box 13027

Malmo S-200 44

SWEDEN AIR MAIL

457. John Mange1s

Ceradyne, Inc.

3169 Redhill Avenue

Costa Mesa,- - CA 92626

458. Russell V. Mann

Matec Applied Sciences, Inc.

75 South Street

Hopkinton, MA 01748

459. William R. Manning

Champion Aviation Products

Division

0ld Norris Road

P.0. Box 686

Liberty, SC 29657

460. Ken Marnoch

Amercom, Inc.

8928 Fullbright Avenue

Chatsworth, CA 91311

461. Robert A. Marra

Aluminum Company of America

Alcoa Technical Center

Advanced Ceramics Center - E

Alcoa Center, PA 15069

462. Chauncey L. Martin

3M Company

3M Center, Building 60-1N-01

St. Paul, MN 55144

463. Steven C. Martin

Advanced Refractory

Technologies, Inc.

699 Hertel Avenue

Buffalo, NY 14207

464. Kelly J. Mather

Williams International

Corporation

2280 West Maple Road

P.0. Box 200

Walled Lake, MI 48088 
465. James P. Mathers

3M Company

3M Center

Building 201-3N-06

St. Pau1, MN 55144

466. Marshal1 Mayer

Instron Corporation

3815 Presidential Parkway, Suite 100

Atlanta, GA 30340

467. Ron Mayville

Arthur D. Little, Inc.

15-163 Acorn Park

Cambridge, MA 02140

461. F. N. Mazadarany

General Electric Company

Research Laboratory

Building K-1, Room MB-159

P.0. Box 8

Schenectady, NY 12301

469. James W. McCauley

Alfred University

NYS College of Ceramics

Binns-Merrill Hall

A]fred, NY 14802

470. Carolyn McCormick

Allied-Signal Aerospace Company

Garrett Auxiliary Power Division

B1dg. 1303-206

P.0. Box 5227, MS:9317-2

Phoenix, AZ 85010

471. Louis R. Mccreight

2763 San Ramon Drive

Rancho Palos Verdes, CA 90274

472. Col in F. McDonald

McDonald Thermal Engineering

1730 Castellana Road

La Jolla, CA 92037

473. B. J. McEntire

Norton Company, TRW Ceramics Goddard Road

Northboro, MA 01532-1545
474. Chuck McFadden

Coors Ceramics Company

600 9th Street

Golden CO 80401

475. Henry McFadden

Magnetic Bearings, Inc.

Engineering Library

609 Rock Road

Radford, VA- 24141

476. Thomas D. McGee

Iowa State University

Materials Science and

Engineering Department

110 Engineering Annex

Ames, IA 50011

477. Carol McGill

Corning Inc.

Sullivan Park, FR-02.08

Corning, NY 14831

478. T. C. McLaren

Cameron Forged Products Company

P.0. Box 1212

Houston, TX 77251-1212

479. James McLaughl in

Sundstrand Power Systems

4400 Ruffin Road

P.0. Box 85757

San Diego, CA 92186-5757

480. Arthur F. McLean

6225 North Camino Almonte

Tucson, AZ 85718

481. Matt McMonigle

U.S. Department of Energy

Improved Energy Productivity Division

Forrestal Building, CE-231

Washington, DC 20585

482. Denris McMurtry

EG\&G Idaho, Inc.

Idaho National Engineering Laboratory

P.0. Box 1625

Idaho Falls, ID 83415 
483. D. B. Meadowcroft

National Power Technology and Environmental Centre

Kelvin Avenue

Leatherhead Surrey

KT22 7SE

ENGLAND AIR MAIL

484. Jo Meglen

11004 Birdfoot Court

Reston, VA 22091

485. Pankaj K. Mehrotra

Kennametal, Inc.

P.0. Box 639

Greensburg, PA 15601

486. Joseph J. Meindl

Reynolds International, Inc.

6603 West Broad Street

P. 0. B0x 27002

Richmond, VA 23261-7003

487. Michael D. Meiser

Allied-Signal Aerospace Company

Garrett Ceramic Components

Division

19800 South Van Ness Avenue

Torrance, CA 90509

488. George Messenger

National Research Council of Canada

Engine Laboratory

Building M-7

Ottawa Ontario K1A OR6

CANADA AIR MAIL

489. D. Messier

U.S. Army Materials Technology Laboratory

SLCMT-EMC

405 Arsenal Street

Watertown, MA 02172-0001

490. Gary L. Messing

Pennsylvania State University

Ceramic Science and Engineering Department

119 Steidle Building

University Park, PA 16802
491. Arthur G. Metcalfe

Arthur G. Metcalfe and

Assoctates, Inc.

2108 East 24 th Street

National City, CA 91950

492. R. Metselaar

Eindhoven University

Centre for Technical Ceramics

P.0. Box 5.13

Eindhoven 5600 MB

THE NETHERLANDS

AIR MAIL

493. Nancy S. Meyers

U.S. Department of Energy

Transportation Technologies

CE-30, Forrestal Building 6B-094

Washington, DC 20585

494. David J. Michael

Harbison-Halker Refractories Company

P.0. Box 98037

Pittsburgh, PA 15227

495. Ken Michaels

Chrysler Motors Corporation

Ceramics Development Metallurgical Processes

P.0. Box 1118, CIMS:418-17-09

Detroit, MI 48288

496. Bernd Michel

Institute of Mechanics

Fracture and Micromechanics Department

P.0. Box 408

D-9010 Cheminitz

GERMANY AIR MAIL

45i. Wavid E. Miles

Commission of the European Conmunities

rue de la Loi, 200

B.1049 Brussels

BELGIUM

AIR MAIL

498. John V. Milewski

Superkinetics, Inc.

P.0. Box 8029

Santa Fe, NM 87504 
499. Carl E. Miller

AC Rochester

1300 North Dort Highway, MS: $32-31$

Engineering Butlding $B$

Flint, MI 48556

500. Mike Miller

McGraw-Hill Aviation Week

Performance Materials

1156 15th Street, N.W.

Washington, $D C 20005$

501. Charles W. Miller, Jr.

Centorr Furnaces/Vacuum Industries

542 Amherst Street

Nashua, NH 03063

502. R. Mininnt

Enichem America

2000 Cornwall Road

Monmouth Junction, NJ 08852

503. Michele V. Mitchell

Allied-Signal Aerospace

Company

Garrett Ceramic Components

Division

19800 South Van Ness Avenue

Torrance, CA 90501-1149

504. Howard Mizuhara

GTE - WESGO

477 Harbor Boulevard

Belmont, CA 94002

505. He\}en Moeller

Babcock \& Wilcox

P.0. Box 11165

Lynchburg, VA 24506-1165

506. Francois R. Mollard

Metalworking Technology, Inc.

1450 Scalp Ävenue

Johnistown, PA 15904

507. Phi1 Mooney

Panametrics

NDE Division

221 Crescent Street

Waltham, MA 02254
508. Thumas Morel

Ricardo North America

645 Blackhawk. Drive

Westmont, IL 60559

509. Geoffrey P. Morris

3M Company

3M Traffic Control Materials Division

Bldg. 209-BW-10, 3M Center

St. Paul, MN 55144-1000

510. Jay A. Morrison

Rolls-Royce, Inc.

Engineering and Information Center, Overlook 1

2849 Paces Ferry Road, Suite 450

Atlanta, GA 30339-3769

511. Joel P. Moskowitz

Ceradyne, Inc.

3169 Redhill Avenue

Costa Mesa, CA 92626

512. Brij Moudgit

University of Florida

Material Science and Engineering

Gainesville, FL 32611

513. Christoph J. Mueller

Sprechsaal Publishing Group

P.0. Box 2962, Mauer 2

D-8630 Coburg

GERMANY AIR MAIL

514. Thomas W. Mullan

Vapor Technologies Inc.

345 Route 17 South

Upper Saddle River, NJ 07458

515. M. K. Murthy

MKM Consurtants International

10 Avoca Avenue, Unit 1906

Toronto Ontario M4T 2B7

CANADA AIR MAIL

516. Solomon Musikant

Transcon Technologies, Inc.

Materials Science \& Engineering 1508 Waynesboro Road

Paoli, PA 19301 
517. David L. Mustoe

Custom Technical Ceramics 8041 West 1-70 Service Road, Unit 6

Arvada, CO 80002

518. Curtis V. Nakaishit

U.S. Department of Energy

Morgantown Energy Technology Center

Collins Ferry Road

P.0. Box 880

Morgantown, WV 26507-0880

519. Yoshio Nakamura

Faicera Research Institute 2-5-8 Hyyakunin-cho Shinjuku-Ko

Tokyo

JAPAN AIR MAIL

520. K. S. Narasimhan Hoeganaes C rporation

River Road

Riverton, N, 08077

521. Samue1 Nat insohn

GTE Laboratories, Inc.

40 Sylvan Road

Wal tham, MA 02254

522. Robert Naum

Applied Resources, Inc.

P.0. Box 241

Pittsford, NY 14534

523. Malcolm Naylor

Cummins Engine Company, Inc.

P.0. Box 3005, Mail Code 50183

Columbus, IN 47202-3005

524. Jeffrey Neil

GTE Laboratories, Inc.

40 Sylvan Road

Waltham, MA 02254

525. Fred A. Nichols

Argonne National Laboratory

9700 South Cass Avenue

MCT - Building 212

Argonne, IL 60439
526. H. Nickel

Furschungszentrum Jüelich (KFA)

P.0. Box 1913

Jüe]tch 1-5170 BRD NRW

GERMANY AIR MAIL

527. Dale E. Niesz

Rutgers University

Center for Ceramic Research

P.0. Box 90.9.

Piscataway, NJ 08855-0909

528. David M. Nissley

United Technologies Corporation

Pratt \& Whitney Aircraft

400 Main Street, MS: 163-10

East Hartford, CT 06108

529. Richard D. Nixdorf

ReMaxCo Technologies, Inc.

11317 Snyder Road

Knoxville, TN 37932

530. Bernard North

Kennametal, Inc.

P.0. Box 639

Greensburg, PA 15601

531. Bruce E. Novich

Ceramics Process Systems Corporation

155 Fortune Boulevard

Milford, MA 01757

532. Daniel Oblas

GTE Laboratories, Inc.

40 Sylvan Road

Waltham, MA 02254

533. Don Ohanehi

Magnetic Bearings, Inc.

1908 Sussex Road

B1 acksburg, VA 24060

534. Robert Orenstein

General Electric Company

55-112, River Road

Schenectady, NY 12345 
535. Norb Osborn

Aerodyne Dallas

151 Regal Row,

Suite 120

Dallas, TX 75247

536. A. M. Paddick

$B P$ International Limited

BP Research Centre, Main

Library

Chertsey Road

Sunbury-on-Thames

Middlesex TW16 7LN

UNITED KINGDOM

AIR MAIL

537. Russel1 J. Page

Kanthal-Artcor

3001 Redhill Avenue, II-109

Costa Mesa, CA 92705

538. Richard Palicka

Cercom, Inc.

1960 Watson Way

Vista, CA 92083

539. Muktesh Paliwal

GTE Products Corporation

Hawes Street

Towanda, PA 18848

540. Joseph E. Palko

General Electric Company

55-113, River Road

Schenectady, NY 12345

541. Hayne Palmour, III

North Carolina State University

Materials Science and Engineering Dept.

Raleigh, NC 27605-7905

542. Joseph N. Panzarino

Norton Company

Advanced Ceramics

Goddard Road

Northboro, MA 01532-1545

543. Pellegrino Papa

Corning Inc.

MP-WX-02-1

Corning, NY 14831
544. E. Beth Pardue

Technology for Energy

Corporation

One Energy Center

P.0. Box 22996

Knoxvilie, TN 37933-0996

545. Soon C. Park

3M Company

3M Center

Building 142-4N-02

P.O. Box 2963

St. Paui, MN 55144

546. Hartmut Paschke

Schott Glaswerke

Christoph-Dorner-Strasse 29

D-8300 Landshut

GERMANY

AIR MAIL

547. Marina R. Pascucci

GTE Laboratories, Inc.

40 Sylvan Road

Waltham, MA 02254

548. James W. Patten

Cummins Engine Company, Inc.

Materials Engineering

P.0. Box 3005, Mail Code 50183

Columbus, IN 47202-3005

549. Robert A. Penty

Eastman Kodak Company

KAD/D73 - 35612

901 Elmgrove Road

Rochester, NY 14653

550. Robert W. Pepper

Textron Specialty Materials

2 Industrial Avenue

Lowe11, MA 01851

551. Peter Perdue

Detroit Diesel Corporation

Research Advanced Development Group

13400 West Outer Drive, Speed Code A-07

Detroit, MI 48239-4001 
552. Bruce Peters

Dow Chemical Company

Building 52

Midl and, MI 48667

553. John J. Petrovic

Los Al amos National Laboratory

Group MST-4, MS: 6771

Los Al anos, NM 87545

554. Frederick S. Pettit

University of Pittsburgh

Pittsburgh, PA 15261

555. Ben A. Phillips

Phillips Engineering Company

721 Pleasant Street

St. Joseph, MI 49085

556. Richard C. Phoenix

Ohmtek, Inc.

2160 Liberty Drive

Niagara Falls, NY 14302

557. Bruce J. Pletka

Michigan Technological University

Metallurgical and Materials Engineering Department

Houghton, MI 49931

558. John P. Pollinger

Garrett Ceramic Components

19800 Van Ness Avenue

Torrance, CA 90501

559. P. Popper

High Technology Ceramics International Journal

22 Pembroke Drive Westl ands Newcastle-under-Lyme Staffs ST5 2JN

ENGLAND AIR MAIL

560. F. Porz

Universitat Karlsruhe

Institut fur Keramik Im

Maschinendau

Postfach 6980

D-7500 Karlsruhe

GERMANY AIR MAIL.
561. Harry L. Potma

Royal Netherlands Embassy

Science and Technology

4200 Linnean Avenue, N.W.

Washington, DC 20008

562. Bob R. Powe 11

General Motors Research Laboratories

: $=$ tal l urgy. Bepartment

$\$ 0500$ Mound Road

i3ox 9055

Warren, MI 48090-9055

563. Stephen C. Pred

ICD Group, Inc.

1100 Valley Brook Avenue

Lyndhurst, NJ 07071

564. Karl M. Prewo

United Technologies Research

Center

411 Silver Lane

MS: 24

East Hartford, CT 06108

565. Peter E. Price

Industrial Materials Technology, Inc.

P.0. Box 9565

Andover, MA 01810

566. Joseph M. Proud

GTE Laboratories, Inc.

Materials Science Laboratory

40 Sylvan Road

Waltham, MA 02254

567. Vimal K. Pujari

Norton Company

Advanced Ceramics

Goddard Road

Northboro, MA 01532:-1545

568. George Quinn

National Institute of

Standards and Teclinnology

Ceramics Division, BIdg. 223

Gaithersburg, MD 20899 
569. Ramas V. Raman

Ceracon, Inc.

1101 North Market Boulevard, Suite 9

Sacramento, CA 95834

570. Charles F. Rapp

Owens Corning Fiberglass

2790 Columbus Road

Granville, OH 13023-1200

571. Dennis W. Readey

Colorado School of Mines

Department of Metallurgy and Materials Engineering Golden, CO 80401

572. Wilfred J. Rebello

PAR Enterprises, Inc.

12601 Clifton Hunt Lane

Clifton, VA 22024

573. Harold Rechter

Chicago Fire Brick Company

R\&D

7531 South Ashland Avenue

Chicago, Il 60620

574. Robert R. Reeber

U.S. Army Research Office

P.0. Box 12211

Research Triangle Park, NC 27709

575. K. L. Reifsnider

Virginia Polytechnic Institute and State University

Department of Engineering

Science and Mechanics

Blacksburg, VA 24061

576. Paul E. Rempes

McDonnell Douglass Missle Systems Company

P.0. Box 516, Mail Code: 1066086

St. Louis, MO 63166-0516

577. Gopal S. Revankar

John Deere Company

Metals Research

3300 River Drive

Moline, IL 61265
578. K. T. Rhee

Rutgers University

Mechanical Engineering

P.0. Bux 909

Piscataway, NJ 08854

579. James Rhodes

Advanced Composite Materials Corporation

1525 South Buncombe Road

Greer, SC 29651

580. Roy W. Rice

W. R. Grace and Company

7379 Route 32

Columbia, MD 21044

581. David W. Richerson

2093 East Delmont Drive

Salt Lake City, UT 84117

582. Tomas Richter

J. H. France Refractories

1944 Clarence Road

Snow Shoe, PA 16874

583. Michel Rigaud

Ecole Polytechnique

Campus Universite De Montreal

P.0. Box 6079, Station A

Montreal, P.Q Quebec H3C $3 A 7$

CANADA AIR MAIL

584. R. E. Riman

Rutgers University

Ceramics Engineering

Department

P.0. Box 909

Piscataway, NJ 08855-0909

585. Barry Ringstrom

Superior Graphite Company

P.0. Box 2373

Smyrna, GA 30081

586. John E. Ritter

University of Massachusetts

Mechanical Engineering

Department

Amherst, MA 01003 
587. Frank L. Roberge

Allied-Signal Aerospace Company

Garrett Auxiliary Power Division

P.0. Box 5227

Phoenix, AZ 85010

588. H. Eric Roberts

Advanced Ceramic Technology, Inc.

990 " $F$ " Enterprise Street

Orange, CA 92667

589. Martha Rohr

U.S. Department of Energy

DOE Oak Ridge Field Office

Building $4500 \mathrm{~N}$

P.0. Box 2008, MS: 6269

Oak Ridge, TN 37831-6269

590. Y. G. Roman

TNO TPD Keramick

P.0. Box 595

Einhoven 5600 AN

HOLLAND AIR MAIL

591. Mark D. Roos

Carborundum Company

P.O. Box 156

Niagara Falls, NY 14302

592. Michael Rossetti

Arthur D. Little, Inc.

15 Acorn Park

Cambridge, MA 01240

593. Barry R. Rossing

Lanxide Corporation

1300 Marrows Road

Newark, DE 19714-6077

594. Steven L. Rotz

Lubrizol Corporation

29400 Lakeland Boulevard

Wickliffe, $\mathrm{OH} 44092$

595. Bruce Rubinger

Global Competitiveness, Inc.

One Devonshire Place,

Suite 1011

Boston, MA 02109
596. Robert Ruh

Wright Laboratory

WL/MLLM

Wright-Patterson AFB, OH 45433

597. Robert J. Russel1

17 Highgate Road

Framingham, MA 01701

598. L. Will iam Sahley

Supermaterials Company

$24400 \mathrm{Highl}$ and Road

Richmond Heights, $\mathrm{OH} 44143$

599. Jon Salem

NASA Lewis Research Center

21000 Brookpark Center

Clevel and, OH 44135

600. W. A. Sanders

NASA Lewis Research Center

21000 Brookpark Road,

MS : 49-3

Clevel and, $\mathrm{OH} 44135$

601. J. Sankar

North Carolina A\&T State University

Department of Mechanical Engineering

Greensboro, NC 27411

602. Yasushi Sato

NGK Spark Plugs (U.S.A.), Inc.

1200 Business Center Drive, Suite 300

Mt. Prospect, IL 60056

603. Maxine L. Savitz

Allied-Signal Aerospace Company

Garrett Ceramic Components Division

19800 South Van Ness Avenue

Torrance, CA 90501

604. Ashok Saxena

Georgia Institute of

Technology

Materials Engineering

Atlanta, GA 30332-0245 
605. David W. Scanlon Instron Corporation 100 Royall Street Canton, MA 02021

606. Charles A. Schacht Schacht Consulting Services 12 Holl and Road Pittsburgh, PA 15235

607. James Schienle

Allied-Signal Aerospace Company

Garrett Auxiliary Power Division

2739 East Washington Street P.O. BOX 5227, MS:1302-2P

Phoenix, AZ 85010

608. John C. Schneider

San Juan Technologies

P.0. Box 49326

Colorado Springs, CO 80949-9326

609. Gary Schnittgrund

Rocketdyne, BA05

6633 Canoga Avenue

Canoga Park, CA 91303

610. Mark Schomp

Lonza, Inc.

Corporate Headquarters

17-17 Route 208

Fair Lann, NJ 07410

611. Joop Schoonman

Delft University of Technology

Laboratory for Inorganic. Chemistry

P.0. Box 5045

2600 GA Delft

THE NETHERLANDS

AIR MAIL

612. John Schuldies

Industrial Ceramic Technology, Inc.

37 Enterprise Drive

Ann Arbor, MI 48103
613. Robert B. Schulz

U.S. Department of Energy

Office of Transportation

Materials

CE-34, Forrestal Building

Washington, DC 20585

614. Murray A. Schwartz

Materials Technoiogy

Consulting, Inc.

30 Orchard Way, North

Potomac, MD 20854

615. Peter Schwarzkopf

SRI International

333 Ravenswood Avenue

Menlo Park, CA 94025

616. Thomas C. Schweizer

Princeton Economic Research, Inc.

12300 Twinbrook Pkwy., Suite 650

Rockville, MD 20852

617. William T. Schwessinger

Multi-Arc Scientific Coatings

1064 Chicago Road

Troy, MI 48083-4297

618. W. D. Scott

University of Washington

Materials Science Department

Mail Stop:FB10

Seattle, WA 98195

619. Nancy Scoville

Thermo Electron Technologies

74 West Street

P.0. Box 9046

Wal tham, MA 02254-9046

620. Brian Seegmiller

Coors Ceramics Company

600 9th Street

Golden, CO 80401 
621. T. B. Selover

AICRE/DIPPR

3575 Traver Road

Shaker Heights, $\mathrm{OH} 44122$

622. J. H. Selverian

GTE Laboratories, Inc.

40 Sylvan Road

Waltham, MA 02254

623. Charles E. Semler

Semler Materials Services

4160 Mumford Court

Columbus, $\mathrm{OH} \mathbf{4 3 2 2 0}$

624. Thomas Service

Service Engineering Laboratory

$324 \mathrm{Wells}$ Street

Greenfield, MA 01301

625. Kish Seth

Ethyl Corporation

R\&D Labora:ories

P.0. Box 341

Baton Rouge, LA 70821

626. Karleen Seybold

Allied-Signal Aerospace Company

Garrett Auxiliary Power Division

P.0. Box 5227

Phoenix, AZ 85010

627. William J. Shack

Argonne National Laboratory

9700 South Cass Avenue

Building 212

Argonne, IL 60439

628. Peter T. B. Shaffer

Technical Ceramics Laboratories, Inc. 4045 Nine/McFarland Drive Alpharetta, GA 30201

629. Richard K. Shaltens

NASA Lewis Research Center

21000 Brookpark Road, MS : $301-2$

Cleveland, OH 44135
630. Robert S. Shane

238 Hemlock Road

Wynnewood, PA 19096

631. Daniel Shanefield

Rutgers University

Ceramics Engineering Department

P.0. Box 909

Piscataway, - NJ 08855-0909

632. Ravi Shankar

Chromalloy

Research and Technology

Division

Blaisdell Road

Orangeburg, NY 10962

633. Terence Sheehan

Alpex Wheel Company

727 Berkley Street

New Milford, NJ 07646

634. Dinesh K. Shetty

University of Utah

304 EMRO, Dept. of Materials

Science and Engineering

salt Lake City, UT 84112

635. Masahide Shimizu

Ceramic Society of Japan

2-2-503 Takiyama 6-chome

Higashikurume-Shi Tokyo 203

JAPAN AIR MAIL

636. John Shipinski

Toyota Technical Center U.S.A., Inc.

Technical Research Department

2000 Town Center, Suite 500

Southfield, MI 48075

637. Thomas Shreves

American Ceramic Society, Inc.

Library

757 Brooksedge Plaza Drive

Westerville, $\mathrm{OH}$ 43081-2821

638. Jack D. Sibold

Coors Ceramics Company

Contracts for Corporate

Technology

4545 McIntyre Street

Golden, CO 80403 
705. Janet Wade

Allted-Signal Aerospace Company

Garrett Auxtliary Power Division, Department 93-772

P.0. Box 5227, MS:1303-2

Phoenix, AZ 85010

706. Richard L. Wagner

Ceramic Technologies, Inc.

537 Turtle Creek South Drive, Suite 240

Indianapolis, IN 46227

707. J. Bruce Wagner, Jr.

Arizona State University

Center for Solid State Science

Tempe, AZ 85287-1704

708. Daniel J. Wahlen

Kohler, Co.

$444 \mathrm{Highl}$ and Drive

Kohler, WI 53044

709. Ingrid Wahlgren

Royal Institute of Technology

Studsvik Library

S-611 82 Nykoping

SWEDEN AIR MÄIL

710. Ron H. Walecki

Allied-Signal Aerospace Company

Garrett Ceramic Components Division

19800 South Van Ness Avenue

Torrance, CA 90501

711. Michael S. Walsh

Vapor Technologies Inc.

2100 Central Avenue

Boulder, CO 80301

712. Chien-Min Wang

Industrial Technology Research Institute

Materials Research Laboratories

195 Chung-Hsing Road, Sec. 4

Chutung Hsinchu 31015 R.O.C.

TAIWAN

AIR MAIL
713. Robert M. Washburn

ASMT

11203 Colima Road

Whittier, CA 90604

714. Gerald Q. Heaver

Carborundum Specialty Products

42 Linus Allain Avenue

Gardner, MA 01440-2478

715. Karen E. Weber

Detroit Diesel Corporation

Technology and Planning

13400 West Outer Drive

Detroit, MI 48239-4001

716. R. W. Weeks

Argonne National Laboratory

MCT-212

9700 South Cass Avenue

Argonne, IL 60439

717. Ludwig Weiler

ASEA Brown Boveri AG

Corporate Research

Eppelheimer Str. 82

D-6900 Heidelberg

GERMANY AIR MAIL

718. James Wessel

Dow Corning Corporation

1800 "M" Street, N.W., Suite 325 South

Washington, DC 20036

719. Robert $D$. West

Therm Advanced Ceramics

P.0. Box 220

Ithaca, NY 14851

720. Thomas J. Whalen

Ford Motor Company

26362 Harriet

Dearborn Heights, MI 48127

721. Ian A. White

Hoeganaes Corporation

River Road

Riverton, NJ 08077 
689. L. J. Trostel, Jr.

Box 199

Princeton, MA 01541

690. W. T. Tucker

General Electric Company

Corporate R\&D

Butlding K1-4C35

P.0. Box 8

Schenectady, NY 12301

691. Masanori Ueki

Nippon Steel Corporation

Central R\&D Bureau

1618 Ida

Nakahara-Ku Kawasaki 211

JAPAN AIR MAIL

692. Filippo M. Ugolini

ATA Studio

Via Degli Scipioni, 268A

ROMA 00192

ITALY AIR MAIL

693. Donald L. Vaccari

Allison Gas Turbines

P.0. Box 420

Speed Code 549

Indianapol is, IN 46206-0420

694. Carl F. Van Conant

Boride Products, Inc.

2879 Aero Park Drive

Traverse City, MI 49684

695. Marcel H. Van De Voorde

Commission of the European Communities

Institute for Advanced

Materials

Joint Research Centre

P.0. Box 2

1755 ZG Petten

THE NETHERLANDS

AIR MAIL

696. O. Van Der Biest

Katholieke Universiteit Leuven

Departement Metaalkunde en oegepaste

de Croylaan 2

B-3030 Leuven

BELGIUM AIR MAIL
697. Michael Vannier Washington University,

St. Louis

Mallinckrodt Institute of Radiology

510 South Kings Highway

St. Louis, MO 63110

698. Stan Venkatesan

Southern Coke \& Coal

Corporation

P.0. Box 52383

Knoxville, TN 37950

699. V. Venkateswaran

Carborundum Company

Niagara Falls R\&D Center

P.0. Box 832

Niagara Falls, NY 14302

700. Dennis Viechnicki

U.S. Army Materials Technology Laboratory

405 Arsenal Street

Watertown, MA 02172-0001

701. Ted Vojnovich

U.S. Department of Energy

Office of Energy Research, ER-42

Washington, DC 20585

702. John D. Volt

E. I. Dupont de Nemours \& Company, Inc.

P.0. Box 80262

W1mington, DE 19880

703. John B. Wachtman

Rutgers University

Ceramics Department

P.0. Box 909

Piscataway, NJ 08855

704. Shigetaka Wada

Toyota Central Research Labs, Inc.

Nagakute Aichi 480-11

JAPAN AIR MAIL. 
672. Patrick L. Sutton

U.S. Department of Energy Advanced Propulsion Division CE-322, Forrestal Building Washington, DC 20585

673. Willard H. Sutton United Technologies Corporation Research Center, MS: 24

Silver Lane

East Hartford, CT 06108

674. Ron Sviben

100 Indel Avenue

Rancocas, NJ 08073

675. J. J. Swab

U.S. Arniv Materials Technology Laboratiry

Ceramics Research Division

SLCMT-EMC

405 Arsenal Sireet

Watertown, MA 0?.172

676. Robert E. Swanson

Metalworking Technology, Inc. 1450 Scalp Avenue Johnstown, PA 15904

677. Scott L. Swartz

Battelle Columbus

Laboratories

Metals and Ceramics

505 King Avenue

Columbus, $\mathrm{OH} 43201$

678. Steve Szaruga

Air Force Wright Aeronautical Laboratory

Materials Directorate

WL/MLBC

Wright-Patterson

$A F B, O H$ 45433-6533

679. Yo Tajima

NGK Spark Plug Company, Ltd.

NTK Technical Ceramic Division 2808 Iwasaki

Komaki-shi Aichi-ken 485

JAPAN AIR MAIL
680. Fred Teeter

5 Tralee Terrace

East Amherst, NY 14051

681. Monika 0. Ten Eyck

Carborundum Company

Technology Division

P.0. Box 832

Niagara Falls, NY 14302

682. David F. Thompson

Corning Glass Works

SP-DV-02-1

Corning, NY 14831

683. Merle L. Thorpe

Hobart Tafa Technologies, Inc.

146 Pembroke Road

Concord, NH 03301

684. Eberhard Tiefenbacher

Daimler-Benz AG Abt. FIS

Mercedes-Strabe 136

Stuttgart 60

GERMANY AIR MAIL

685. T. Y. Tien

University of Michigan

Materials Science and

Engineering Department

Dow Building

Ann Arbor, MI 48103

686. Julian M. Tishkoff

Air Force Office of Scientific Research

IAFOSR/NA

Bolling AFB, DC 20332-6448

687. D. M. Tracey

Norton Company

Advanced Ceramics

Goddard Road

Northboro, MA 01532-1545

688. Dick Trippett

General Motors Corporation

Allison Gas Turbine Division

P.0. Box 420, MS:W-16

Indianapol is, IN 46206-0420 
639. George H. Siege1

Point North Associates, Inc.

P.0. Box 907

Madison, NJ 07940

640. Ilichard Silberglitt

rechnology Assessment and Transfer, Inc.

133 Defense Highway, \#212

Annapolis, MD 21401

641. Mary Silverberg

Norton Company

Advanced Ceramics Library

Goddard Road

Northboro, MA 01532-1545

642. Gurpreet Singh

Department of the Navy

Internal Combustion \& Gas

Turbine Engine Division Code 56×31

Washington, DC 20362-5101

643. Maurice J. Sinnott

University of Michigan

Chemical and Metallurgical Engineering

5106 IST Bullding

Ann Arbor, MI 48109-2099

644. John Skildum

3M Company

3M Center

Building 224-2S-25

St. Paul, MN 55144

645. David P. Smith

Hoskins, Rees \& Smith

1910 Cochran Road

Manor Oak II, Suite 658

Pittsburgh, PA 15220

646. Richard H. Smoak

Smoak \& Associates

3554 Hollyslope Road

Altadena, CA 91001-3923
647. Jay R. Smyth

Allied-Signal Aerospace Company

Garrett Auxiliary Power Division

2739 East Washington Street

P.0. Box 5227

MS: $93-173 / 1303-207$

Phoenix, AZ 85010

648. Edward A. Snajdr

Premier Refractories and Chemicals, Inc.

P.0. Box 392

Findlay, $\mathrm{OH} 44815$

649. Rafal A. Sobotowski

British Petroleum Company

Technical Center, Broadway

3092 Broadway Avenue

Cleveland, $\mathrm{OH} 44115$

650. A. G. Solomah

SAC International Ltd.

1445 Bonhill Road, \#13

Mississauga Ontario L5T IV3

CANADA AIR MAIL

651. S. Somiya

Nishi Tokyo University

3-7-19 Seijo, Setagaya

Tokyo 157

JAPAN AIR MAIL

652. Boyd W. Sorenson

DuPont Lanxide Composites

1300 Marrows Road

P.0. Box 6077

Neward, DE 19707

653. Charles A. Sorrel1

U.S. Department of Energy

Advanced Industrial

Concepts Division

CE-232, Forrestal

Building

Washington, DC 20585 
554. C. Spencer

EA Technology

Capenhurst Chester

CH1 6ES

UNITED KINGDOM AIR MAIL.

655. Alten Spizzo

Hercules, Inc.

Hercules Plaza

Wilmington, DE 19894

656. Richard M. Spriggs

Alfred University

Center for Advanced Ceramic Technology

Alfred, NY 14802

657. Charles Spuckler

NASA Lewis Research Center

21000 Brookpark Road

MS : $5-11$

Cleveland, $\mathrm{OH}$ 44135-3191

658. M. Srinivasan

Material Solutions

P.0. Box 663

Grand Is land, NY 14702-0663

659. Gordon L. Starr

Cummins Engine Company, Inc.

Design \& Technology

P.0. Box 3005

Mail Code 50182

Columbus, IN 47202-3005

660. Jim Stevenson

Windrock, Incorporated

154 Fairbanks Plaza

Oak Ridge, TN 37830

661. Tom Stillwagon

Allied-Signal Aerospace Company

Garrett Ceramic Components Division

19800 South Van Ness Avenue

Torrance, CA 90501

662. Harold L. Stocker

General Motors Corporation

Allison Gas Turbine Division P. 0 . Box 420

Indianapolis, IN 46206
663. Paul D. Stone

Dow Chemical USA

1776 "Eye" Sireet, N.W., Suite 575

Washington, DC 20006

664. Roger S. Storm

Carborundum Company

Technology Division

P.0. Box 337

Niagara Falls, NY 14302-0337

665. Peter A. Stranges

4 Chittenden Lane

Owings Mills, MD 21117

666. F. W. Stringer

Aero \& Industrial Technology Ltd.

P.0. Box 46, Wood Top

Burnley Lancashire BBIL 4BX

UNITED KINGDOM AIR MAIL

667. Thomas N. Strom

NASA Lewis Research Center

21000 Brookpark Road

MS: 86- 6

Cleveland, $\mathrm{OH} 44135$

668. M. F. Stroosnijder

Institute for Advanced

Materials

Joint Research Centre

21020 Ispra (VA)

ITALY AIR MAIL

669. Karsten Styhr

30604 Ganado Drive

Rancho Palos Verdes, CA 90274

670. T. S. Sudarshan

Materials Modification, Inc.

2929-Pl Eskridge Center

Fairfax, VA 22031

671. M. J. Sundaresan

University of Miami

Mechanical Engineering Department

P.0. Box 248294

Coral Gables, FL 33124 
722. Alan Whitehead

General Electric Company

1 River Road, 55-111

Schenectady, NY 12345

723. Sheldon M. Wiederhorn National Institute of Standards and Technology Butlding 223, Room A329 Gaithersburg, MD 20899

724. John F. Wight Alfred University McMahon Building Alfred, NY 14802

725. D. S. Wilkinson McMaster University Materials Science and Engineering Department 1280 Main Street, West Hamilton Ontario L8S 4L7 CANADA AIR MAIL

726. James C. Williams General Electric Company Engineering Materials Technology Labs One Neumann Way

Mat1 Drop: H85

Cincinnati, OH 45215-6301

727. Janette R. Williams

Kollmorgen Corporation

PCK Technology Division

150 Motor Parkway, \#262 Hauppauge, NY 11788-5108

728. Steve J. Williams RCG Hagler Bailily, Inc. 1530 Wilson Boulevard, Suite 900 Arlington, VA 22209-2406

729. Craig A. Willikens Norton Company Advanced Ceramics Goddard Road Northboro, MA 01532-1545
730. Roger R. Wills

TRW, Inc.

Valve Division

1455 East 185th Street

Clevel and, $\mathrm{OH} 44110$

731. David Gordon Wilson

Massachusetts Institute of Technology

Mechanical-Engineering Department

77 Massachusetts Avenue, Room 3-455

Cambridge, MA 02139

732. Matthew F. Winkler

Seaworthy Systems, Inc.

P.0. Box. 965

Essex, CT 06426

733. Gerhard Winter

Hermann C. Starck Berlin GmbH, Werk Goslar

P.0. Box 2540

D-3380 Gos lar 3380

GERMANY AIR MAIL

734. W. L. Winterbottom

Ford Motor Company

Materfal Systems Reliability

Department

20000 Rotunda Drive

SRL, Room E-3182

P.O. Box 2053

Dearborn, MI 48121

735. David G. Wirth

Coors Ceramics Company

600 9th Street

Golden, CO 80401

736. Thomas J. Wissing

Eaton Corporation

Engineering \& Research Center

P.0. Box 766

Southfield, MI 48037

737. James C. Withers

MER Corporation

7960 South Kolb Road

Building $F$

Tucson, AZ 85706 
738. Dale E. Wittmer

Southern Ill inois University

Mechanical Engineering Department

Carbondale, IL 6290]

739. Warren W. Wolf

Owens Corning Fiberglass

2790 Columbus Road, Route 16 Granville, OH 43023

740. George W. Wolter

Howmet Turbine Components Corporation

Technical Center

699 Beriston Road

Whiteha11, MI 49461

741. James C. Wood

NASA Lewis Research Center

21000 Brookpark Road

MS: 86-6

Cleveland, $\mathrm{OH} 44135$

742. Marril1 Wood

LECO Corporation

Augusta Division

P.0. Box 211688

Augusta, GA 30917-1688

743. Wayne L. Worre11

University of Pennsylvania

Department of Materials

Science and Engineering

3231 Wainut Street

Philadelphia, PA 19104

744. John F. Wosinski

Corning Inc.

$M E-2$ E-5 H8

Corning, NY 14830

745. Ian G. Wright

Battelle Columbus Laboratories

$505 \mathrm{King}$ Avenue

Columbus, $\mathrm{OH} 43201$

746. Ruth Wroe

ERDC

Metals \& Materials Industries Division

Capenhurst Chester CH1 GES

ENGLAND

AIR MAIL.
747. Bernard J. Wrona

Advanred Composite Materials Corporation

1525 South Buncombe Road

Greer, SC 29651

748. Car1 C. M. Wu

Naval Research Laboratory

Ceramic Branch, Code 6373

Washington, $D C 20375$

749. John C. Wurst

Untversity of Dayton Research Institute

300 College Park

Dayton, OH 45469-0101

750. Neil Wyant

ARCH Development Corp.

9700 South Cass Avenue

Building 202.

Argonne, IL 60439

751. Roy Yamamoto

Texaco Inc.

P.0. Box 509

Beacon, NY 12508-0509

752. John Yamanis

Allied-Signal, Inc.

Ceramics Program

P.0. Box 1021

Morristown, NJ 07962-1021

753. Harry C. Yeh

Allied-Signal Aerospace

Company

Garrett Ceramic Components Division

19800 South Van Ness Avenue

'Torrance, CA 90509

754. Hiroshi Yokoyama

Hitachi Research Lab

4026 Kujl-Cho

Hitachi-shi Ibaraki 319-12

JAPAN AIR MAIL

755. Thomas M. Yonushonis

Cummins Engine Company, Inc.

P.0. Box 3005

Mail Code 50183

Columbus, IN 47202-3005 
756. Thomas J. Yost

Corntng, Inc.

Technical Products Division, Main P1 ant 21-1-2

Corning, NY 14831

757. Jong Yung

Sundstrand Aviation Operations

Department 789-6

4747 Harrison Avenue

Rockford, IL. 61125

758. A. L. Zadoks

Caterpillar Inc.

Technical Center, Building L

P.0. Box 1875

Peorla, IL 61656-1875

759. Avi Zangvil

University of Il1inois

Materials Research Laboratory

104 South Goodwin Avenue

Urbana, IL 61801

760. Charles H. Zenuk

Transtech

6529 East Calle Cavalier

Tucson, AZ 85715

761. Anne Marie Zerega

U.S. Department of Energy

Office of Energy Research, ER-42

Washington, DC 20585

762. Ken Zillmer

Applied Test Systems, Inc.

2571 Mt. Gallant Road

Rock Hill, SC 29730

763. Carl Zweben

General Electric Company

P.0. Box 8555, VFSC/V4019

Philadelphia, PA 19101

764. Klaus M. Zwilsky

National Research Council

National Materials

Advisory Board

2101 Constitution Avenue

Washington, DC 20418
765. Departwant of Energy DOE Ftaid Office, Oak Ridge Assistant Manager for Energy Research and Development P.0. Box 2001

Oak Ridge, TN 37831-8501

766-775. Department of Energy

office of Scientific and Technical Information office of Information Servites

P.0. Box 62

Oak Ridge, TN 37831

For distribution by microfiche as shown in DOE/OSTI-4500, Distribution Category UC-332 (Ceramics/Advanced Materials). 

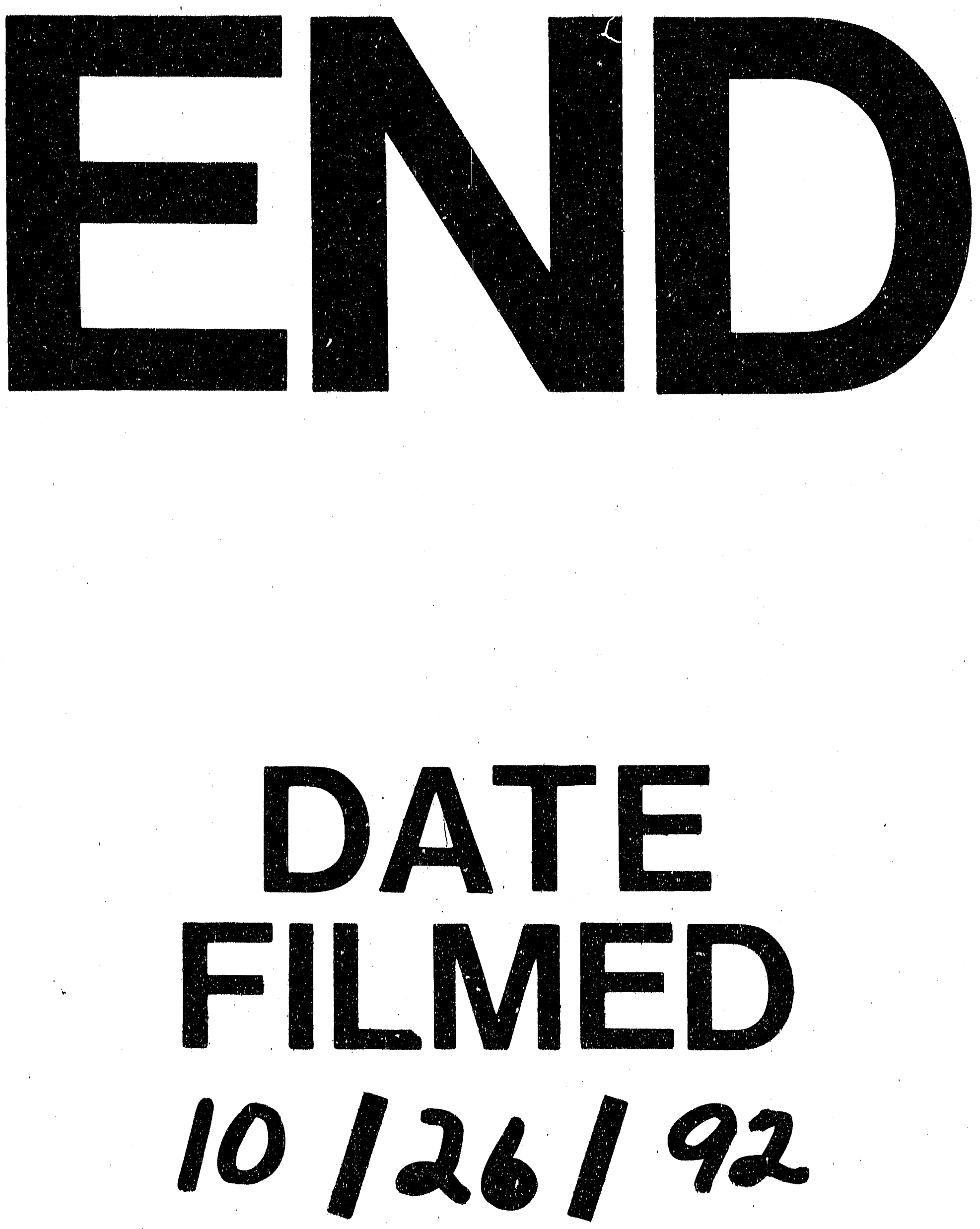